Prepared for the U.S. Department of Energy

Under Contract DE-AC05-76RL01830

\title{
Hanford Tank 241-S-112 \\ Residual Waste Composition \\ and Leach Test Data
}
KJ Cantrell
MJ Lindberg
KM Krupka
BW Arey
KN Geiszler
HT Schaef

August 2008

\section{Pacific Northwest}




\title{
DISCLAIMER
}

This report was prepared as an account of work sponsored by an agency of the United States Government. Neither the United States Government nor any agency thereof, nor Battelle Memorial Institute, nor any of their employees, makes any warranty, express or implied, or assumes any legal liability or responsibility for the accuracy, completeness, or usefulness of any information, apparatus, product, or process disclosed, or represents that its use would not infringe privately owned rights. Reference herein to any specific commercial product, process, or service by trade name, trademark, manufacturer, or otherwise does not necessarily constitute or imply its endorsement, recommendation, or favoring by the United States Government or any agency thereof, or Battelle Memorial Institute. The views and opinions of authors expressed herein do not necessarily state or reflect those of the United States Government or any agency thereof.

\author{
PACIFIC NORTHWEST NATIONAL LABORATORY \\ operated by \\ BATTELLE \\ for the \\ UNITED STATES DEPARTMENT OF ENERGY \\ under Contract DE-AC05-76RL01830
}

Printed in the United States of America
Available to DOE and DOE contractors from the Office of Scientific and Technical Information,
P.O. Box 62, Oak Ridge, TN 37831-0062;
ph: (865) 576-8401
fax: (865) 576-5728
email: reports@adonis.osti.gov

\begin{abstract}
Available to the public from the National Technical Information Service, U.S. Department of Commerce, 5285 Port Royal Rd., Springfield, VA 22161

ph: (800) 553-6847

fax: (703) 605-6900

email: orders@ntis.fedworld.gov

online ordering: http://www.ntis.gov/ordering.htm
\end{abstract}

This document was printed on recycled paper. 


\title{
Hanford Tank 241-S-112 Residual Waste Composition and Leach Test Data
}

\author{
KJ Cantrell \\ MJ Lindberg \\ KM Krupka \\ BW Arey \\ KN Geiszler \\ HT Schaef
}

August 2008

Prepared for

CH2M HILL Hanford Group, Inc., and the U.S. Department of Energy

under Contract DE-AC05-76RL01830

Pacific Northwest National Laboratory

Richland, Washington 99352 



\section{Summary}

As directed by Congress, the U.S. Department of Energy (DOE) established the Office of River Protection in 1998 to manage DOE's largest, most complex environmental cleanup project - retrieval of radioactive waste from Hanford Site tanks for treatment and eventual disposal. Sixty percent by volume of the nation's high-level radioactive waste is stored at the Hanford Site in aging, deteriorating tanks. If not cleaned up, this waste is a threat to the nearby Columbia River and the Pacific Northwest.

CH2M HILL Hanford Group, Inc. is the DOE Office of River Protection's prime contractor responsible for the storage, retrieval, and disposal of Hanford Site tank waste. As part of this effort, CH2M HILL Hanford Group, Inc. contracted with Pacific Northwest National Laboratory (PNNL) to conduct testing for selected key contaminants present in residual waste remaining in the single-shell tank 241-S-112 (S-112).

This report presents the results of laboratory characterization, testing, and analysis of two samples (designated 20406 and 20407) of residual waste collected from tank S-112 after final waste retrieval. These studies were completed to characterize the residual waste and assess the leachability of contaminants from the solids. This is the first report from this PNNL project to describe the composition and leach test data for residual waste from a salt cake tank. All previous PNNL reports describing contaminant release models, and characterization and testing results for residual waste in single-shell tanks were based on samples from sludge tanks. ${ }^{1,2}$

X-ray diffraction (XRD) results for sample 20407 indicate that the primary crystalline phase in the residual waste is gibbsite $\left[\mathrm{Al}(\mathrm{OH})_{3}\right]$ and comprises more than $~ 90 \mathrm{wt} \%$ of the solid material. Scanning electron microscopy/energy dispersive spectrometry (SEM/EDS) results are consistent with the XRD results, indicating the primary solid phase is $\mathrm{Al}-\mathrm{O}( \pm \mathrm{H} \pm \mathrm{C})$ with a composition that is $39 \mathrm{wt} \% \mathrm{Al}$ and $60 \mathrm{wt} \% \mathrm{O}$ (consistent with the composition of gibbsite). The SEM/EDS results also indicate that the gibbsite particles are likely coated with an $\mathrm{Al}-\mathrm{Na}-\mathrm{O}( \pm \mathrm{H} \pm \mathrm{C})$ solid. The phase composition of this encrustation could not be established with certainty but appears to have a composition of $29 \mathrm{wt} \% \mathrm{Na}$, $18 \mathrm{wt} \% \mathrm{Al}$, and $52 \mathrm{wt} \% \mathrm{O}$. Results of geochemical modeling indicate dawsonite $\left[\mathrm{NaAlCO}_{3}(\mathrm{OH})_{2}\right]$ was near equilibrium with 1-month double-deionized water extracts, which suggests this phase may be an

${ }^{1}$ Cantrell KJ, KM Krupka, WJ Deutsch, MJ Lindberg, HT Schaef, KN Geiszler and BW Arey. 2008. Hanford Tank 241-C-103 Residual Waste Contaminant Release Models and Supporting Data. PNNL-16738, Pacific Northwest National Laboratory, Richland, Washington.

${ }^{2}$ Deutsch WJ, KM Krupka MJ Lindberg, KJ Cantrell, CF Brown, and HT Schaef. 2006. Hanford Tanks 241-C-106: Impact of Cement Reactions on Release of Contaminant from Residual Waste. PNNL-15544, Pacific Northwest National Laboratory, Richland, Washington.

Deutsch WJ, KM Krupka MJ Lindberg, KJ Cantrell, CF Brown, and HT Schaef. 2007a. Hanford Tanks 241-C-106: Residual Waste Contaminant Release Model and Supporting Data. PNNL-15187, Rev. 1, Pacific Northwest National Laboratory, Richland, Washington.

Deutsch WJ, KM Krupka, MJ Lindberg, KJ Cantrell, CF Brown, and HT Schaef. 2007b. Hanford Tanks 241-C-203 and 241-C-204: Residual Waste Contaminant Release Model and Supporting Data. PNNL-14903, Rev. 1, Pacific Northwest National Laboratory, Richland, Washington.

Deutsch WJ, KM Krupka MJ Lindberg, KJ Cantrell, CF Brown, SV Mattigod, HT Schaef, and BW Arey. 2007c. Hanford Tanks 241-C-202 and 241-C-203 Residual Waste Contaminant Release Models and Supporting Data. PNNL-16229, Pacific Northwest National Laboratory, Richland, Washington. 
important component of this encrustation. The SEM/EDS analysis also revealed the presence of Fe oxides, a Ca-Cr-O phase, a $\mathrm{Pb}-\mathrm{Cl} \pm \mathrm{O}$ phase, and possibly one or more silicate phases, but particles with these compositions were very rare in the tank S-112 residual waste.

Results of the Tier 1 analysis of the bulk composition of tank S-112 samples indicate that $\mathrm{Al}$ is the largest, single metal component of the waste (7.1 to $8.4 \mathrm{wt} \%$ for the two samples). Other major metal components ( $\mathrm{Na}, \mathrm{Fe}, \mathrm{Cr}$, and $\mathrm{Si}$ ) occurred at lower concentrations, ranging from 4.7 to $5.2 \%, 0.21$ to $0.24 \%, 0.17$ to $0.18 \%$, and 0.10 to $0.14 \%$, respectively, for the two samples. Based on these results and assuming $\mathrm{Al}$ occurs primarily as gibbsite, this $\mathrm{Al}$ phase would account for 21 to $24 \mathrm{wt} \%$ of the residual waste. The residual waste compositions determined in this study were generally consistent with those determined by the 222-S Laboratory, except for the concentrations determined for $\mathrm{Al}^{3}$ The average $\mathrm{Al}$ concentration determined from the 222-S Laboratory results was $29.1 \mathrm{wt} \%$ (dry wt basis). If all Al occurred as gibbsite, this would account for $84 \%$ of the mass of the residual waste. This result is more consistent with PNNL's XRD and SEM/EDS results compared to those from the bulk composition analyses. Based on these comparisons, PNNL's Al concentrations for the unleached (as received) bulk solid appear to be underestimated. The reason for this discrepancy has not been determined to date. Our initial assessment indicates that some $\mathrm{Al}$ may have precipitated as fine particulates that were filtered out subsequent to the microwave acid digestion.

Chromium was the most concentrated contaminant of concern in the tank S-112 residual waste samples, occurring at 1,690 to $1,750 \mu \mathrm{g} / \mathrm{g}$-dry waste. The other important contaminants, ${ }^{99} \mathrm{Tc}$ and ${ }^{238} \mathrm{U}$, were measured in the residual waste at concentrations that ranged from 0.46 to $0.48 \mu \mathrm{g} / \mathrm{g}$ and 17 to $36 \mu \mathrm{g} / \mathrm{g}$, respectively.

Some solution analyses were conducted on supernatant from as-received sample 20406 and on leachates from sample 20407 extracted by a 1-month single-contact leach test with double deionized water at a water-to-waste ratio of 100:1. The percentages of ${ }^{99} \mathrm{Tc},{ }^{238} \mathrm{U}$, and $\mathrm{Cr}$ that were extractable in the 1-month single-contact leachates were $17 \%, 0.65 \%$, and $10.7 \%$, respectively, relative to the measured concentrations in the unleached bulk solid. Significant percentages of other metals in the extract leachates include $\mathrm{Al}(9.3 \%)$, $\mathrm{Ca}(81 \%)$, and $\mathrm{Na}(87 \%)$ relative to the bulk waste composition. Concentrations of all major anions determined by ion chromatography were below the detection limit, indicating that hydroxide and carbonate were the major anions in the water leachates.

Calculations were made to estimate a hypothetical pore water composition that would occur if all the dissolved components measured in the sample 20407 1-month single-contact leach tests were initially dissolved in the entrained pore water. These concentrations were compared with concentrations measured for the supernatant solution present in sample 20406. These results indicate the majority of the ${ }^{99} \mathrm{Tc}, \mathrm{Al}$, and $\mathrm{Na}$ in the 1-month double-deionized water extracts come from dilution of residual supernatant in the waste sample. In the case of ${ }^{238} \mathrm{U}$, it appears dilution of pore fluid results in precipitation of most of the ${ }^{238} \mathrm{U}$. This may have occurred as a result of diminished hydrolysis and carbonate complexation upon dilution (Le Chatelier's principle). For Ca, researchers determined that nearly all Ca in the extracts came

\footnotetext{
${ }^{3}$ Parker DL and WB Barton. 2007. Retrieval Data Report for Single-Shell Tank 241-S-112. RPP-RPT-35112, CH2M HILL Hanford Group, Inc., Richland, Washington.
} 
from dissolution of a Ca-containing solid phase. For Cr, calculations indicate approximately half of the $\mathrm{Cr}$ in the leachants came from the pore fluid, and a nearly equal quantity came from dissolution from a solid phase. 



\section{Acknowledgments}

The authors wish to acknowledge M. Connelly and J. G. Kristofzski at CH2M HILL Hanford Group, Inc. (Richland, Washington) for providing project funding and technical guidance. We greatly appreciate the technical reviews provided by F. M. Mann and J. N. Appel (both from CH2M HILL Hanford Group, Inc.), and W. J. Deutsch (PNNL). The authors would also like to thank S. R. Baum, E. T. Clayton, and I. V. Kutnyakov (all from PNNL) for completing the chemical analyses of the solution samples from our studies. We are particularly grateful to H. E. Matthews (PNNL) for completing the editorial review and K. R. Neiderhiser (PNNL) for final word processing of this technical report. 



\section{Acronyms and Abbreviations}

\begin{tabular}{|c|c|}
\hline ASTM & American Society for Testing and Materials \\
\hline BSE & backscattered electron \\
\hline $\mathrm{CCV}$ & continuing calibration verification \\
\hline CFR & Code of Federal Regulations \\
\hline DDI & double-deionized (water) \\
\hline DOE & U.S. Department of Energy \\
\hline Dup (or dup) & duplicate \\
\hline EDS & energy dispersive spectrometry \\
\hline EPA & U.S. Environmental Protection Agency \\
\hline EQL & estimated quantification limit \\
\hline GWB & Geochemist’s Workbench ${ }^{\circledR 1}$ \\
\hline HASQARD & Hanford Analytical Services Quality Assurance Requirements Document \\
\hline IC & ion chromatography (chromatograph) \\
\hline ICDD & International Center for Diffraction Data \\
\hline ICP-MS & inductively coupled plasma-mass spectrometry (spectrometer) \\
\hline ICP-OES & inductively coupled plasma-optical emission spectroscopy (same as ICP-AES) \\
\hline JCPDS & Joint Committee on Powder Diffraction Standards \\
\hline NIST & National Institute of Standards and Technology \\
\hline $\mathrm{PDF}^{\mathrm{TM}}$ & powder diffraction file \\
\hline $\mathrm{pH}$ & $\begin{array}{l}\text { measure of the acidity of a solution, where } \mathrm{pH} \text { is the negative of the logarithm of } \\
\text { the activity of } \mathrm{H}^{+} \text {in solution }\end{array}$ \\
\hline PNNL & Pacific Northwest National Laboratory \\
\hline QA & quality assurance \\
\hline redox & reduction-oxidation (process) \\
\hline RWL & remote water lance \\
\hline S-112 & single-shell tank 241-S-112 (Hanford Site) \\
\hline SEM & scanning electron microscopy (or microscope) \\
\hline SI & saturation index \\
\hline SRM & standard reference material \\
\hline SST & single-shell tank \\
\hline XRD & x-ray powder diffractometry analysis (commonly called x-ray diffraction) \\
\hline
\end{tabular}

\footnotetext{
${ }^{1}$ The Geochemist’s Workbench is a registered trademark of the University of Illinois.
} 



\section{Units of Measure}

$\theta$

${ }^{\circ} \mathrm{C}$

$\mathrm{cm}$

$\mathrm{ft}$

g

gallon

in.

L

$\mu$

$\mu \mathrm{Ci}$

$\mu \mathrm{g}$

$\mu \mathrm{m}$

$\mathrm{M}$

$\mathrm{mL}$

$\mathrm{mM}$

rpm

$\mathrm{I} / \mathrm{I}_{0}$

$\lambda$

$\mathrm{wt} \%$ angle of incidence (Bragg angle)

temperature in degrees Celsius $\left.\left[\mathrm{T}\left({ }^{\circ} \mathrm{C}\right)=\mathrm{T}(\mathrm{K})-273.15\right)\right]$

centimeter

foot

gram

gallon

inch

liter

micro (prefix, $10^{-6}$ )

microCurie

microgram

micrometer

molarity, $\mathrm{mol} / \mathrm{L}$

milliliter

molarity, millimol/L

revolution per minute

relative intensity of an x-ray powder diffractometry analysis peak to the most intense peak

wavelength

weight percent 



\section{Contents}

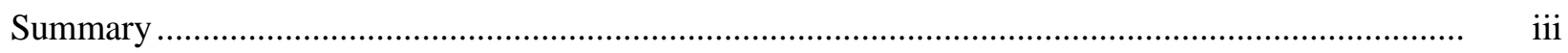

Acknowledgments................................................................................................................... vii

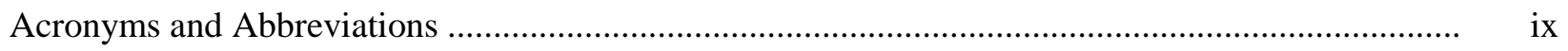

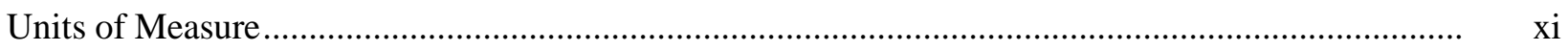

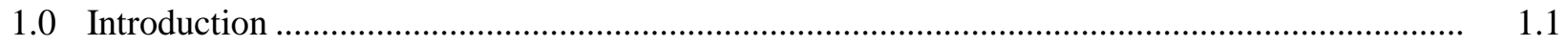

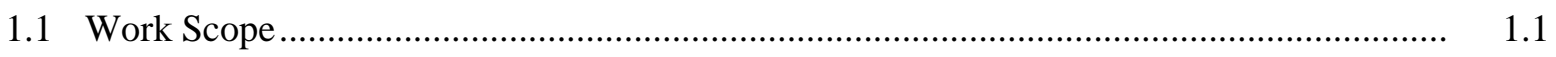

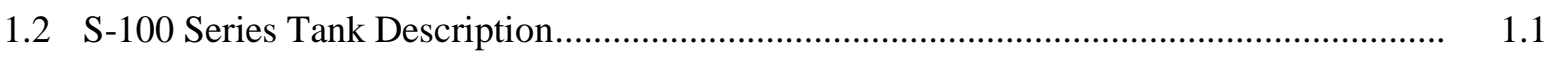

2.0 Materials and Laboratory Test Methods............................................................................... 2.1

2.1 Tank S-112 Residual Waste Samples............................................................................ 2.1

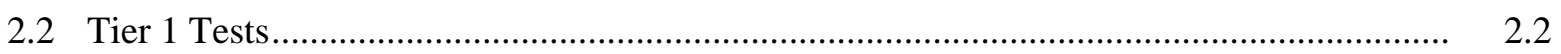

2.2.1 Residual Waste Composition by Acid Digestion .................................................... 2.2

2.2.2 Moisture Content .............................................................................................. 2.3

2.2.3 Single-Contact Residual Waste Extraction Tests and Analysis of Residual Supernatant ................................................................................................ 2.4

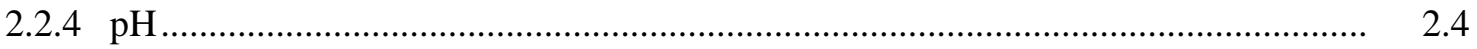

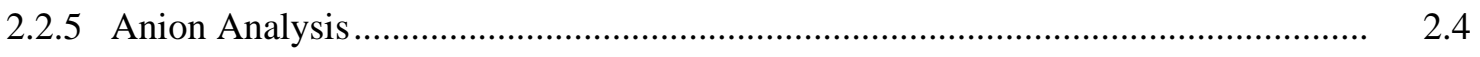

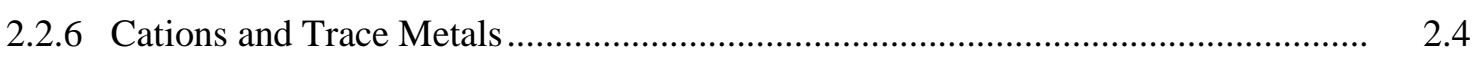

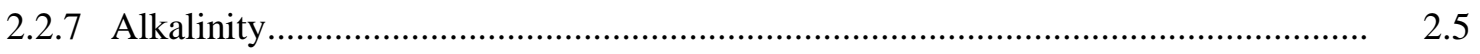

2.3 X-Ray Powder Diffractometry ...................................................................................... 2.5

2.4 Scanning Electron Microscopy/Energy Dispersive Spectrometry Analysis ...................... 2.7

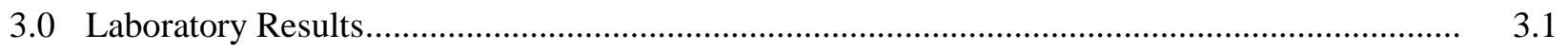

3.1 Residual Waste Composition ..................................................................................... 3.1

3.1.1 Comparison of Analytical Results S-112 Residual Waste with 222-S Results........ 3.2

3.2 Double-Deionized Water-Leach Tests and Supernatant Composition................................. 3.6

3.2.1 Residual Waste to Double-Deionized Water Ratios: Single-Contact Double-Deionized Water Extracts...................................................................... 3.6

3.2.2 Water Extract $\mathrm{pH}$ and Alkalinity - Supernatant and Single-Contact Double-Deionized Water Extracts....................................................................... 3.7

3.2.3 Dissolved Concentrations of ${ }^{99} \mathrm{Tc}$ and ${ }^{238} \mathrm{U}$ - Supernatant and Single-Contact Water Extracts .............................................................................................. 3.7

3.2.4 Extractable ${ }^{99}$ Tc and ${ }^{238} \mathrm{U}$ - Single-Contact Water Extracts................................... 3.8

3.2.5 Dissolved Concentrations of Metals - Supernatant and Single-Contact Water

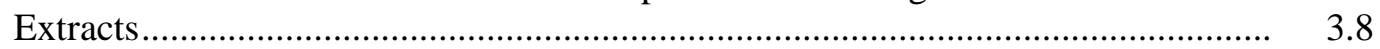

3.2.6 Extractable Metal Concentrations - Single-Contact Double-Deionized Water

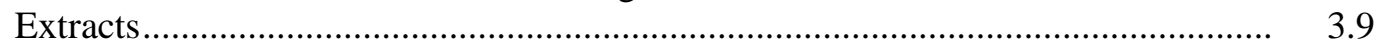

3.2.7 Extractable Anion Concentrations - Single-Contact Water Extracts......................... 3.10

3.3 X-Ray Diffraction Results....................................................................................... 3.10

3.4 Scanning Electron Microscopy/ Energy Dispersive Spectrometry Results......................... 3.13 


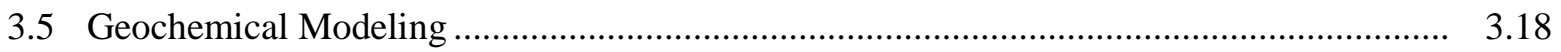

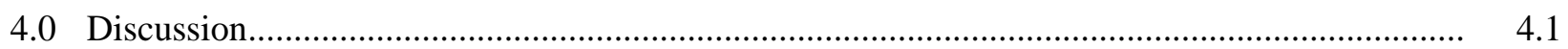

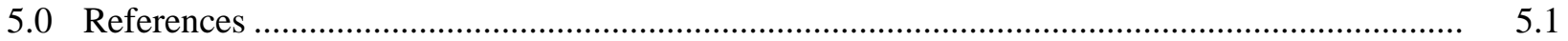

Appendix SEM Micrographs and EDS Results for Unleached Residual Waste from Tank S-112 ..... A.1

\section{Figures}

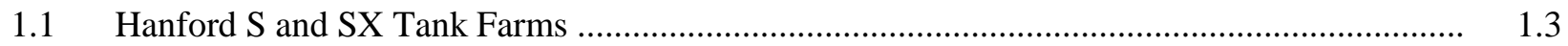

1.2 Generalized Profile View of a 100-Series Tank Such as Tank S-112 ................................... 1.4

$2.1 \quad$ Tank S-112 Residual Waste (Sample 20406)..................................................................... 2.1

2.2 Tank S-112 Residual Waste (Sample 20407) ...................................................................... 2.2

$2.3 \quad$ Exploded Schematic View of the XRD Sample Holder ......................................................... 2.6

2.4 XRD Pattern for Collodion Film Measured in the Absence of Any Residual Waste

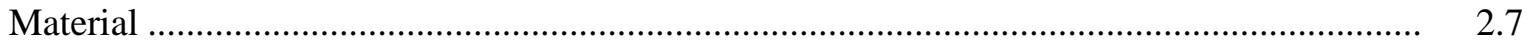

3.1 As-Measured and Background-Subtracted XRD Patterns for Subsample 20407 of Unleached Tank S-112 Residual Waste

3.2 As-Measured and Background-Subtracted XRD Patterns for Subsample 20407 dup of Unleached Tank S-112 Residual Waste ....

3.3 Low-Magnification Backscattered Electron SEM Images of Typical Particles in Unleached Subsample 20407 of Tank S-112 Residual Waste

3.4 Backscattered Electron SEM Images Showing Evidence for Na-Rich Surface Coating on Typical Particles and Corresponding EDS Spectra for Na-Rich and Na-Poor Areas of Such Particles in Unleached Subsamples 20407 and 20407 dup of Tank S-112 Residual Waste......

3.5 Backscattered Electron SEM Images Showing Fe Oxide Particles Present in Unleached Subsamples 20407 and 20407 dup of Tank S-112 Residual Waste

3.6 Backscattered Electron SEM Images Showing $\mathrm{Ca}-\mathrm{Cr}-\mathrm{O}$ and $\mathrm{Pb}-\mathrm{Cl} \pm \mathrm{O}$ Particles Present in Unleached Subsample 20407 dup of Tank S-112 Residual Waste..

3.7 Backscattered Electron SEM Images Showing Silicate Particles and Needle-Like Phase Present in Unleached Subsample 20407 dup of Tank S-112 Residual Waste 


\section{Tables}

2.1 Tank S-112 Samples Provided to PNNL by 222-S Laboratory .............................................. 2.1

2.2 Digestion Factors for Residual Waste Solids Used for the EPA Acid Digestion Treatment .... 2.3

3.1 Moisture Contents of Tank S-112 Residual Waste Samples .................................................. 3.1

3.2 Residual Waste Composition Measured by ICP-OES (Al through Cu) .................................. 3.3

3.3 Residual Waste Composition Measured by ICP-OES (Fe through Pb).................................. 3.3

3.4 Residual Waste Composition Measured by ICP-OES (S through Zr).................................... 3.4

3.5 Average Compositions for Tank S-112 Residual Waste Samples 20406 and 20407

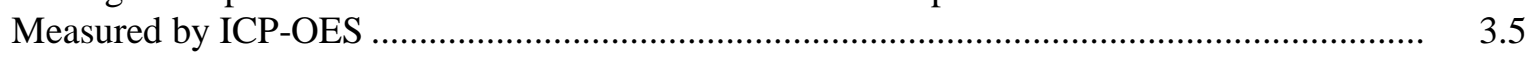

3.6 Concentrations of ${ }^{99}$ Tc and ${ }^{238} \mathrm{U}$ Measured in Tank S-112 Residual Waste by ICP-MS.......... 3.5

3.7 Comparisons of Average Compositions for Tank S-112 Residual Waste Samples 20406 and 20407 Measured by ICP-OES with Results from 222-S Laboratory ................................ 3.6

3.8 Residual Waste to Double-Deionized Water Ratios Used in Leach Tests .............................. 3.7

3.9 The pH and Alkalinity Values for Supernatant and Single-Contact Water Extract ................. 3.7

3.10 Dissolved ${ }^{99}$ Tc and ${ }^{238} \mathrm{U}$ Concentrations in Supernatant, DDI Water Extracts, and

3.11 Concentrations and Average Water-Leachable Percentages of ${ }^{99} \mathrm{Tc}$ and ${ }^{238} \mathrm{U}$ Extracted from Tank S-112 Residual Waste Sample 20407 Using Single-Contact Water-Leach Tests ... 3.8

3.12 Dissolved Metal Concentrations in Supernatant, Double-Deionized Water Extracts, and Calculated Pore Water from Tank S-112 Residual Waste Samples

3.13 Concentrations and Average Water-Leachable Percentages of Metals in Single-Contact Water Extractions from Tank S-112 Residual Waste Sample 20407.

3.14 Average Extractable Anion Concentrations Determined from Single-Contact Double-Deionized Water Extractions from Tank S-112 Residual Waste Sample 20407

3.15 Calculated Saturation Indices for Relevant Al-, Na-, Ca-, Cr-, and U-Containing Minerals Based on Compositions of Tank S-112 Double-Deionized 1-Month Single-Contact Extracts. 



\subsection{Introduction}

CH2M HILL Hanford Group, Inc. is the U.S. Department of Energy (DOE) Office of River Protection's prime contractor responsible for the storage, retrieval, and disposal of Hanford Site tank waste. As part of this effort, CH2M HILL Hanford Group, Inc. contracted with Pacific Northwest National Laboratory (PNNL) to conduct testing for selected key contaminants present in residual waste remaining in the single-shell tank 241-S-112 (S-112) after final waste retrieval. Tank S-112 is located at the Hanford Site in Richland, Washington.

This report describes results of testing and analyses conducted on residual waste in single-shell tank (SST) 241-S-112 (S-112). These tests were completed to characterize the residual waste and assess the leachability of contaminants from residual solid waste. This is the first report from this PNNL project to describe the composition and leach test data for residual waste from a salt-cake tank. All previous PNNL reports (Cantrell et al. 2008; Deutsch et al. 2006, 2007a, 2007b, 2007c) describing characterization and testing results and contaminant release models for residual waste in SSTs were based on samples from sludge tanks.

PNNL uses a tiered approach to the characterization and testing of the tank residual waste. Initial (Tier 1) laboratory tests include determination of the inventory of contaminants and bulk constituents of the residual waste and quantification of the concentrations of water-leachable contaminants and other waste components, and x-ray diffraction (XRD). Tier 2 analyses are designed based upon the results of the Tier 1 tests, priorities, and available resources. Tier 2 tests typically consist of scanning electron microscopy/energy dispersive spectrometry (SEM/EDS) analyses of the solids to identify reactive phases. In some cases, additional studies or analyses may include solubility tests, selective extractions, and application of synchrotron-based x-ray techniques and Mössbauer spectroscopy.

\subsection{Work Scope}

A set of Tier 1 laboratory tests were conducted to characterize the residual waste and identify some water-leachable constituents. The Tier 1 tests and analyses consisted of acid digestion of the as-received waste sample to measure elemental concentrations in the solid and analyses of leachates from a 1-month, single-contact water leach of contaminants from the residual waste to estimate soluble concentrations of

${ }^{99} \mathrm{Tc},{ }^{238} \mathrm{U}$, major metals, and anions. In addition, bulk XRD and SEM/EDS analyses were completed on the as-received tank S-112 residual waste. The XRD analysis was conducted to identify crystalline mineral phases present in the residual waste. For this tank S-112 study, the only Tier 2 analysis completed was SEM/EDS. Results of the SEM/EDS analyses provided information on the morphologies and compositions of solid particles in the as-received residual waste samples.

\subsection{S-100 Series Tank Description}

Tank S-112 is one of 12 SSTs located at the 241-S Tank Farm in the 200 West Area of the Hanford Site (Figure 1.1). The tank is $22.9 \mathrm{~m}$ (75 ft) in diameter with a design capacity of 758,000 gal $\left(101,330 \mathrm{ft}^{3}\right)$. The tank is constructed of 1.25 -ft-thick reinforced concrete with a 1.25 -ft-thick concrete 
top. The tank is lined with 3/8-in.-thick carbon steel at the bottom and 5/16-in.-thick plates at the sides that transition to 0.25 -in.-thick plates. Figure 1.2 presents a generalized profile view of a 100 -series tank such as SST S-112 (Parker and Barton 2007).

Tank S-112 went into service in 1952 and was declared inactive in 1976 (Parker and Barton 2007). During its service life, the tank was used to store waste from many sources, including waste from the reduction-oxidation (redox) process, evaporator bottoms, and recycling streams from the 242-S Evaporator-Crystallizer. The Hanford Defined Waste (HDW) model (Agnew 1997) indicates that tank S-112 received two waste types: a sludge waste R1 (redox) and a salt-cake waste (S1-SltCk). From 1952 through the first quarter of 1957, the tank received redox first cycle waste via cascade overflow. In 1974 and 1975, the tank received 242-S Evaporator bottoms and recycle supernatants. The tank was removed from service in the second quarter of 1976, declared inactive during the third quarter of 1976, primary stabilized in 1979, and partially isolated in December 1982.

Waste retrieval of tank S-112 occurred in two phases. The first phase of the tank S-112 retrieval demonstration used salt-cake dissolution and modified sluicing to meet the Hanford Federal Facility Agreement and Consent Order Milestone M-45-03C (Ecology et al. 1996). Phase I occurred from September 26, 2003, through May 17, 2005. This first retrieval phase reached its waste retrieval capacity limit with an estimated 31,000 gal (4,144 $\left.\mathrm{ft}^{3}\right)$ of waste remaining (approximately 95\%). This remaining volume was later revised to 28,465 gal $\left(3,805 \mathrm{ft}^{3}\right)$ when it was discovered the tank bottom was higher than originally estimated (Parker and Barton 2007).

In the second phase of tank S-112 waste retrieval, the remote water lance (RWL) was installed to retrieve the remaining hard heel. Use of this device was followed by two $25 \%$ caustic $(\mathrm{NaOH})$ additions, enhanced sluicing operations, and finally a 50-wt \% caustic addition. After final retrieval, the total residual waste volume in tank S-112 was estimated to be 2,390 gal (319 ft ${ }^{3}$ ) (Parker and Barton 2007). 


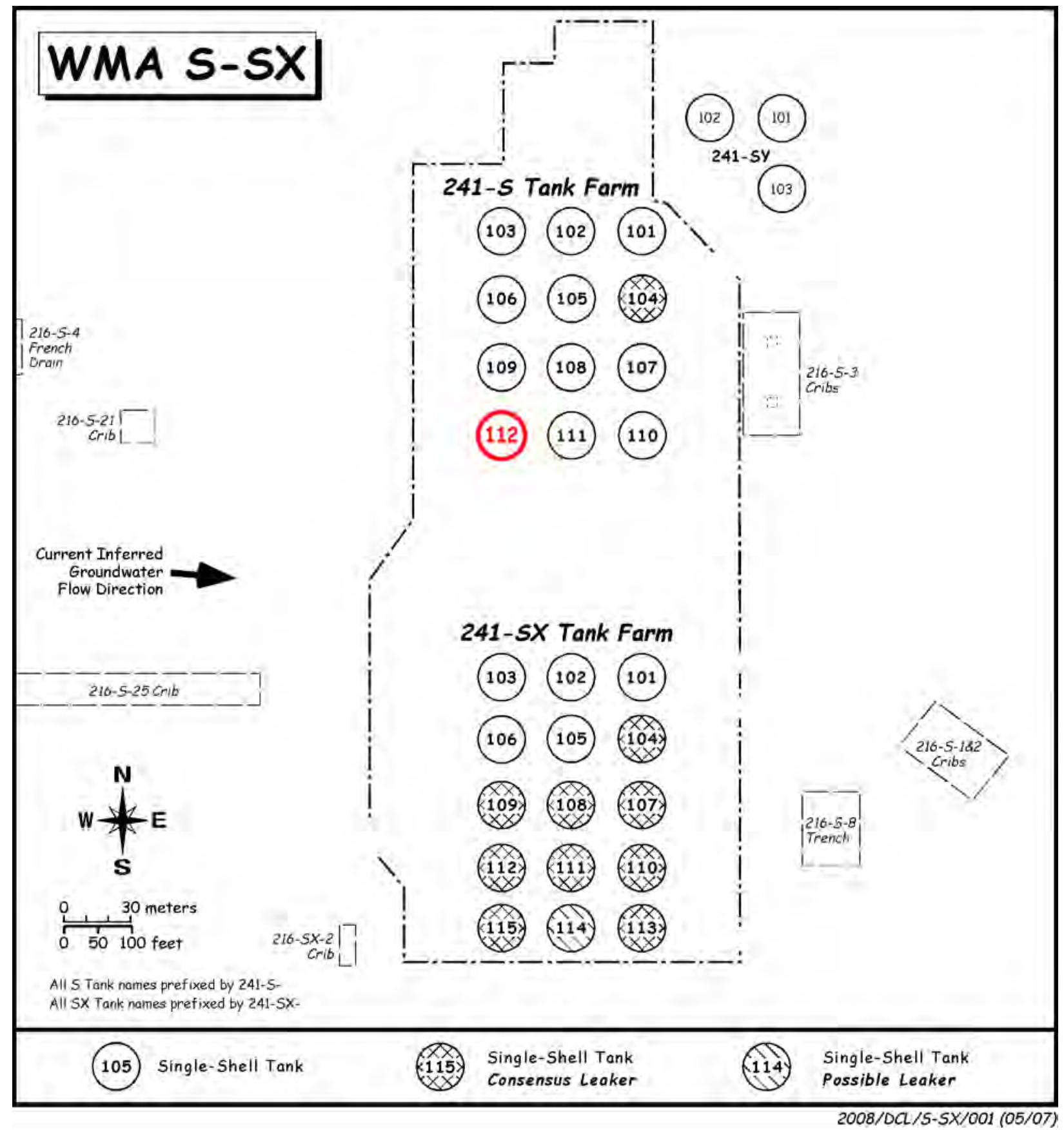

Figure 1.1. Hanford S and SX Tank Farms 


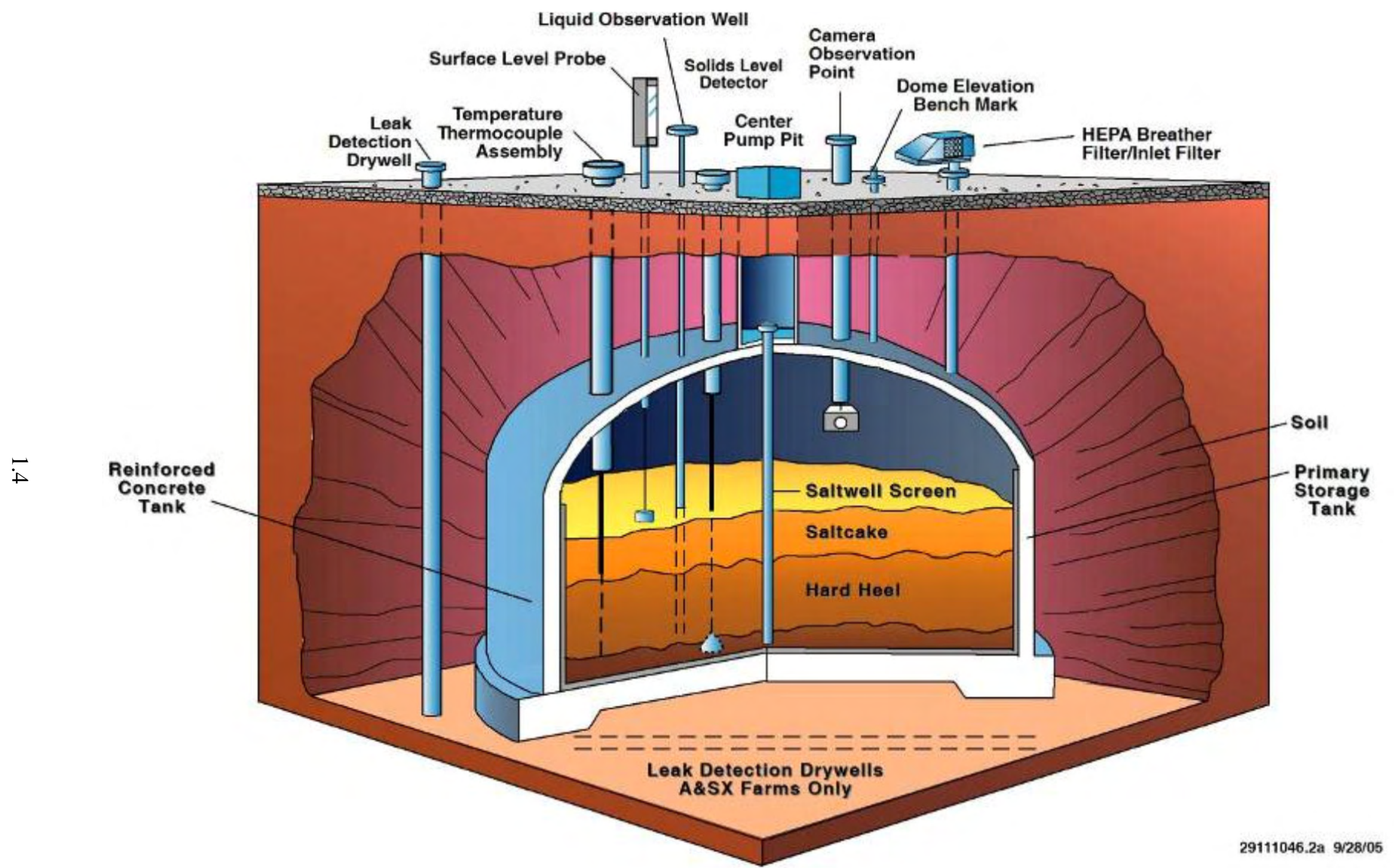

Figure 1.2. Generalized Profile View of a 100-Series Tank Such as Tank S-112 (Parker and Barton 2007) 


\subsection{Materials and Laboratory Test Methods}

This section describes residual waste samples provided to PNNL and the analytical methods and various tests used to characterize the material and measure contaminant release.

\subsection{Tank S-112 Residual Waste Samples}

Residual waste samples from tank S-112 were collected by CH2M HILL Hanford Group, Inc. during post-retrieval activities in June 2006. The material from tank S-112 (samples 20406 and 20407) was provided to PNNL on June 7, 2007 (Table 2.1). Figure 2.1 and 2.2 show as-received samples 20406, and 20407, respectively.

Table 2.1. Tank S-112 Samples Provided to PNNL by 222-S Laboratory

\begin{tabular}{|c|c|c|c||}
\hline $\begin{array}{c}\text { Sample } \\
\text { Number }\end{array}$ & Jar Size (mL) & Labcore Number & $\begin{array}{c}\text { Net Weight of Sample } \\
\text { Received (g) }\end{array}$ \\
\hline \hline 20406 & 125 & S07T006451 & 60 \\
\hline 20407 & 125 & S07T006452 & 60 \\
\hline
\end{tabular}

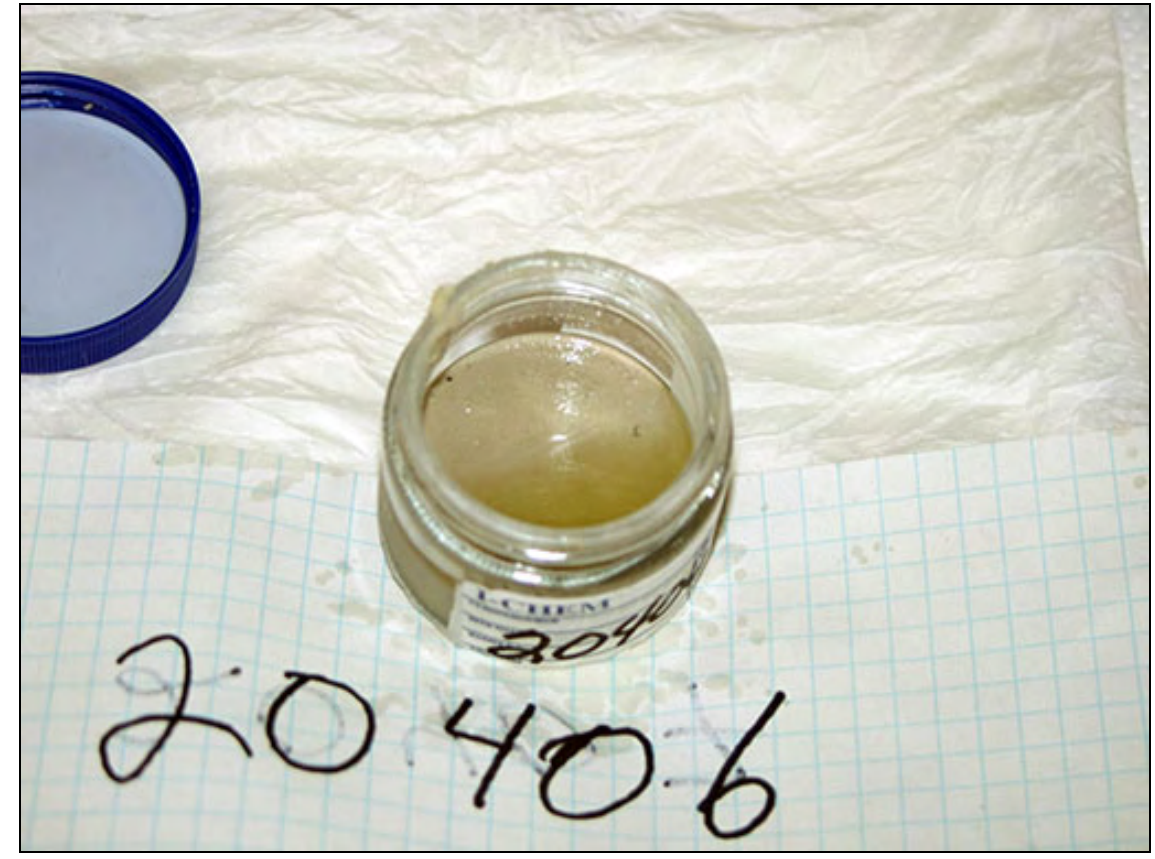

Figure 2.1. Tank S-112 Residual Waste (Sample 20406) 


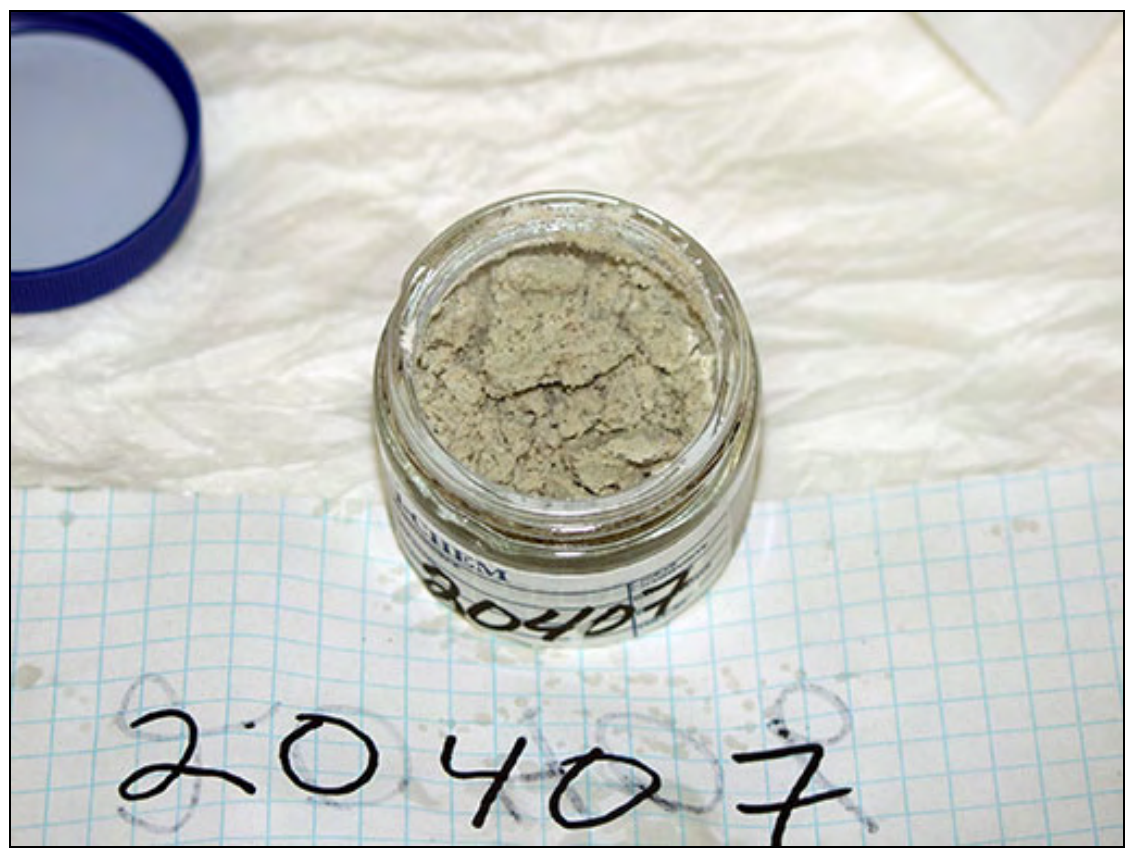

Figure 2.2. Tank S-112 Residual Waste (Sample 20407)

\subsection{Tier 1 Tests}

Tier 1 tests used in this study are described in this section. Studies of tank waste samples are generally completed using a tiered approach similar to the one developed for investigating contaminant fate and transport issues associated with past SST leaks in the vadose zone (e.g., Brown et al. 2007). Such an approach allows for initial (Tier 1) screening of samples using relatively inexpensive analytical techniques. This is followed by data analysis to determine the need for further testing (Tier 2). The only Tier 2 analysis method used on tank S-112 residual waste was SEM/EDS.

All laboratory activities were conducted in accordance with the requirements of Title 10, Code of Federal Regulations, Part 830.120, “Quality Assurance” (10 CFR 830.120), and the Hanford Analytical Services Quality Assurance Requirements Documents (HASQARD) (DOE-RL 2007). These requirements were implemented using PNNL's online quality assurance (QA) plan, “Conducting Analytical Work in Support of Regulatory Programs.” PNNL's QA plan is based on the requirements of DOE Order 414.1A as described in PNNL's Standards-Based Management System, the HASQARD relevant elements of NQA-1, as well as recognized industry standards (e.g., U.S. Environmental Protection Agency [EPA], American Society for Testing and Materials [ASTM], and American National Standards Institute).

\subsubsection{Residual Waste Composition by Acid Digestion}

Bulk compositions of residual waste solids were determined using EPA SW-846 Method 3052 (EPA 1996a) with substitutions. The substitutions to EPA SW-846 Method 3052 consist of 1) decreasing the concentrated nitric acid $\left(\mathrm{HNO}_{3}\right)$ volume from $9 \mathrm{~mL}$ to $5 \mathrm{~mL}$ and 2) increasing the double-deionized (DDI) water volume from the recommended volume of 0 to $5 \mathrm{~mL}$ up to $10 \mathrm{~mL}$. This method was used to measure metals concentrations and a limited number of nonmetals (e.g., $\mathrm{P}$ and $\mathrm{S}$ ) in the residual waste. This method is not appropriate for the anion concentrations (e.g., $\mathrm{NO}_{3}, \mathrm{Cl}, \mathrm{F}$, and $\mathrm{BO}_{3}$ ) because of the 
addition of acids used in the procedure and analyses. The anion compositions were measured separately in solutions obtained by water leaching of the solids (see Section 2.2.5).

The basic acid-digestion procedure is described in EPA SW-846 Method 3052 (EPA 1996a). In this procedure, $300 \mathrm{mg}$ of the sample is placed in a Teflon ${ }^{\circledR}$ microwave digestion vessel; 10 -mL water, 5 -mL $16 \mathrm{M} \mathrm{HNO}_{3}$, 2-mL $12 \mathrm{M} \mathrm{HCl}$, and 1-mL $29 \mathrm{M} \mathrm{HF}$ are added to the sample; and the vessel is sealed and placed in a microwave-assisted digestion system. ${ }^{1}$ The samples are treated at the EPA-recommended temperatures and times. The sample is then allowed to cool, and $0.45 \mathrm{~g}$ of boric acid $\left(\mathrm{H}_{3} \mathrm{BO}_{3}\right)$ is added to the digestate and shaken by hand. Samples are filtered through a $0.45-\mu \mathrm{m}$ pore-size syringe filter prior to analysis. There were no visible solids when the digestions were complete.

Table 2.2 lists the digestion factors (wet solid-to-solution ratios) for residual waste samples 20406 and 20407 used for the EPA acid digestions. These factors were calculated from the wet weight of waste material divided by the volume of extracting solution. The digestion factors were then multiplied by the percentage solids, as determined from moisture content analysis, to convert to a dry weight basis. The dissolved metal concentrations of the filtered solutions were then analyzed by a combination of methods, including inductively coupled plasma-mass spectrometry (ICP-MS) and inductively coupled plasmaoptical emission spectroscopy (ICP-OES). These analytical methods are described in Lindberg and Deutsch (2003).

Table 2.2. Digestion Factors for Residual Waste Solids Used for the EPA Acid Digestion Treatment

\begin{tabular}{||l|c||}
\hline \multicolumn{1}{||c||}{ Sample Number } & $\begin{array}{c}\text { Dry Weight Corrected } \\
\text { Digestion Factor (g/L) }\end{array}$ \\
\hline \hline 20406 & 8.83 \\
\hline 20406 Dup $^{(a)}$ & 7.64 \\
\hline 20407 & 9.30 \\
\hline 20407 Dup & 8.27 \\
\hline Dup = Duplicate sample. \\
\hline
\end{tabular}

\subsubsection{Moisture Content}

The moisture contents of the tank waste samples were measured to calculate dry weight concentrations for constituents in the waste. Dry weight concentrations provide a consistent measurement unit for comparison purposes that eliminates the effect of variable water content on sample concentrations.

Gravimetric water content of the waste material was determined using the ASTM procedure D2216-98, Standard Test Method for Laboratory Determination of Water (Moisture) Content of Soil and Rock by Mass (ASTM 1998), with the following minor exceptions: 1) the volume of sample recommended was decreased due to radiological concerns; and 2) the sample was dried at a lower oven temperature, $105^{\circ} \mathrm{C}$, for a longer period of time to prevent dehydration of the solids.

Residual waste samples were placed in tared containers, weighed, and dried in an oven until a constant weight was achieved, usually 24 to 48 hours. The container was then removed from the oven,

\footnotetext{
${ }^{1}$ Teflon is a registered trademark of E.I. du Pont de Nemours and Company.
} 
sealed, cooled, and weighed. All measurements were performed using a calibrated balance. The gravimetric water content is computed as the percentage change in waste sample weight before and after oven drying (i.e., [ [wet weight - dry weight $\} /$ dry weight]).

\subsubsection{Single-Contact Residual Waste Extraction Tests and Analysis of Residual Supernatant}

Water-soluble inorganic constituents were determined using a DDI water extraction method. The extract was prepared by adding $30 \mathrm{~mL}$ of DDI water to a quantity of residual waste ranging from 0.200 to 0.600 g contained in a $50-\mathrm{mL}$ polypropylene centrifuge tube. The centrifuge tube was sealed, briefly shaken by hand, and then placed on a mechanical orbital shaker for 1 month. After being shaken for the predetermined time, the tube was placed in a centrifuge and spun at 4,000 revolutions per minute (rpm) for 20 minutes. The supernatant was carefully decanted and filtered through $0.45-\mu \mathrm{m}$ pore-size membrane. More details can be found in ASTM procedure D3987-85 Standard Test Method for Shake Extraction of Solid Waste with Water (ASTM 1999).

In addition to these single-contact extraction tests, supernatant from sample 20406 was analyzed for dissolved constituents. Besides providing composition information about the residual supernatant that may still remain in the tank, the composition of the supernatant provides a baseline for comparing the leachate compositions from the DDI water extraction tests.

\subsection{4 $\quad \mathrm{pH}$}

The pH of the solutions was measured using EPA SW-846 Method 9040C (EPA 2004) with a modification. The modification consists of using a solid-state $\mathrm{pH}$ electrode instead of the recommended glass electrode.

\subsubsection{Anion Analysis}

Anion analysis was performed using an ion chromatograph (IC) following the technical procedure AGG-IC-001 (Lindberg 2004). ${ }^{2}$ Chloride, $\mathrm{NO}_{2}, \mathrm{Br}, \mathrm{NO}_{3}, \mathrm{SO}_{4}$, and $\mathrm{PO}_{4}$ were separated on a Dionex AS17 column with a gradient elution technique from 1-mM to 35-mM NaOH and measured using a conductivity detector. This methodology is a substitution for EPA SW-846 Method 9056A (EPA 2007), with the exception of using gradient elution with $\mathrm{NaOH}$ instead of the recommended isocratic elution with a $\mathrm{HCO}_{3}$ buffer.

\subsubsection{Cations and Trace Metals}

Major cation analysis (including $\mathrm{Al}, \mathrm{Si}, \mathrm{Ca}, \mathrm{Mg}, \mathrm{Na}, \mathrm{K}, \mathrm{Fe}$, and $\mathrm{Mn}$ ) was performed by ICP-OES following PNNL-AGG-ICP-AES (Baum 2008). ${ }^{3}$ Selected trace metals analysis ( ${ }^{99}$ Tc and U isotopes) was performed by ICP-MS following PNNL-AGG-415 (Clayton 2008). ${ }^{4}$

\footnotetext{
${ }^{2}$ Lindberg MJ. 2004. Determinations by Ion Chromatography (IC). AGG-IC-001 (Rev. 0). Unpublished PNNL technical procedure, Pacific Northwest National Laboratory, Richland, Washington.

${ }^{3}$ Baum SR. 2008. Inductively Coupled Plasma -Optical Emission Spectrometry (ICP-OES) Analysis. PNNL-AGG-ICP-AES (Rev. 2). Unpublished PNNL technical procedure, Pacific Northwest National Laboratory, Richland, Washington.
} 
For both ICP-OES and ICP-MS, high-purity calibration standards were used to generate calibration curves and to verify continuing calibration during the analysis. Dilutions of 10 and 5 times were made for each sample and analyzed to investigate and correct for matrix interferences.

\subsubsection{Alkalinity}

The sample alkalinity was measured by standard titration. A volume of standardized sulfuric acid was added to the sample to an endpoint of $\mathrm{pH} 4.5$ to measure total alkalinity. Alkalinity is reported is terms of an equivalent mass of $\mathrm{CaCO}_{3}$. The alkalinity procedure follows Standard Method $2320 \mathrm{~B}$, “Alkalinity by Titration” (Clesceri et al. 1998).

\subsection{X-Ray Powder Diffractometry}

Standard bulk powder XRD techniques were used to identify crystalline phases present in two as-received tank S-112 residual waste subsamples, designated as 20407 and 20407 duplicate (dup).

Because the residual waste samples were highly radioactive dispersible powders, it was necessary to prepare the XRD mounts of these samples inside a fume hood regulated for handling radioactive materials. Residual waste samples were prepared for XRD analysis by placing milligram quantities of each sample into a mixture of water and collodion solution. The collodion solution consists of $2 \%$ nitrocellulose dissolved in amyl acetate and is an x-ray amorphous, viscous binder commonly used to make random powder mounts for XRD when only a limited amount of sample is available. A trace quantity of reference-material corundum powder $\left(\alpha-\mathrm{Al}_{2} \mathrm{O}_{3}\right.$, alumina) (National Institute of Standards and Technology Standard Reference Material [NIST SRM] 676 [NIST 2005]) was added to each sample slurry as internal $2 \theta$ standard to correct for any observed peak shifts caused by slight misalignments of the mounted samples.

A pipette was used to transfer sample slurry onto a circular platform $(1 \mathrm{~cm}$ [0.39 in.] in diameter) that was placed on top of the post located on the base inside a disposable XRD-specimen holder (Figure 2.3). This specimen holder was designed specifically for safe handling of dispersible powders containing highly radioactive or hazardous materials (Strachan et al. 2003). After the samples were allowed to air-dry overnight, the holder was assembled and a piece of Kapton ${ }^{\circledR}$ film was placed between the cap and the retainer. ${ }^{5}$ The holder was sealed with wicking glue and removed from the fume hood.

Each sample was analyzed using a Scintag XRD unit equipped with a Peltier thermoelectrically cooled detector and a copper x-ray tube. The diffractometer was operated at $45 \mathrm{kV}$ and $40 \mathrm{~mA}$. Individual scans were obtained from 2 to $65^{\circ} 2 \theta$ with a step size of $0.02^{\circ}$ and dwell time of 2 seconds. Scans were collected electronically and processed using the Jade ${ }^{\circledR}$ XRD pattern-processing software. ${ }^{6}$

\footnotetext{
${ }^{4}$ Clayton ET. 2008. Inductively Coupled Plasma Mass Spectrophotometry (ICP-MS) Analysis. PNNL-AGG-415 (Rev. 2). Unpublished PNNL technical procedure, Pacific Northwest National Laboratory, Richland, Washington.

${ }^{5}$ Kapton is a registered trademark of E.I. du Pont de Nemours and Company.

${ }^{6}$ Jade is a registered trademark of Materials Data Inc.
} 


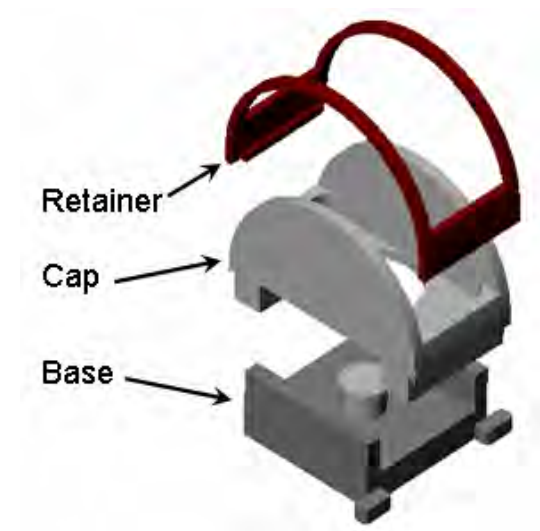

Figure 2.3. Exploded Schematic View of the XRD Sample Holder (Kapton ${ }^{\circledR}$ film not shown) (see Strachan et al. 2003)

A sample consisting of only a dry film of the collodion solution was previously prepared and analyzed by XRD (Krupka et al. 2004) so that its contribution relative to the background signals of the XRD patterns for the residual waste samples could be quantified. The resulting XRD pattern for the collodion solution film is shown in Figure 2.4. The most obvious feature of this diffraction pattern is the broad peak positioned between $10^{\circ}$ and $30^{\circ} 2 \theta$. The symmetry of this peak is characteristic of those resulting from the XRD of amorphous (noncrystalline) material. Although subtracting the collodion background from residual waste XRD patterns allows for better phase matching, this process may eliminate minor reflections and inconspicuous pattern features. Therefore, each as-measured XRD pattern was examined before and after background subtraction to ensure that the integrity of the pattern was maintained. For background subtraction, the Jade software provides the user with control over the selection of background-subtraction points. This process allows a better fit to $2 \theta$ regions under broad reflections, such as those resulting from amorphous materials. On average, 30 to 40 background points were selected from each XRD pattern, and a cubic-spline curve was then fit through each set of points. Adjustments to this curve were made by selecting additional background points in regions of a pattern that were difficult to fit. Once a well-matched curve was fitted to a pattern, the background was subtracted from each as-measured XRD pattern, resulting in a smooth tracing.

Identification of the mineral phases in XRD patterns was based on a comparison of the patterns measured for the residual waste samples with the mineral powder diffraction files (PDFTM) published by the Joint Committee on Powder Diffraction Standards (JCPDS) International Center for Diffraction Data (ICDD). As a general rule, a crystalline phase must be present at greater than $\sim 5$ to $10 \mathrm{wt} \%$ of the total sample mass (greater than $1 \mathrm{wt} \%$ under optimum conditions) to be readily detected by XRD. In general, the measured peak intensities depend on several factors, including the combined mass of each crystalline phase in the sample. Because of the physical characteristics of these residual waste samples, such as high radioactivity, high dispersibility, and variable moisture content, the mass of residual waste combined with the collodion solution for each XRD mount could not be controlled or easily determined. Dissimilarities in mineral segregation (settling) resulting from the different densities of minerals mixed with the collodion solution and associated effects on relative peak intensities also influence the overall pattern intensity. The combined effect of these factors could have some effect on the characteristic mineral peak intensities, which precluded quantitative comparisons of peak intensities for equivalent reflections in background-subtracted XRD patterns for different residual waste samples. 


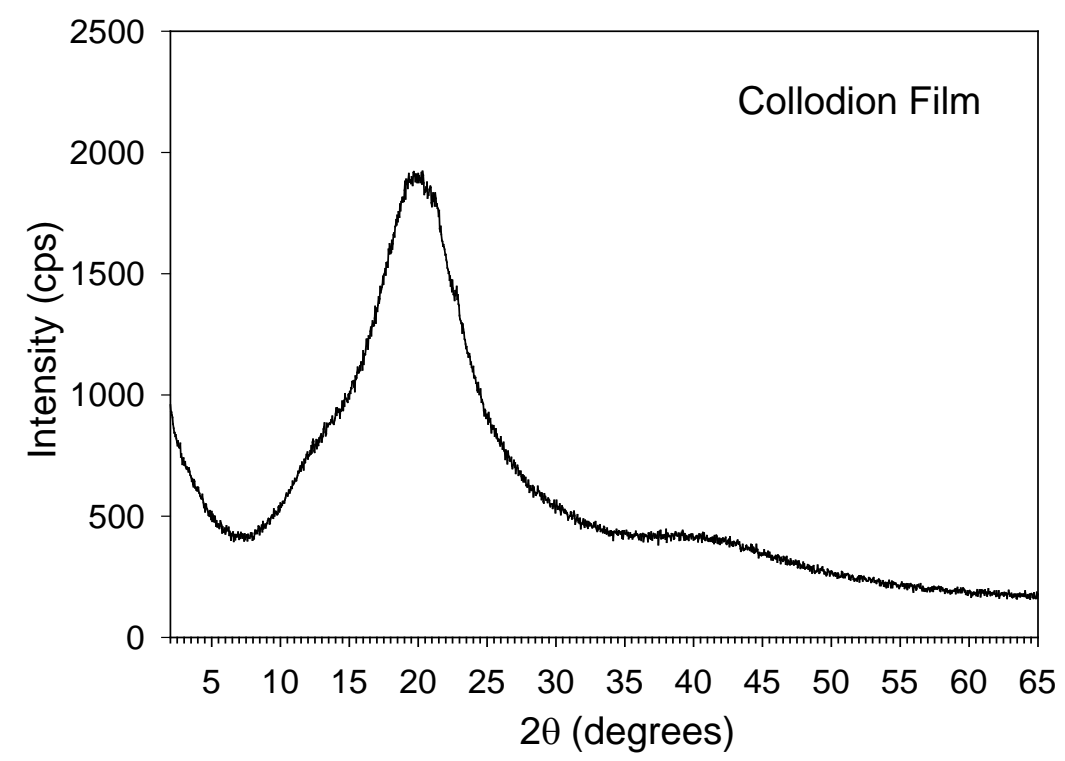

Figure 2.4. XRD Pattern for Collodion Film Measured in the Absence of Any Residual Waste Material (from Krupka et al. 2004)

\subsection{Scanning Electron Microscopy/Energy Dispersive Spectrometry Analysis}

Analyses by SEM/EDS were completed to characterize the morphologies and compositions of solid phases present in two as-received tank S-112 residual waste samples, designated as 20407 and 20407 dup. Two mounts were prepared for the sample to compensate for the possibility that a less-than-optimum mount of the sample might occur, thus improving the likelihood of obtaining representative SEM images of each sample. The mounts used for SEM/EDS consisted of double-sided carbon (C) tape attached to standard Al-mounting stubs. For each mount, small aliquots of each residual waste sample were placed on the exposed upper surface of the $\mathrm{C}$ tape using a micro spatula. Each mount was then coated with $\mathrm{C}$ using a vacuum sputter-coater to improve the conductivity of the samples and, thus, the quality of the SEM images and EDS signals.

A JEOL JSM-840 SEM was used for high-resolution imaging of micrometer/submicrometer-size particles in the residual waste samples. The EDS system provided qualitative elemental analysis for scanned areas of particles. The SEM is equipped with an INCA Energy EDS System ${ }^{7}$ to automate the collection of EDS spectra over multi-micrometer-size areas of an SEM-imaged sample. The EDS software was calibrated to a copper reference standard mounted on a specimen holder. Operating conditions consisted of $20 \mathrm{keV}$ for SEM imaging and 20-keV 100 live seconds ${ }^{8}$ for the EDS analyses. The EDS analyses are limited to elements with atomic weights heavier than boron (B). Compositions

\footnotetext{
${ }^{7}$ Oxford Instruments, Concord, Massachusetts.

${ }^{8}$ Live time is when (real time less dead time) the EDS system is available to detect incoming x-ray photons. Dead time is the portion of the total analyzing time that is actually spent processing or measuring $x$-rays. While each $\mathrm{x}$-ray pulse is being measured, the system cannot measure another x-ray that may enter the detector and is, therefore, referred to as "dead."
} 
determined by EDS are qualitative and have large uncertainties resulting from alignment artifacts caused by the variable sample and detector configurations that exist when different particles are imaged by SEM.

Photomicrographs of high-resolution backscattered electron (BSE) images were obtained as digital images and stored in electronic format. To help identify particles that contain elements with large atomic numbers, such as Tc, the SEM was operated in the BSE mode. Backscattered electron emission intensity is a function of the element's atomic number - the larger the atomic number, the brighter the signal.

Each SEM mount was examined by the SEM to identify those particles and surface features that were typical or unusual for the sample. During this examination, a SEM micrograph was first recorded at low magnification for a representative area of the mount to provide a general perspective of the sizes, types, and distributions of particles that comprise each SEM mount. Additional SEM micrographs were then recorded of particles at greater magnifications to provide a more detailed representation of the particles' characteristics, and selected points on these particles were then analyzed by EDS. 


\subsection{Laboratory Results}

This section provides results of tests conducted on residual waste samples 20406 and 20407 from tank S-112. Section 3.1 includes a description of the residual waste composition obtained from acid digestion methods. The results of the residual waste leach test and analysis of the residual waste supernatant in sample 20406 are described in Section 3.2. Residual waste characterization data generated by using XRD and SEM/EDS are discussed in Sections 3.3 and 3.4, respectively.

\subsection{Residual Waste Composition}

An important component of contaminant release-rate calculations is an accurate measurement of the total concentrations of the contaminants in the source material. As described in Section 2.2.1, the total metals and radionuclide concentrations of the residual wastes were measured using an acid digestion method. The results of these analyses are described in this section. The anionic (nonmetal) composition of the residual waste was estimated by water extraction as part of the Tier 1 analyses (Section 2.2.5). Tier 1 anion results are discussed in Section 3.2.

Table 3.1 lists the moisture content ([ \{wet wt - dry wt \}/dry wt] x 100\%) of the tank S-112 residual waste samples used for the EPA acid digestions. These values are used with the digestion factors (Table 2.2) to convert the solution analyses of the extracts from the treatments to dry weight solid concentrations. The moisture contents of the residual waste samples ranged from 25.0 to $30.5 \%$. Note that in the case of sample 20406, the moisture content was made on a sample from which free liquid was drained as it was collected from the sample container with a spatula.

Table 3.1. Moisture Contents of Tank S-112 Residual Waste Samples

\begin{tabular}{||l|c|}
\hline \multicolumn{1}{|c|}{ Sample Number } & Moisture Content \\
\hline \hline 20406 & $30.5 \%$ \\
\hline 20407 & $25.0 \%$ \\
\hline
\end{tabular}

Concentrations listed in parentheses in the following tables are defined as less than the estimated quantification limit (EQL) but greater than a zero instrument signal (concentration of zero). These values are reported for informational purposes only. They may reflect actual concentrations that are real but have larger associated uncertainties than values above the EQL or may reflect values that were calculated from the instrument's background signal and are not representative of actual residual waste composition. The EQL of an element is determined by analyzing a suite of continuing calibration verification (CCV) standards at the beginning and end of each analytical run. The lowest CCV standard that is within $\pm 10 \%$ of its certified value is multiplied by the dilution factor for the sample to determine the EQL for the element for the particular analytical run. The EQL may vary with each analysis, depending on sample matrix, dilution factors, and instrument performance. Concentrations listed as less-than $(<)$ values in the tables refer to instrument measurements that are less than zero. In these instances, the reported analyte concentration is assigned a value of " $\angle \mathrm{EQL}$ " using the EQL value appropriate for that particular analyte and set of analytical conditions. 
The following discussion of element concentrations of the residual waste is organized in terms of the analytical method used to measure concentrations in the solution extract. These methods were ICP-OES, ICP-MS, and IC. For the tables, the solution concentrations have been converted from a mass-per-liter basis to a dry, residual solid-mass basis.

The results of elemental analyses by ICP-OES are listed in Table 3.2 through Table 3.4. Boron values from acid digestion are not reported because boric acid was used in the digestion process. Among the suite of 30 elements that were analyzed, 23 elements were present above the instrumental detection limits in all samples. These elements included $\mathrm{Al}, \mathrm{As}, \mathrm{Ba}, \mathrm{Bi}, \mathrm{Ca}, \mathrm{Cd}, \mathrm{Cr}, \mathrm{Cu}, \mathrm{Fe}, \mathrm{K}, \mathrm{Li}, \mathrm{Mg}, \mathrm{Mn}, \mathrm{Na}, \mathrm{Ni}$, $\mathrm{P}, \mathrm{Pb}, \mathrm{Si}, \mathrm{Sb}, \mathrm{Sr}, \mathrm{Ti}, \mathrm{Zn}$, and $\mathrm{Zr}$. Average concentrations of the elements that were present in measurable concentrations are listed in Table 3.5.

Comparison of the elemental compositions from the ICP-OES analyses of the two residual waste samples (Table 3.5) indicates that the two samples are generally quite similar, with all elemental concentrations being well within $\pm 20 \%$ of the average for the two samples. Aluminum is clearly the dominant metal component, with an average concentration of $7.7 \mathrm{wt} \%$ (for the two samples). Other significant components include $\mathrm{Na}, \mathrm{Fe}, \mathrm{Cr}$, and $\mathrm{Si}$, with average concentrations of 4.9, 2.3, 1.7, and $1.2 \mathrm{wt} \%$, respectively.

The concentrations of ${ }^{99} \mathrm{Tc}$ and ${ }^{238} \mathrm{U}$ measured by ICP-MS are listed in Table 3.6. The average ${ }^{99} \mathrm{Tc}$ concentrations determined by acid digestion for the two samples 20406 and 20407 were 0.476 and $0.472 \mu \mathrm{g} / \mathrm{g}$ waste, respectively. The average ${ }^{238} \mathrm{U}$ concentrations determined by acid digestion for the two samples 20406 and 20407 were 28.8 and $18.7 \mu \mathrm{g} / \mathrm{g}$ waste, respectively.

\subsubsection{Comparison of Analytical Results S-112 Residual Waste with 222-S Results}

The ICP-OES and ICP-MS results reported here are compared with those determined by the 222-S Laboratory (Parker and Barton 2007) in Table 3.7. The 222-S Laboratory results in Table 3.7 were corrected to a dry weight basis for the comparison. Differences between elemental concentrations can be expected as a result of heterogeneity of the different samples analyzed by the two laboratories. For most elements, the ICP-OES and ICP-MS results reported above the EQL were reasonably consistent with those determined by the 222-S Laboratory (Parker and Barton 2007) (Cr, Fe, Mn, Ti, ${ }^{99} \mathrm{Tc}$, and ${ }^{238} \mathrm{U}$ ). For several elements ( $\mathrm{Ca}, \mathrm{Cu}, \mathrm{Pb}, \mathrm{Sb}, \mathrm{Ti}, \mathrm{Zr}$ ), meaningful comparisons cannot be made because results from one of the laboratories were below their quantification limit. Significantly higher concentrations of Si and $\mathrm{Zn}$ were determined here relative to the results of the 222-S Laboratory. It is believed that the microwave digestion procedure, similar to EPA SW-846 Method 3052 (EPA 1996a) is a more effective digestion for these elements than EPA SW-846 Method 3050B (EPA 1996b) performed by the 222-S Laboratory. Al concentrations reported here were considerably less than concentrations measured at the 222-S Laboratory. The average Al concentration determined by the 222-S Laboratory was 291,000 $\mu \mathrm{g} / \mathrm{g}$ dry waste, while the average concentration reported here was 77,200 $\mu \mathrm{g} / \mathrm{g}$ dry waste. If it is assumed that the 222-S Laboratory result for $\mathrm{Al}$ is correct and all the $\mathrm{Al}$ occurs as gibbsite, then gibbsite would account for $84 \%$ of the mass of the residual waste. This result is more consistent with the XRD and SEM/EDS results (see Sections 3.3 and 3.4) than those from the bulk composition analyses reported here. Based on these comparisons, the $\mathrm{Al}$ concentrations for the unleached (as-received) bulk sludge appear to be underestimated. The reason for this discrepancy is being evaluated. Our preliminary assumption is that the method similar to EPA SW-846 Method 3052 (EPA 1996a) may result in the formation of fine particulate Al precipitates in samples with very high concentrations of Al that were filtered out by a $0.45-\mu \mathrm{m}$ filter. There is also the potential for $\mathrm{Al}$ to adsorb to surfaces of the reaction vessel after the digestion. 
Table 3.2. Residual Waste Composition Measured by ICP-OES (Al through Cu)

\begin{tabular}{|c|c|c|c|c|c|c|c|c|c|c|}
\hline & Al & As & $\mathbf{B a}$ & $\mathrm{Be}$ & $\mathbf{B i}$ & $\mathbf{C a}$ & Cd & Co & $\mathrm{Cr}$ & $\mathrm{Cu}$ \\
\hline Sample Number & \multicolumn{10}{|c|}{$\mu g / g$ Dry Waste } \\
\hline \multicolumn{11}{|c|}{ EPA Acid Digestion } \\
\hline 20406 & $8.18 \mathrm{E}+04$ & $(5.48 \mathrm{E}+01)$ & $1.22 \mathrm{E}+01$ & $(3.52 \mathrm{E}-01)$ & $(3.90 \mathrm{E}+00)$ & $(4.77 \mathrm{E}+01)$ & $(1.31 \mathrm{E}+00)$ & $<5.66 \mathrm{E}+00$ & $1.79 \mathrm{E}+03$ & $2.08 \mathrm{E}+01$ \\
\hline 20406 Dup & $8.59 \mathrm{E}+04$ & $(5.09 \mathrm{E}+01)$ & $1.37 \mathrm{E}+01$ & $(9.80 \mathrm{E}-02)$ & $(1.67 \mathrm{E}+00)$ & $(6.01 \mathrm{E}+01)$ & $(1.07 \mathrm{E}+00)$ & $<6.55 \mathrm{E}+00$ & $1.71 \mathrm{E}+03$ & $1.96 \mathrm{E}+01$ \\
\hline 20407 & $7.82 \mathrm{E}+04$ & $(4.94 \mathrm{E}+01)$ & $1.12 \mathrm{E}+01$ & $(5.01 \mathrm{E}-02)$ & $(3.61 \mathrm{E}+00)$ & $(3.71 \mathrm{E}+01)$ & $(1.07 \mathrm{E}+00)$ & $<5.38 \mathrm{E}+00$ & $1.68 \mathrm{E}+03$ & $1.63 \mathrm{E}+01$ \\
\hline 20407 Dup & $6.27 \mathrm{E}+04$ & $(2.13 \mathrm{E}+01)$ & $1.33 \mathrm{E}+01$ & $<3.02 \mathrm{E}+00$ & $(1.99 \mathrm{E}+00)$ & $8.25 E+01$ & $(1.45 \mathrm{E}+00)$ & $<6.04 \mathrm{E}+00$ & $1.69 \mathrm{E}+03$ & $1.57 \mathrm{E}+01$ \\
\hline 20406 Avg & $8.39 \mathrm{E}+04$ & $(5.28 \mathrm{E}+01)$ & $1.29 \mathrm{E}+01$ & $(2.25 \mathrm{E}-01)$ & $(2.79 \mathrm{E}+00)$ & $(5.39 \mathrm{E}+01)$ & $(1.19 \mathrm{E}+00)$ & $<6.10 \mathrm{E}+00$ & $1.75 \mathrm{E}+03$ & $2.02 \mathrm{E}+01$ \\
\hline 20407 Avg & $7.05 \mathrm{E}+04$ & $(3.54 \mathrm{E}+01)$ & $1.23 \mathrm{E}+01$ & $(1.54 \mathrm{E}+00)$ & \begin{tabular}{|l|}
$(2.80 \mathrm{E}+00)$ \\
\end{tabular} & $5.98 \mathrm{E}+01$ & $(1.26 \mathrm{E}+00)$ & $<5.71 \mathrm{E}+00$ & $1.69 \mathrm{E}+03$ & $1.60 \mathrm{E}+01$ \\
\hline
\end{tabular}

Table 3.3. Residual Waste Composition Measured by ICP-OES (Fe through Pb)

\begin{tabular}{|c|c|c|c|c|c|c|c|c|c|c|}
\hline \multirow{2}{*}{$\begin{array}{c}\text { Sample } \\
\text { Number }\end{array}$} & $\mathbf{F e}$ & $\mathbf{K}$ & $\mathbf{L i}$ & Mg & Mn & Mo & $\mathrm{Na}$ & $\mathrm{Ni}$ & $\mathbf{P}$ & $\mathbf{P b}$ \\
\hline & \multicolumn{10}{|c|}{$\mu \mathrm{\mu} / \mathrm{g}$ Dry Waste } \\
\hline \multicolumn{11}{|c|}{ EPA Acid Digestion } \\
\hline 20406 & $1.99 \mathrm{E}+03$ & $(6.84 \mathrm{E}+01)$ & $(6.13 \mathrm{E}+00)$ & $(2.32 \mathrm{E}+00)$ & $1.37 \mathrm{E}+01$ & $(6.04 \mathrm{E}+00)$ & $5.20 \mathrm{E}+04$ & $(9.28 \mathrm{E}+00)$ & $(4.15 E+01)$ & $(8.96 \mathrm{E}+00)$ \\
\hline 20406 Dup & $2.24 \mathrm{E}+03$ & $(8.17 \mathrm{E}+01)$ & $(6.90 \mathrm{E}+00)$ & $(4.57 \mathrm{E}+00)$ & $1.45 \mathrm{E}+01$ & $(3.41 \mathrm{E}+00)$ & $5.13 \mathrm{E}+04$ & $(8.42 \mathrm{E}+00)$ & $(5.21 \mathrm{E}+01)$ & $(5.05 \mathrm{E}+00)$ \\
\hline 20407 & $2.30 \mathrm{E}+03$ & $(5.93 E+01)$ & $(6.63 \mathrm{E}+00)$ & $(3.69 \mathrm{E}+00)$ & $1.34 \mathrm{E}+01$ & $(2.85 E+00)$ & $4.57 \mathrm{E}+04$ & $(8.33 E+00)$ & $(4.51 \mathrm{E}+01)$ & $(5.53 \mathrm{E}+00)$ \\
\hline 20407 Dup & $2.57 \mathrm{E}+03$ & $(6.63 E+01)$ & $(4.16 \mathrm{E}+00)$ & $(8.71 \mathrm{E}+00)$ & $1.58 \mathrm{E}+01$ & $<1.21 \mathrm{E}+01$ & $4.74 \mathrm{E}+04$ & $(1.00 \mathrm{E}+01)$ & $(3.10 \mathrm{E}+01)$ & $(8.88 \mathrm{E}+00)$ \\
\hline 20406 Avg & $2.11 \mathrm{E}+03$ & $(7.50 \mathrm{E}+01)$ & $(6.51 \mathrm{E}+00)$ & $(3.45 \mathrm{E}+00)$ & $1.41 \mathrm{E}+01$ & $(4.73 E+00)$ & $5.17 \mathrm{E}+04$ & $(8.85 \mathrm{E}+00)$ & $(4.68 \mathrm{E}+01)$ & $(7.00 \mathrm{E}+00)$ \\
\hline 20407 Avg & $2.43 E+03$ & $(6.28 \mathrm{E}+01)$ & $(5.40 \mathrm{E}+00)$ & $(6.20 \mathrm{E}+00)$ & $1.46 \mathrm{E}+01$ & $(7.47 \mathrm{E}+00)$ & $4.66 \mathrm{E}+04$ & $(9.17 \mathrm{E}+00)$ & $(3.80 \mathrm{E}+01)$ & $(7.21 \mathrm{E}+00)$ \\
\hline \multicolumn{11}{|c|}{$\begin{array}{l}\text { Avg = Average. } \\
\text { Dup = Duplicate. } \\
\text { EQL = Estimated quantfication limit. } \\
\text { Concentrations listed in parentheses were <EQL. }\end{array}$} \\
\hline
\end{tabular}


Table 3.4. Residual Waste Composition Measured by ICP-OES (S through Zr)

\begin{tabular}{|c|c|c|c|c|c|c|c|c|c|c|}
\hline \multirow{2}{*}{$\begin{array}{c}\text { Sample } \\
\text { Number }\end{array}$} & S & Sb & Se & Si & $\mathrm{Sr}$ & $\mathbf{T i}$ & Tl & $\mathbf{V}$ & Zn & $\mathrm{Zr}$ \\
\hline & \multicolumn{10}{|c|}{$\mu g / g$ Dry Waste } \\
\hline \multicolumn{11}{|c|}{ EPA Acid Digestion } \\
\hline 20406 & $(5.89 \mathrm{E}+00)$ & $4.75 E+01$ & $<1.13 \mathrm{E}+03$ & $1.56 \mathrm{E}+03$ & $(4.03 E+00)$ & $1.59 \mathrm{E}+01$ & $(1.31 \mathrm{E}+01)$ & $<1.42 \mathrm{E}+01$ & $5.01 \mathrm{E}+01$ & $4.82 \mathrm{E}+00$ \\
\hline 20406 Dup & $<2.62 \mathrm{E}+02$ & $5.55 \mathrm{E}+01$ & $<1.31 \mathrm{E}+03$ & $1.24 \mathrm{E}+03$ & $(4.67 \mathrm{E}+00)$ & $1.07 \mathrm{E}+01$ & $<1.31 \mathrm{E}+02$ & $<1.64 \mathrm{E}+01$ & $5.01 \mathrm{E}+01$ & $4.81 \mathrm{E}+00$ \\
\hline 20407 & $<2.15 \mathrm{E}+02$ & $3.81 \mathrm{E}+01$ & $<1.08 \mathrm{E}+03$ & $9.72 \mathrm{E}+02$ & $(2.97 \mathrm{E}+00)$ & $9.81 \mathrm{E}+00$ & $(1.39 \mathrm{E}+01)$ & (7.36E-02) & $4.64 \mathrm{E}+01$ & $3.95 \mathrm{E}+00$ \\
\hline 20407 Dup & $<2.42 \mathrm{E}+02$ & $4.60 \mathrm{E}+01$ & $<1.21 \mathrm{E}+03$ & $1.11 \mathrm{E}+03$ & $(4.42 \mathrm{E}+00)$ & $8.59 \mathrm{E}+00$ & $(1.32 \mathrm{E}+01)$ & $<1.51 \mathrm{E}+01$ & $4.57 \mathrm{E}+01$ & $4.02 \mathrm{E}+00$ \\
\hline 20406 Avg & $(1.34 \mathrm{E}+02)$ & $5.15 \mathrm{E}+01$ & $<1.22 \mathrm{E}+03$ & $1.40 \mathrm{E}+03$ & $(4.35 \mathrm{E}+00)$ & $1.33 \mathrm{E}+01$ & $(7.20 \mathrm{E}+01)$ & $<1.53 \mathrm{E}+01$ & $5.01 \mathrm{E}+01$ & $4.81 \mathrm{E}+00$ \\
\hline 20407 Avg & $<2.28 \mathrm{E}+02$ & $4.20 \mathrm{E}+01$ & $<1.14 \mathrm{E}+03$ & $1.04 \mathrm{E}+03$ & $(3.70 \mathrm{E}+00)$ & $9.20 \mathrm{E}+00$ & $(1.35 \mathrm{E}+01)$ & $(7.59 \mathrm{E}+00)$ & $4.61 \mathrm{E}+01$ & $3.98 \mathrm{E}+00$ \\
\hline \multicolumn{11}{|c|}{$\begin{array}{l}\text { Avg = Average. } \\
\text { Dup = Duplicate. } \\
\text { EQL = Estimated quantification limit. } \\
\text { Concentrations listed in parentheses were }<\text { EQL. }\end{array}$} \\
\hline
\end{tabular}


Table 3.5. Average Compositions for Tank S-112 Residual Waste Samples 20406 and 20407 Measured by ICP-OES

\begin{tabular}{||c|c|c||}
\hline \multirow{2}{*}{ Element } & $\mathbf{2 0 4 0 6}$ & $\mathbf{2 0 4 0 7}$ \\
\cline { 2 - 3 } & \multicolumn{2}{|c|}{$\mathbf{\mu g / g}$ Dry Waste } \\
\hline \hline $\mathrm{Al}$ & 83,900 & 70,500 \\
\hline $\mathrm{Ba}$ & 12.9 & 12.3 \\
\hline $\mathrm{Ca}$ & $(53.9)$ & $\mathbf{( 5 9 . 8 )}$ \\
\hline $\mathrm{Cr}$ & 1,750 & 1,690 \\
\hline $\mathrm{Cu}$ & 20.2 & 16.0 \\
\hline $\mathrm{Fe}$ & 2,110 & 2,430 \\
\hline $\mathrm{Mn}$ & 14.1 & 14.6 \\
\hline $\mathrm{Na}$ & 51,700 & 46,600 \\
\hline $\mathrm{Sb}$ & 51.5 & 42.0 \\
\hline $\mathrm{Si}$ & 1,400 & 1,040 \\
\hline $\mathrm{Ti}$ & 13.3 & 9.20 \\
\hline $\mathrm{Zn}$ & 50.1 & 46.1 \\
\hline $\mathrm{Zr}$ & 4.81 & 3.98 \\
\hline $\begin{array}{l}\text { Concentrations listed in parentheses were }<\text { EQL. } \\
\text { EQL = Estimated quantification limit. }\end{array}$ \\
\hline
\end{tabular}

Table 3.6. Concentrations of ${ }^{99} \mathrm{Tc}$ and ${ }^{238} \mathrm{U}$ Measured in Tank S-112 Residual Waste by ICP-MS

\begin{tabular}{|c|c|c|}
\hline \multirow[b]{2}{*}{ Sample Number } & 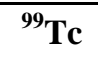 & $\overline{{ }^{238} \mathrm{U}}$ \\
\hline & \multicolumn{2}{|c|}{ pg/g Dry Waste } \\
\hline \multicolumn{3}{|c|}{ EPA Acid Digestion } \\
\hline 20406 & 0.479 & 35.5 \\
\hline 20406 Dup & 0.473 & 22.1 \\
\hline 20407 & 0.483 & 20.4 \\
\hline 20407 Dup & 0.460 & 17.0 \\
\hline 20406 Avg & 0.476 & 28.8 \\
\hline 20407 Avg & 0.472 & 18.7 \\
\hline $\begin{array}{l}\text { Avg }=\text { Average } . \\
\text { Dup = Duplicate } .\end{array}$ & & \\
\hline
\end{tabular}


Table 3.7. Comparisons of Average Compositions for Tank S-112 Residual Waste Samples 20406 and 20407 Measured by ICP-OES with Results from 222-S Laboratory

\begin{tabular}{|c|c|c|c|}
\hline \multirow[b]{2}{*}{ Element } & 20406 & 20407 & 222-S \\
\hline & \multicolumn{3}{|c|}{$\mu g / g$ Dry Waste } \\
\hline $\mathrm{Al}$ & 83,900 & 70,500 & 291,000 \\
\hline Са & (53.9) & (59.8) & 512 \\
\hline $\mathrm{Cr}$ & 1,750 & 1,690 & 1,438 \\
\hline $\mathrm{Cu}$ & 20.2 & 16.0 & (7.03) \\
\hline $\mathrm{Fe}$ & 2,110 & 2,430 & 1,477 \\
\hline Mn & 14.1 & 14.6 & 14.8 \\
\hline $\mathrm{Na}$ & 51,700 & 46,600 & 59,200 \\
\hline $\mathrm{Pb}$ & $(7.0)$ & (7.2) & 83.2 \\
\hline $\mathrm{Sb}$ & 51.5 & 42.0 & (84.2) \\
\hline $\mathrm{Si}$ & 1,400 & 1,040 & 71.9 \\
\hline $\mathrm{Ti}$ & 13.3 & 9.20 & (7.36) \\
\hline $\mathrm{Zn}$ & 50.1 & 46.1 & 16.4 \\
\hline $\mathrm{Zr}$ & 4.81 & 3.98 & (6.92) \\
\hline${ }^{99} \mathrm{Tc}$ & 0.476 & 0.472 & 0.641 \\
\hline${ }^{238} \mathrm{U}$ & 28.8 & 18.7 & 15.3 \\
\hline
\end{tabular}

\subsection{Double-Deionized Water-Leach Tests and Supernatant Composition}

Data obtained from the water-leach tests on residual waste subsamples 20407 and 20407 dup are presented in this section. Because sample 20406 contained supernatant, the water-leach test was not conducted on this sample. Concentrations of dissolved constituents in the supernatant were determined in place of the extract concentrations for sample 20406. The single-contact, water-leach tests were run in duplicate with an equilibration time of 1 month. Double-deionized water was used as the leachant. Concentrations of the constituents in the water extracts tabulated in this section are expressed in units of microCurie or microgram per gram of dry residual waste.

\subsubsection{Residual Waste to Double-Deionized Water Ratios: Single-Contact Double-Deionized Water Extracts}

In the single-contact DDI water extractions, $30 \mathrm{ml}$ of DDI water was contacted with about $0.3 \mathrm{~g}$ of moist residual waste. The moisture content of these 20407 residual waste subsamples was $25.0 \%$ by mass (Table 3.1). The dry residual waste masses calculated from moisture content measurements were used to compute the dry residual waste to DDI water ratios (Table 3.8). These ratios ranged from about 7.64 to $9.85 \mathrm{~g} / \mathrm{L}$. 
Table 3.8. Residual Waste to Double-Deionized Water Ratios Used in Leach Tests

\begin{tabular}{||l|c|}
\hline \multicolumn{1}{|c|}{ Sample Number } & Waste to DDI Water Ratio (g/L) \\
\hline \hline 20407 & 7.64 \\
\hline 20407 Dup & 9.85 \\
\hline Dup = Duplicate. \\
\hline
\end{tabular}

\subsubsection{Water Extract pH and Alkalinity - Supernatant and Single-Contact Double-Deionized Water Extracts}

The alkalinities and $\mathrm{pH}$ values measured in duplicate samples of the 20406 supernatant and the 1-month DDI water extract for 20407 are listed in Table 3.9. The average $\mathrm{pH}$ and alkalinity values for the 20406 supernatant (>12 and 370,000 mg/L, respectively) are significantly higher than those of the water extracts for sample 20407 (10.80 and $902 \mathrm{mg} / \mathrm{L}$, respectively). Because a ratio of water to solid of approximately $100 \mathrm{~mL} / \mathrm{g}$ was used in the water-leach tests, these results suggest that the alkalinity components leached from sample 20407 were likely derived from residual solution entrained in the sample.

Table 3.9. The $\mathrm{pH}$ and Alkalinity Values for Supernatant (20406) and Single-Contact Water Extract (20407)

\begin{tabular}{||l|c|c||}
\hline \multicolumn{1}{|c|}{ Sample Number } & pH & $\begin{array}{c}\text { Total Alkalinity (as CaCO } \\
\text { pH } \text { ) at }\end{array}$ \\
\hline \hline 20406 (supernatant) & $>12$ & 380,000 \\
\hline 20406 Dup (supernatant) & $>12$ & 361,000 \\
\hline 20407 (1-month DDI water extract) & 10.81 & 783 \\
\hline 20407 Dup (1-month DDI water extract) & 10.78 & 1,020 \\
\hline Dup = Duplicate.
\end{tabular}

\subsubsection{Dissolved Concentrations of ${ }^{99} \mathrm{Tc}$ and ${ }^{238} \mathrm{U}$ - Supernatant and Single-Contact Water Extracts}

The radionuclides ${ }^{99} \mathrm{Tc}$ and ${ }^{238} \mathrm{U}$ pose a long-term environmental risk because of their long half-lives and high mobility in the dissolved state. Dissolved concentrations of ${ }^{99} \mathrm{Tc}$ and ${ }^{238} \mathrm{U}$ determined in the 20406 supernatants and 20407 1-month DDI water extracts are shown in Table 3.10. In addition to these concentrations, pore water concentrations of ${ }^{99} \mathrm{Tc}$ and ${ }^{238} \mathrm{U}$ were calculated from the 20407 water extract measurements under the assumption that all dissolved constituents came from entrained pore water that was diluted by the water added for the DDI water extractions. Comparison of these pore water values for ${ }^{99}$ Tc with the 20406 supernatant results indicates the calculated pore water concentrations are somewhat higher than those of the supernatant. This suggests the majority of the ${ }^{99} \mathrm{Tc}$ in the DDI water extracts came from the pore water. Concentrations of ${ }^{238} \mathrm{U}$ in the supernatant are much higher than the calculated pore water concentrations. This result suggests that a major portion of the ${ }^{238} \mathrm{U}$ in the pore water precipitated during the 1-month DDI water extraction. This could occur as a result of a decrease in complexation of dissolved $U$ as the concentrations of dissolved hydroxide and carbonate (major complexanting agents of uranyl ions) were diluted by the DDI. 
Table 3.10. Dissolved ${ }^{99}$ Tc and ${ }^{238} \mathrm{U}$ Concentrations in Supernatant (20406), DDI Water Extracts (20407), and Calculated Pore Water (20407) from Tank S-112 Residual Waste Samples

\begin{tabular}{||l|c|c|c|c||}
\hline \multirow{2}{*}{\multicolumn{1}{|c|}{ Sample Number }} & ${ }^{{ }^{99}} \mathbf{T c}$ & ${ }^{238} \mathbf{U}$ & ${ }^{99}$ Tc & ${ }^{238} \mathbf{U}$ \\
\cline { 2 - 6 } & \multicolumn{2}{|c|}{$\mu \mathbf{g} / \mathbf{L}$} & \multicolumn{2}{c||}{$\mu \mathbf{C i} / \mathbf{L}$} \\
\hline \hline 20406 (supernatant) & 160 & 2,310 & 2.71 & $7.76 \mathrm{E}-4$ \\
\hline 20406 Dup (supernatant) & 136 & 2,070 & 2.31 & $6.96 \mathrm{E}-4$ \\
\hline 20407 (1-month DDI water extract) & 0.550 & 0.740 & 0.00935 & $2.49 \mathrm{E}-7$ \\
\hline 20407 Dup (1-month DDI water extract) & 0.850 & 1.43 & 0.0145 & $4.80 \mathrm{E}-7$ \\
\hline 20407 (calculated pore water) & 177 & 238 & 3.00 & $7.99 \mathrm{E}-5$ \\
\hline 20407 Dup (calculated pore water) & 273 & 459 & 4.64 & $1.54 \mathrm{E}-4$ \\
\hline
\end{tabular}

\subsubsection{Extractable ${ }^{99}$ Tc and ${ }^{238} \mathrm{U}-$ Single-Contact Water Extracts}

The DDI extractable concentrations of ${ }^{99} \mathrm{Tc}$ and ${ }^{238} \mathrm{U}$ per gram of dry waste after 1 month of contact for sample 20407 are listed in Table 3.11. The average concentration of ${ }^{99} \mathrm{Tc}$ extracted from the single-contact extracts from sample 20407 was fairly low $(0.079 \mu \mathrm{g} / \mathrm{g}$ waste). When compared to the total ${ }^{99} \mathrm{Tc}$ in the residual waste as measured by acid digestion (Table 3.6), the average water leachable concentration represents about $17 \%$ of the ${ }^{99} \mathrm{Tc}$ in the residual wastes (Table 3.11).

Table 3.11. Concentrations and Average Water-Leachable Percentages of ${ }^{99} \mathrm{Tc}$ and ${ }^{238} \mathrm{U}$ Extracted from Tank S-112 Residual Waste Sample 20407 Using Single-Contact Water-Leach Tests

\begin{tabular}{||l|c|c|c|c|c|c||}
\hline \multirow{2}{*}{ Sample Number } & ${ }^{99}$ Tc & ${ }^{238} \mathbf{U}$ & ${ }^{99}$ Tc & ${ }^{238} \mathbf{U}$ & ${ }^{99}$ Tc & ${ }^{238} \mathbf{U}$ \\
\cline { 2 - 7 } & \multicolumn{2}{|c|}{$\mu \mathbf{g} / g$ Dry Waste } & \multicolumn{2}{|c||}{$\boldsymbol{\mu C i / g}$ Dry Waste } & \multicolumn{2}{c||}{$\begin{array}{c}\text { Percent Water } \\
\text { Leachable (\%) }\end{array}$} \\
\hline \hline 20407 & 0.0719 & 0.0968 & $1.22 \mathrm{E}-03$ & $3.25 \mathrm{E}-08$ & & \\
\hline 20407 Dup & 0.0863 & 0.145 & $1.47 \mathrm{E}-03$ & $4.88 \mathrm{E}-08$ & & \\
\hline 20407 Average & 0.0791 & 0.121 & $1.34 \mathrm{E}-03$ & $4.06 \mathrm{E}-08$ & $16.8 \%$ & $0.65 \%$ \\
\hline
\end{tabular}

The concentration of ${ }^{238} \mathrm{U}$ extracted from the tank S-112 residual waste with DDI was relatively low. The average extractable ${ }^{238} \mathrm{U}$ concentration for sample 20407 was $0.12 \mu \mathrm{g} / \mathrm{g}$ waste. The percentages calculated using the acid digestion concentrations for the total values indicate that $0.65 \%{ }^{238} \mathrm{U}$ leached from the residual waste (Table 3.11). These low percentages, especially when compared to those for Na and Ca (discussed in Section 3.2.4), indicate that ${ }^{238} \mathrm{U}$ and possibly ${ }^{99} \mathrm{Tc}$ are present in the as-received residual waste in solid forms with relatively low solubilities or slow dissolution rates.

\subsubsection{Dissolved Concentrations of Metals - Supernatant and Single-Contact Water Extracts}

Concentrations of several metals, such as $\mathrm{Al}$, As, B, Ba, Be, Bi, Ca, Cd, Co, Cr, Cu, Fe, K, Li, Mg, Mn, Mo, Na, Ni, P, Pb, S, Se, Si, Sr, Ti, Tl, V, Zn, and Zr in the DDI water extracts, were measured by ICP-OES. Among these, only four metals ( $\mathrm{Al}, \mathrm{Ca}, \mathrm{Cr}$, and $\mathrm{Na}$ ) were present in concentrations above the EQL (Table 3.12). Dissolved concentrations of Al, Ca, Cr, and Na determined in the 20406 supernatants 
and 20407 water extracts are shown in Table 3.12. In addition to these concentrations, pore water concentrations calculated from the 20407 water extract measurements were made assuming that all the dissolved metals came from pore water entrained in the sample, which was diluted by the water added for the DDI water extractions. Comparison of the concentrations of the 20407 calculated pore water concentrations for $\mathrm{Al}$ and $\mathrm{Na}$ with the 20406 supernatant are quite similar, indicating that dissolved $\mathrm{Al}$ and $\mathrm{Na}$ in the 20407 DDI water extracts were likely derived from diluted pore water in the sample. The calculated 20407 pore water concentrations of $\mathrm{Ca}$ are over 200 times that of the supernatant, indicating that essentially all the Ca in the 20407 DDI water extracts was derived from dissolution of a solid phase in the as-received waste sample. The calculated 20407 pore water concentrations of $\mathrm{Cr}$ are nearly twice that of the supernatant, indicating that approximately half the Cr in the 20407 DDI water extracts was derived from the pore fluid and half from dissolution of a solid in the sample.

Table 3.12. Dissolved Metal Concentrations in Supernatant (20406), Double-Deionized Water Extracts (20407), and Calculated Pore Water (20407) from Tank S-112 Residual Waste Samples

\begin{tabular}{||l|c|c|c|c|c||}
\hline \multirow{2}{*}{\multicolumn{1}{c|}{ Sample Number }} & Al & Ca & Cr & Na \\
\cline { 2 - 6 } & \multicolumn{5}{c||}{$\mu \mathbf{g} / \mathbf{L}$} \\
\hline \hline 20406 (supernatant) & $2.16 \mathrm{E}+07$ & $(5.15 \mathrm{E}+02)$ & $2.81 \mathrm{E}+05$ & $1.59 \mathrm{E}+08$ \\
\hline 20406 Dup (supernatant) & $2.16 \mathrm{E}+07$ & $(3.00 \mathrm{E}+02)$ & $2.80 \mathrm{E}+05$ & $1.54 \mathrm{E}+08$ \\
\hline 20407 (1-month DDI water extract) & $4.90 \mathrm{E}+04$ & $4.14 \mathrm{E}+02$ & $1.37 \mathrm{E}+03$ & $3.08 \mathrm{E}+05$ \\
\hline 20407 Dup (1-month DDI water extract) & $6.64 \mathrm{E}+04$ & $4.23 \mathrm{E}+02$ & $1.79 \mathrm{E}+03$ & $4.05 \mathrm{E}+05$ \\
\hline 20407 (calculated pore water) & $1.57 \mathrm{E}+07$ & $1.33 \mathrm{E}+05$ & $4.41 \mathrm{E}+05$ & $9.88 \mathrm{E}+07$ \\
\hline 20407 Dup (calculated pore water) & $2.13 \mathrm{E}+07$ & $1.36 \mathrm{E}+05$ & $5.74 \mathrm{E}+05$ & $1.30 \mathrm{E}+08$ \\
\hline $\begin{array}{l}\text { Dup = Duplicate. } \\
\text { Concentrations listed in parentheses were }<\mathrm{EQL} .\end{array}$ \\
\hline
\end{tabular}

\subsubsection{Extractable Metal Concentrations - Single-Contact Double-Deionized Water Extracts}

Table 3.13 lists concentrations of extractable metals that were measured at concentrations about the EQL ( $\mathrm{Al}, \mathrm{Ca}, \mathrm{Cr}$, and $\mathrm{Na}$ ) in the DDI water extracts after 1 month of contact with residual waste sample 20407 as determined on a per gram of dry waste basis. The most highly leachable element was Na followed by Al, Cr, and Ca. Percentages of total metals that were DDI water extractable are also listed in Table 3.13. These results indicate that $\mathrm{Na}$ and $\mathrm{Ca}$ are both highly extractable, while $\mathrm{Al}$ and $\mathrm{Cr}$ are moderately extractable. 
Table 3.13. Concentrations and Average Water-Leachable Percentages of Metals in Single-Contact Water Extractions from Tank S-112 Residual Waste Sample 20407

\begin{tabular}{||l|c|c|c|c||}
\hline \multirow{2}{*}{\multicolumn{1}{|c|}{ Sample Number }} & Al & Ca & Cr & Na \\
\cline { 2 - 5 } & \multicolumn{4}{|c||}{$\mu \mathbf{g} / \mathbf{g}$ Dry Waste } \\
\hline \hline 20407 & $6.41 \mathrm{E}+03$ & $5.42 \mathrm{E}+01$ & $1.80 \mathrm{E}+02$ & $4.02 \mathrm{E}+04$ \\
\hline 20407 Dup & $6.74 \mathrm{E}+03$ & $4.29 \mathrm{E}+01$ & $1.81 \mathrm{E}+02$ & $4.11 \mathrm{E}+04$ \\
\hline 20407 Average & $6.58 \mathrm{E}+03$ & $4.85 \mathrm{E}+01$ & $1.81 \mathrm{E}+02$ & $4.07 \mathrm{E}+04$ \\
\hline & \multicolumn{5}{|c||}{ Percent Water Leachable (\%) } \\
\hline 20407 Average & 9.3 & 81.2 & 10.7 & 87.4 \\
\hline Dup = Duplicate.
\end{tabular}

\subsubsection{Extractable Anion Concentrations - Single-Contact Water Extracts}

Concentrations of anions extractable per gram of dry waste that were present in the DDI water extracts after 1-month contact were measured by IC (Table 3.14). All anions determined by this IC method were below their detection limits; this indicates the major anions in the leachates were hydroxide and carbonate.

Table 3.14. Average Extractable Anion Concentrations Determined from Single-Contact

Double-Deionized Water Extractions from Tank S-112 Residual Waste Sample 20407

\begin{tabular}{|c|c|c|c|c|c|c|}
\hline \multirow[b]{2}{*}{ Sample Number } & $\mathbf{F}$ & $\mathbf{C l}$ & $\mathrm{NO}_{2}$ & $\mathrm{NO}_{3}$ & $\mathrm{SO}_{4}$ & $\mathbf{P O}_{4}$ \\
\hline & \multicolumn{6}{|c|}{$\mu \mathrm{g} / \mathrm{g}$ Dry Waste } \\
\hline 204071 Month & $<2.62 \mathrm{E}+02$ & $<6.54 \mathrm{E}+02$ & $<1.31 \mathrm{E}+03$ & $<1.31 \mathrm{E}+03$ & $<1.96 \mathrm{E}+03$ & $<1.96 \mathrm{E}+03$ \\
\hline 204071 Month Dup & $<2.03 \mathrm{E}+02$ & $<5.07 \mathrm{E}+02$ & $<1.01 \mathrm{E}+03$ & $<1.01 \mathrm{E}+03$ & $<1.52 \mathrm{E}+03$ & $<1.52 \mathrm{E}+03$ \\
\hline
\end{tabular}

\subsection{X-Ray Diffraction Results}

Bulk XRD patterns were measured on two as-received tank S-112 residual waste subsamples (designated 20407 and 20407 dup). The XRD mounts were prepared as described in Section 2.3. The XRD sample mounts of tank S-112 residual waste included the addition of a trace quantity of referencematerial corundum powder ( $\alpha-\mathrm{Al}_{2} \mathrm{O}_{3}$, alumina) (NIST SRM 676 [NIST 2005]) as an internal $2 \theta$ standard for each XRD pattern. Identification of the mineral phases in XRD patterns was based on a comparison of the XRD patterns measured for the residual waste samples with the mineral PDFs ${ }^{\mathrm{TM}}$ published by the JCPDS ICDD.

Figures 3.1 and 3.2 show the XRD patterns for subsamples 20407 and 20407 dup, respectively. In each of these figures, the top XRD pattern (designated A) and bottom XRD pattern (designated B) show, respectively, the as-measured (before background subtraction) and background-subtracted patterns for each subsample. Each XRD pattern is shown as a function of degrees $2 \theta$ based on $\operatorname{CuK}_{\alpha}$ radiation $(\lambda=$ $1.5406 \AA$ ). The vertical axis in each pattern represents the intensity of the XRD peaks. For comparison, the XRD patterns in Figure 3.1 are shown schematically along with the database patterns for gibbsite 


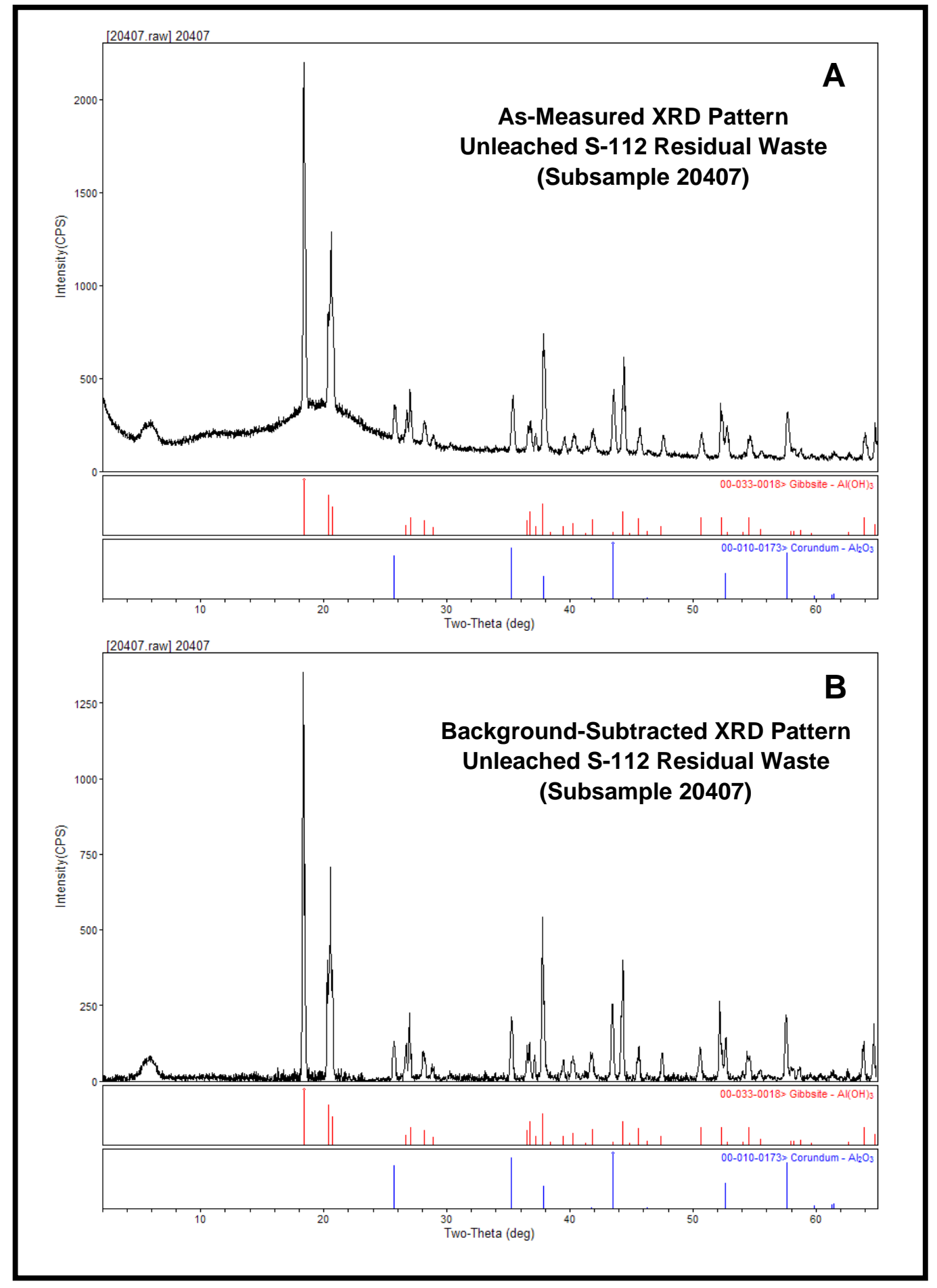

Figure 3.1. As-Measured (A) and Background-Subtracted (B) XRD Patterns for Subsample 20407 of Unleached Tank S-112 Residual Waste 


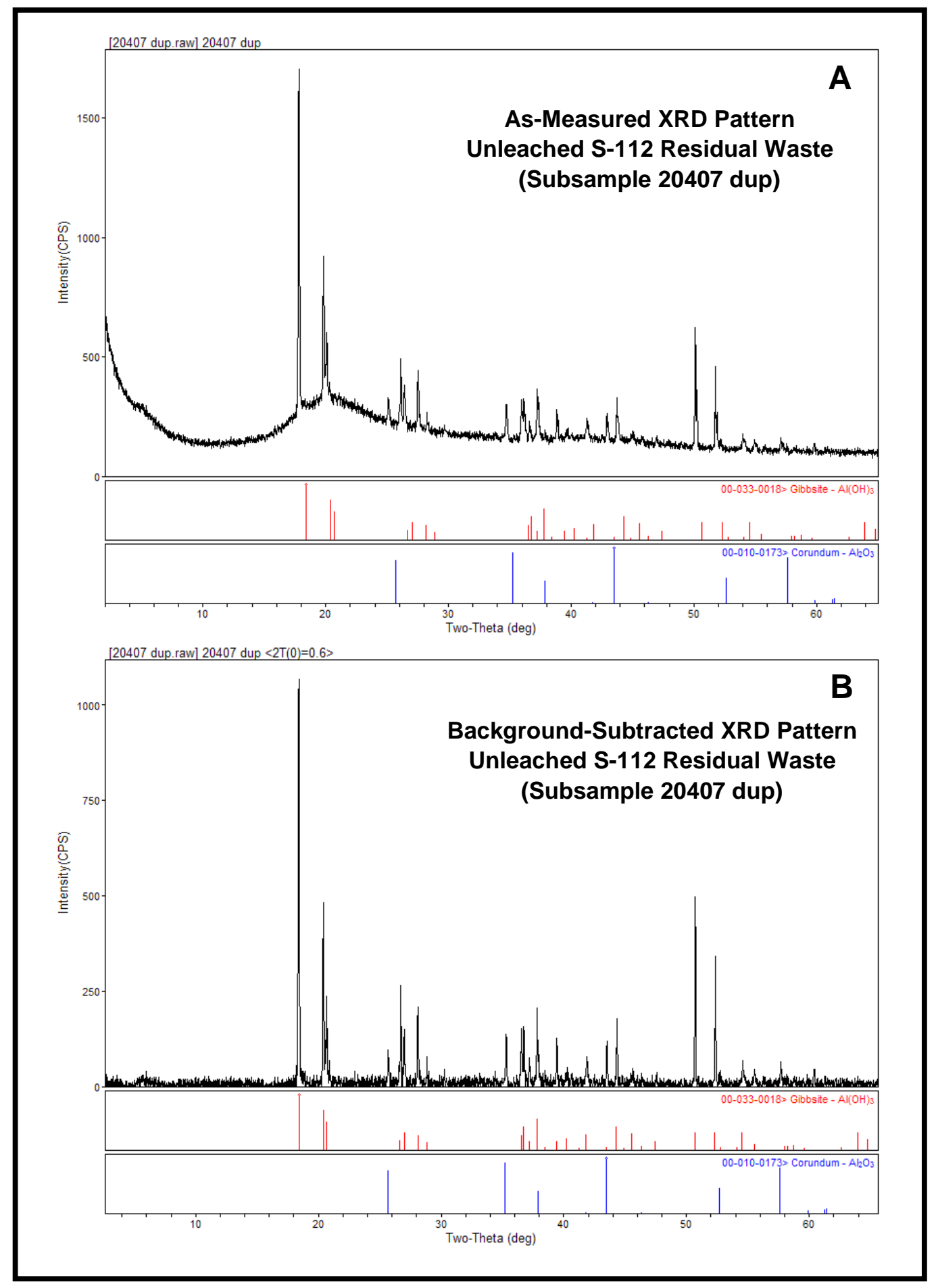

Figure 3.2. As-Measured (A) and Background-Subtracted (B) XRD Patterns for Subsample 20407 dup of Unleached Tank S-112 Residual Waste 
[Al(OH) $\left.)_{3}\right](\mathrm{PDF} \# 00-033-0018)$ and corundum (PDF \#00-010-0173). In the schematic database (PDF) patterns shown in Figure 3.1, the height of each line represents the relative intensity of an XRD peak (i.e., the most intense [the highest] peak has a relative intensity of $100 \%$ ).

Analysis of the XRD patterns for subsamples 20407 and 20407 dup indicate the tank S-112 waste sample 20407 consists essentially of all (more than $~ 90 \%$ ) gibbsite. Typically, a crystalline phase must be present at greater than $~ 5$ to $10 \mathrm{wt} \%$ (greater than $\sim 1 \mathrm{wt} \%$ under optimum conditions) to be readily detected by bulk XRD. All reflections in the XRD patterns for subsamples 20407 and 20407 dup could be matched to peaks in the XRD database patterns for gibbsite or corundum. The absence of any unidentified reflections indicates that these samples do not contain any other crystalline phases present at greater than $\sim 5$ to $10 \mathrm{wt} \%$. The two as-measured XRD patterns (e.g., see Figure 3.1A) contain a broad diffraction profile (or hump) from approximately 10 to $30^{\circ} 2 \theta$. The XRD pattern for subsample 20407 (Figure 3.1) also contains a small, wide reflection at approximately $5.6^{\circ} 2 \theta$. For these samples, diffraction from the nitrocellulose binder and the Kapton ${ }^{\circledR}$ polyimide film used in the sample holder are thought to be the main contributors to the broad diffraction profile from 10 to $30^{\circ} 2 \theta$ and the small reflection at $5.6^{\circ} 2 \theta$, respectively.

\subsection{Scanning Electron Microscopy/ Energy Dispersive Spectrometry Results}

Analysis by SEM/EDS of two subsamples (designated 20407 and 20407 dup) of as-received unleached tank S-112 residual waste was completed. Sample mount preparation and SEM/EDS analyses were completed as described in Section 2.4. The Appendix contains all SEM micrographs for the two subsamples of tank S-112 residual waste and the tabulations of the elemental compositions derived from the EDS analyses of particles in these SEM-analyzed subsamples. All SEM micrographs (including those shown in this section) were collected using BSE emission to facilitate identification of particles that contain elements with large atomic numbers (i.e., the larger the atomic number, the brighter the signal contrast).

Figure 3.3 is a low-magnification micrograph that shows the morphologies, sizes, and surface textures of typical particles present in unleached tank S-112 residual waste. Analysis of the SEM micrographs, such as Figure 3.3, indicates the unleached tank S-112 residual waste is made up primarily of a single phase that likely has a coating of a second phase. Many of the typical particles have external crystal faces and exhibit hexagonal form and possibly basal cleavage (see inserts in Figure 3.3). A few particles (discussed later in this section) distinguished by their brightness and/or in a different form relative to those shown in Figure 3.3 were observed, but these trace phases were extremely rare.

Analysis of the SEM/EDS results indicate the primary phase in unleached tank S-112 residual waste is likely made up of $\mathrm{Al}, \mathrm{O}$, and possibly $\mathrm{H}$ and/or $\mathrm{C}$, but has an encrustation on its surfaces that also contains Na. Close inspection of SEM micrographs for particles typical to Figure 3.3 indicate many (possibly most) of these particles have a multi-micrometer-thick coating on their surfaces. Examples of particles that exhibit surface features suggestive of the presence of this Na-rich coating are shown by areas circled in blue in Figure 3.4. The EDS analyses indicate most particles shown in Figure 3.3 are comprised of Al-Na-O $( \pm \mathrm{H} \pm \mathrm{C})$. However, because the SEM/EDS method is essentially a near-surface characterization technique of the top few micrometers of a probed particle (analysis depth depends on beam voltage and sample composition), the EDS analyses are therefore sensitive to the composition of any micrometer-thick surface coatings. The EDS results also indicate that $\mathrm{Na}$ is absent in the analyses of some particles typical to Figure 3.3 (see EDS analyses in the Appendix). The EDS spectrum (Figure 3.4) 

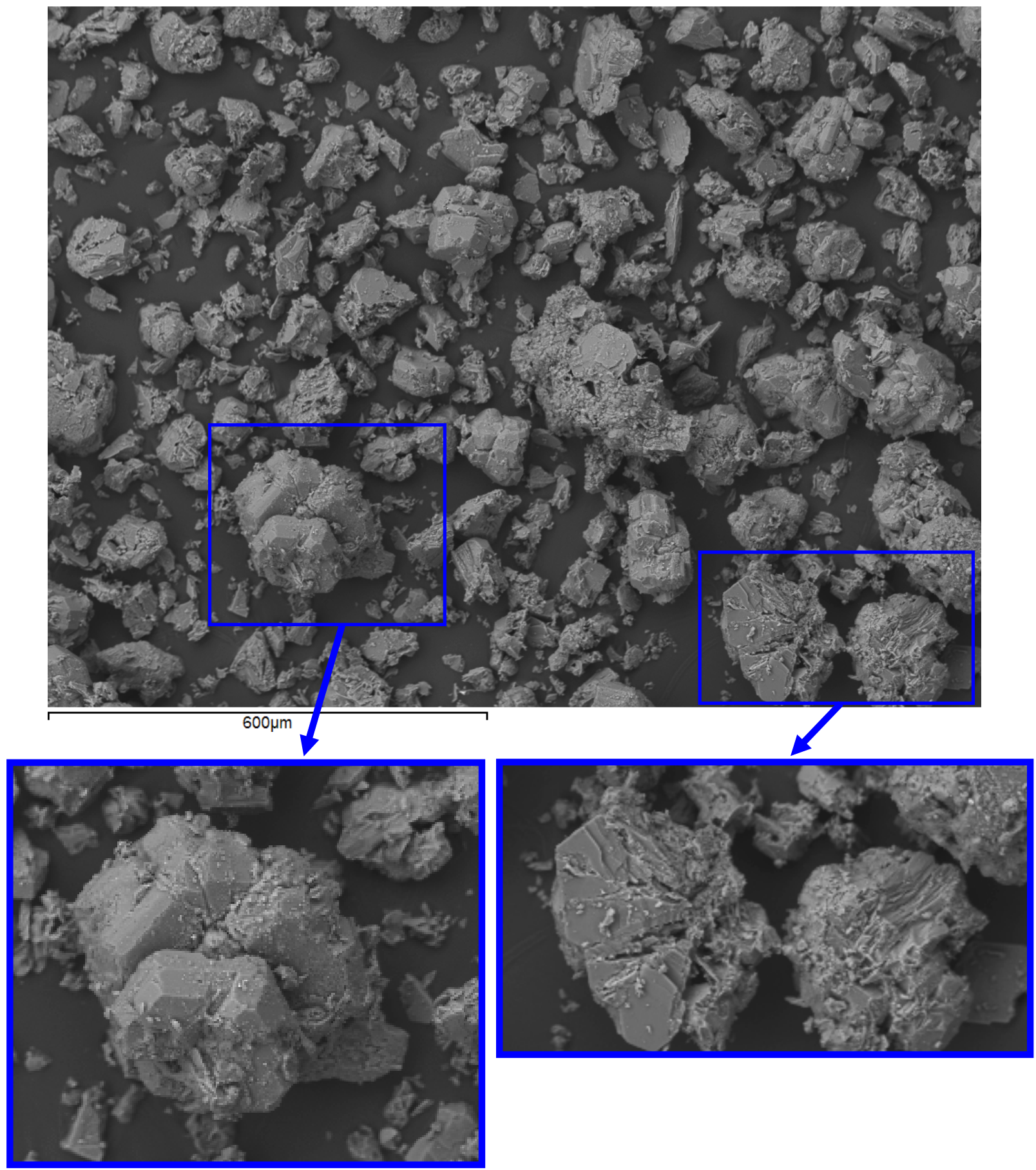

Figure 3.3. Low-Magnification Backscattered Electron SEM Images of Typical Particles in Unleached Subsample 20407 of Tank S-112 Residual Waste 


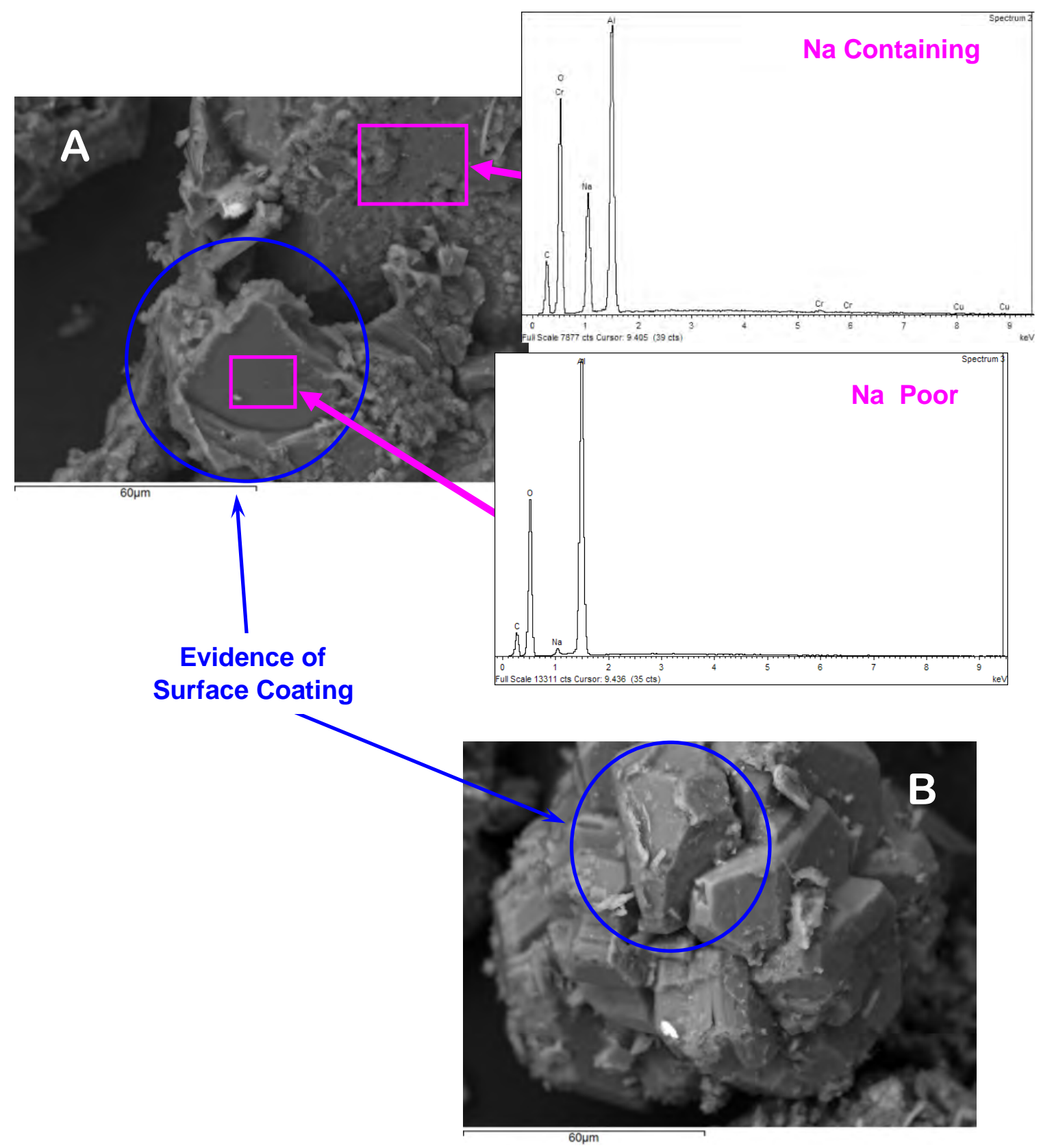

Figure 3.4. Backscattered Electron SEM Images Showing Evidence for Na-Rich Surface Coating on Typical Particles and Corresponding EDS Spectra for Na-Rich and Na-Poor Areas of Such Particles in Unleached Subsamples 20407 (A) and 20407 dup (B) of Tank S-112 Residual Waste 
that shows little or no Na likely reflects the composition for surfaces of $\mathrm{Al}-\mathrm{O}( \pm \mathrm{H} \pm \mathrm{C})$ particles underneath this encrustation, which probably detached during sampling of the residual waste or preparation of the SEM mounts.

The conclusion based on the SEM/EDS results that the primary phase in unleached tank S-112 residual waste is composed of $\mathrm{Al}-\mathrm{O}( \pm \mathrm{H} \pm \mathrm{C})$ is consistent with the XRD results in Section 3.3. The XRD results indicate the crystalline solid in the bulk sample consists essentially of gibbsite $\left[\mathrm{Al}(\mathrm{OH})_{3}\right]$. The EDS composition measured for the Na-poor solid shown in Figure 3.4 is $38.9 \mathrm{wt} \% \mathrm{Al}$ and $60.0 \mathrm{wt} \% \mathrm{O}$, which is close to the ideal composition of gibbsite of $34.6 \mathrm{wt} \% \mathrm{Al}, 61.5 \mathrm{wt} \% \mathrm{O}$, and $3.9 \mathrm{wt} \% \mathrm{H}$. The morphology of the majority of the particles shown in Figure 3.3 (i.e., external crystal faces, hexagonal form, and basal cleavage) is also consistent with gibbsite.

It has not been possible to identify the phase that comprises the surface coating on the gibbsite particles from the XRD and SEM/EDS analyses results. Because there were no unidentified reflections in the XRD patterns, the XRD results do not provide any information regarding the identity of this surface phase. The surface encrustation is either amorphous and thus cannot be detected by XRD, or is crystalline but present at too low a concentration to be detected by XRD. The EDS compositions measured for the Al-Na-O solid do not agree with the ideal compositions for phases such $\mathrm{NaAlO}_{2}$ (sodium aluminate, $28.0 \mathrm{wt} \% \mathrm{Na}, 32.9 \mathrm{wt} \% \mathrm{Al}$, and $39.00 \mathrm{wt} \% \mathrm{O})$ or dawsonite $\left[\mathrm{NaAl}\left(\mathrm{CO}_{3}\right)(\mathrm{OH})_{2}, 16.0 \mathrm{wt} \% \mathrm{Na}, 18.7 \mathrm{wt} \%\right.$ $\mathrm{Al}, 55.6 \mathrm{wt} \% \mathrm{O}, 8.3 \mathrm{wt} \% \mathrm{C}$, and $1.4 \mathrm{wt} \% \mathrm{H}$ ]. For comparison, the EDS composition for the solid having the highest measured concentration of $\mathrm{Na}$ is $29.4 \mathrm{wt} \% \mathrm{Na}, 18.0 \mathrm{wt} \% \mathrm{Al}$, and $51.5 \mathrm{wt} \% \mathrm{O}$. The majority of the EDS analyses for Na-containing solids are estimated to range from approximately 5 to $20 \mathrm{wt} \% \mathrm{Na}$ and 20 to $35 \mathrm{wt} \% \mathrm{Al}$.

A few particles of other compositions were observed by SEM/EDS in the unleached tank S-112 residual waste, but these phases were very rare. These phases were easily distinguished by their brightness and/or different form relative to particles typical to Figure 3.3. These phases include one or more Fe oxides shown by blue arrows in Figure 3.5; a Ca-Cr-O phase shown by the blue arrow in the SEM micrograph in Figure 3.6A; a $\mathrm{Pb}-\mathrm{Cl} \pm \mathrm{O}$ phase shown by the blue arrow in the right SEM micrograph in Figure 3.6B; possibly one or more silicate phases shown by the blue arrows in Figure 3.7; and an acicular (needle-like) phase with an unknown composition shown by the yellow arrows in Figure 3.7. The identities of the phases could not be determined based on the results of the XRD and SEM/EDS analyses. Trace concentrations of $\mathrm{Cr}$ and possibly $\mathrm{Mn}$ were associated with the few Fe oxide particles observed. The complete compositions of the $\mathrm{Ca}-\mathrm{Cr}-\mathrm{O}, \mathrm{Pb}-\mathrm{Cl} \pm \mathrm{O}$, and silicate phases are uncertain because the analyzed particles were likely aggregates that also contain $\mathrm{Al}-\mathrm{Na}-\mathrm{O}$ and/or Fe oxide solids.

Neither Tc, U, nor I was detected in any of the particles in the SEM samples of unleached tank S-112 residual waste analyzed by EDS as part of these studies. 

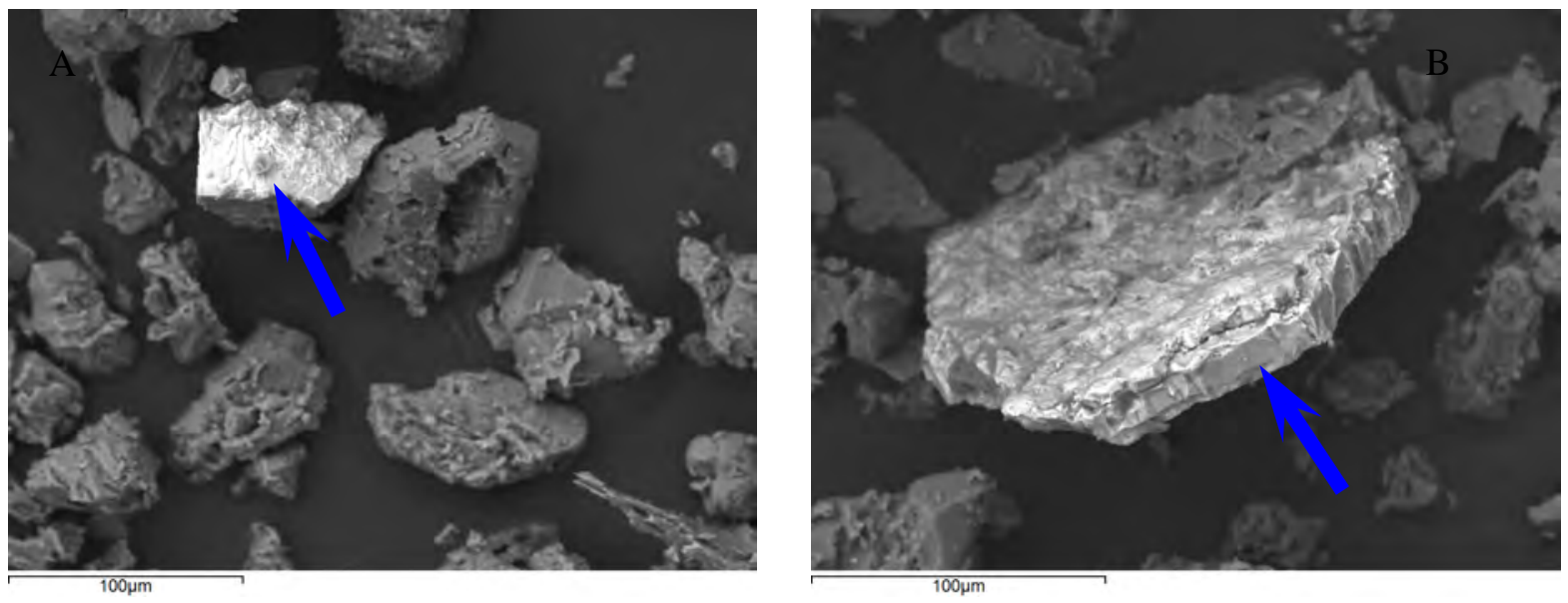

Figure 3.5. Backscattered Electron SEM Images Showing Fe Oxide Particles Present in Unleached Subsamples 20407 (A) and 20407 dup (B) of Tank S-112 Residual Waste
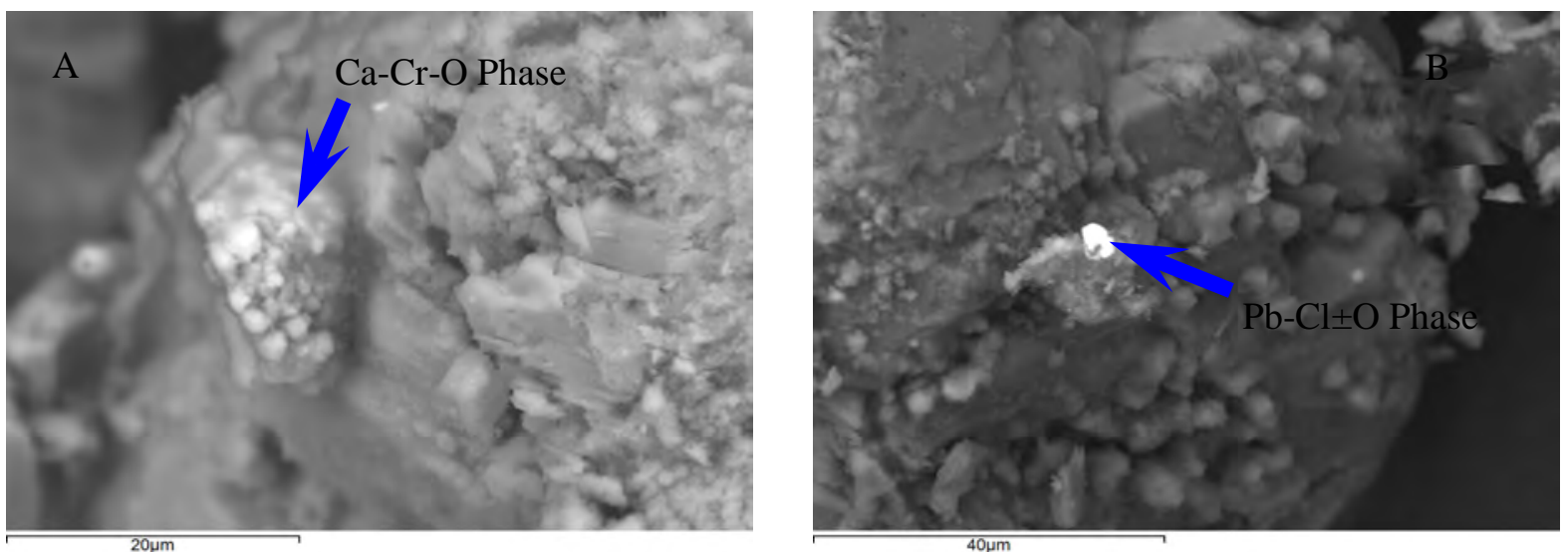

Figure 3.6. Backscattered Electron SEM Images Showing Ca-Cr-O (A) and $\mathrm{Pb}-\mathrm{Cl} \pm \mathrm{O}$ (B) Particles Present in Unleached Subsample 20407 dup of Tank S-112 Residual Waste. (The complete compositions of these phases are uncertain because the analyzed particles were likely aggregates that also contain Al-Na-O and/or Fe oxide solids.) 

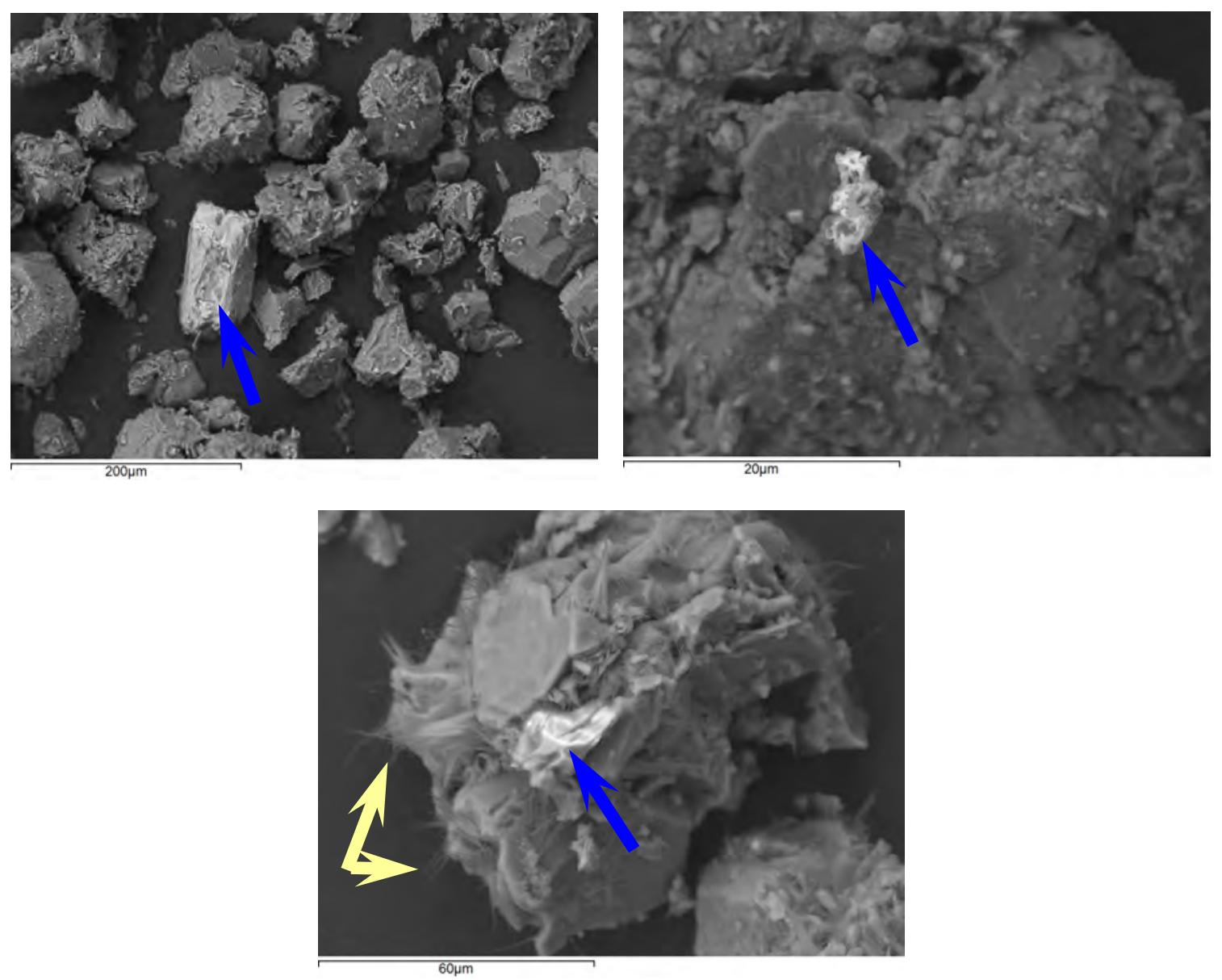

Figure 3.7. Backscattered Electron SEM Images Showing Silicate Particles (shown by blue arrows) and Needle-Like Phase (shown by yellow arrows) Present in Unleached Subsample 20407 dup of Tank S-112 Residual Waste. (The complete compositions of these phases are uncertain because the analyzed particles were likely aggregates that also contain $\mathrm{Al}-\mathrm{Na}-\mathrm{O}$ and/or Fe oxide solids.)

\subsection{Geochemical Modeling}

The React module of Geochemist's Workbench ${ }^{\circledR}$ version 7.0.3 (Bethke and Yeakel 2007) was used to calculate mineral saturation indices (SIs) based on measured compositions of leachates from the DDI 1-month, single-contact extraction tests. The SIs were computed to identify solid phases that were possibly in equilibrium with the leachate solutions. The SI is defined in Equation (3.1):

$$
\mathrm{SI}=\log \left(\mathrm{Q} / \mathrm{K}_{\mathrm{sp}}\right)
$$

where $\mathrm{Q}$ is the activity product and $\mathrm{K}_{\mathrm{sp}}$ is the mineral solubility product at equilibrium at the temperature of interest. Minerals with SI values near zero (within \pm 0.5 , SI values are unitless) are generally considered to be near equilibrium with the solution composition. More positive values are considered oversaturated, and more negative values are considered undersaturated with respect to the solution composition. The SIs were calculated for the 1-month single-contact extracts but not the supernatant solutions. The SI values were not determined for the supernatants because of their exceptionally high concentrations (ionic 
strengths in excess of $10 \mathrm{M}$ ). Such SI calculations would require the use of the Pitzer ion-interaction model (Pitzer and Mayorga 1973; Pitzer 1991), which is more accurate than the Davies or Debye-Hückel activity coefficient models for modeling in high-ionic strength solutions. Although Geochemist's Workbench includes the Pitzer model, its database does not include the Pitzer parameters for Al, which are required for modeling the supernatant compositions.

The SI values for leachates from the DDI 1-month single-contact extraction tests were calculated using the thermodynamic database file thermo.com.V8.R6+.dat that is supplied with Geochemist's Workbench Version 7.0.3. The database was modified to include the stability constant for $\mathrm{NaAlO}_{2}$ (sodium aluminate) using the Gibbs free energy of formation value taken from Wagman et al. (1982). Solubility data for čejkaite $\left[\mathrm{Na}_{4}\left(\mathrm{UO}_{2}\right)\left(\mathrm{CO}_{3}\right)_{3}\right]$ from Felmy et al. (2005), becquerelite $\left[\mathrm{Ca}\left(\mathrm{UO}_{2}\right)_{6} \mathrm{O}_{4}(\mathrm{OH})_{6} \bullet 8 \mathrm{H}_{2} \mathrm{O}\right]$ from Rai et al. (2002), sodium diuranate hydrate $\left[\mathrm{Na}_{2} \mathrm{U}_{2} \mathrm{O}_{7} \bullet \mathrm{xH}_{2} \mathrm{O}\right]$ from Yamamura et al. (1998), andersonite $\left[\mathrm{Na}_{2} \mathrm{Ca}\left(\mathrm{UO}_{2}\right)\left(\mathrm{CO}_{3}\right)_{3} \cdot 5 \mathrm{H}_{2} \mathrm{O}\right]$ and urancalcarite $\left[\mathrm{Ca}\left(\mathrm{UO}_{2}\right)_{3}\left(\mathrm{CO}_{3}\right)(\mathrm{OH})_{6} \cdot 3 \mathrm{H}_{2} \mathrm{O}\right]$ from Chen et al. (1999), and the stability constant for the dissolved species $\mathrm{Ca}_{2} \mathrm{UO}_{2}\left(\mathrm{CO}_{3}\right)_{3}(\mathrm{aq})$ from Kalmykov and Choppin (2000).

Calculated SIs for relevant Al-, Na-, Ca-, Cr- and U-containing minerals based on the measured compositions of the 1-month single-contact samples with SI values greater than -3 are shown in Table 3.15. All SI values calculated for $\mathrm{Al}(\mathrm{oxy})$ hydroxides indicated that these phases were oversaturated. Calcite $\left(\mathrm{CaCO}_{3}\right)$, dawsonite $\left[\mathrm{NaAlCO}_{3}(\mathrm{OH})_{2}\right]$, and aragonite $\left(\mathrm{CaCO}_{3}\right)$ appear to be near equilibrium with the leachate. These results indicate the concentrated $\mathrm{NaOH}$ solutions used during the second phase of final waste retrieval from tank S-112 (Section 1.2) to dissolve the residual sludge, which is composed primarily of gibbsite (Sections 3.3 and 3.4), may have resulted in precipitation of dawsonite. Exposure of the concentrated $\mathrm{NaOH}$ solutions to air would result in absorption of $\mathrm{CO}_{2}$ gas and formation of additional dissolved carbonate, which could lead to precipitation of dawsonite, and calcite or aragonite. The SEM/EDS analysis of the as-received samples indicates the gibbsite particles were coated with a Al-Na$\mathrm{O}( \pm \mathrm{H} \pm \mathrm{C}$ ) phase (Section 3.4). This coating could contain dawsonite possibly enriched with $\mathrm{NaOH}$ as a result of desiccation of entrained supernatant on the sample (Section 3.4). Because analysis by SEM/EDS was not conducted on solids from the DDI water extract samples, it was not possible to determine if this coating persisted through the 1-month extraction tests or if calcite or aragonite precipitated during the tests. The geochemical modeling results did not identify any $\mathrm{Cr}$ or $\mathrm{U}$ solids that were near equilibrium with the compositions of the DDI water extract samples.

Table 3.15. Calculated Saturation Indices (unitless) for Relevant Al-, Na-, Ca-, Cr-, and U-Containing Minerals Based on Compositions of Tank S-112 Double-Deionized 1-Month Single-Contact Extracts

\begin{tabular}{||l|c|c||}
\hline \multirow{2}{*}{\multicolumn{1}{|c|}{ Phase }} & $\begin{array}{c}\text { Sample } \\
\text { 20407 }\end{array}$ & $\begin{array}{c}\text { Sample } \\
\text { 20407 Dup }\end{array}$ \\
\cline { 2 - 3 } & \multicolumn{2}{|c|}{ Saturation Indices (unitless) } \\
\hline \hline Diaspore $[\mathrm{AlO}(\mathrm{OH})]$ & 2.10 & 2.26 \\
\hline Boehmite $[\mathrm{AlO}(\mathrm{OH})]$ & 1.70 & 1.85 \\
\hline Gibbsite $\left[\mathrm{Al}(\mathrm{OH})_{3}\right]$ & 1.51 & 1.66 \\
\hline Calcite $\left.(\mathrm{CaCO})_{3}\right)$ & 0.08 & 0.10 \\
\hline Dawsonite $\left[\mathrm{NaAlCO}_{3}(\mathrm{OH})_{2}\right]$ & 0.08 & 0.46 \\
\hline Aragonite $\left(\mathrm{CaCO}_{3}\right)$ & -0.07 & -0.05 \\
\hline
\end{tabular}





\subsection{Discussion}

This report presents the results of testing conducted on residual waste in Hanford tank S-112 after final waste retrieval. These tests were completed to characterize the residual waste and assess the leachability of contaminants from the solids. This is the first report from this PNNL project to describe the composition and leach test data for residual waste from a salt-cake tank. All previous PNNL reports (Cantrell et al. 2008; Deutsch et al. 2006, 2007a, 2007b, 2007c) describing contaminant release models, and characterization and testing results for residual waste in SSTs were based on samples from sludge tanks.

Crystalline solids in tank S-112 waste consist of essentially all (more than 90\%) gibbsite. SEM/EDS results are consistent with the XRD results, indicating the primary phase in tank S-112 waste is comprised of $\mathrm{Al}-\mathrm{O}( \pm \mathrm{H} \pm \mathrm{C})$ with a composition that is $39 \mathrm{wt} \% \mathrm{Al}$ and $60 \mathrm{wt} \% \mathrm{O}$ (consistent with gibbsite). The SEM/EDS results also indicate the gibbsite particles appear to have a common coating of an Al-Na-O solid. The phase composition of this coating could not be established with certainty, but appeared to have been composed of $29 \mathrm{wt} \% \mathrm{Na}, 18 \mathrm{wt} \% \mathrm{Al}$, and $52 \mathrm{wt} \% \mathrm{O}$. Geochemical modeling indicated that dawsonite $\left[\mathrm{NaAlCO}_{3}(\mathrm{OH})_{2}\right]$ was near equilibrium with the 1-month DDI water extracts. This suggests that dawsonite may be an important component of the coating. Particles with other compositions were very rare in tank S-112 residual waste. The SEM/EDS analyses identified a few particles of Fe oxides, a $\mathrm{Ca}-\mathrm{Cr}-\mathrm{O}$ phase, a $\mathrm{Pb}-\mathrm{Cl} \pm \mathrm{O}$ phase, and possibly one or more silicate phases.

Results of the Tier 1 analysis of the bulk composition of tank S-112 samples indicate $\mathrm{Al}$ is the largest, single metal component of the waste (7.1 to $8.4 \mathrm{wt} \%$ for the two samples). Other major metal components ( $\mathrm{Na}, \mathrm{Fe}, \mathrm{Cr}$, and $\mathrm{Si}$ ) occurred at lower concentrations, ranging from 4.7 to $5.2 \%, 0.21$ to $0.24 \%, 0.17$ to $0.18 \%$, and 0.10 to $0.14 \%$, respectively, for the two samples. Based on these results and assuming the $\mathrm{Al}$ occurs primarily as gibbsite $\left[\mathrm{Al}(\mathrm{OH})_{3}\right]$, this $\mathrm{Al}$ phase would account for 21 to $24 \mathrm{wt} \%$ of the residual waste.

Residual waste compositions determined in this study for tank S-112 samples were generally consistent with those determined by the 222-S Laboratory (Parker and Barton 2007), except for the concentrations determined for $\mathrm{Al}$. The average $\mathrm{Al}$ concentration determined from the 222-S Laboratory results was $29.1 \mathrm{wt} \%$ (dry wt basis). If all $\mathrm{Al}$ occurred as gibbsite, this would account for $84 \%$ of the residual waste mass. This result is more consistent with our XRD and SEM/EDS results than the bulk composition analyses. Based on these comparisons, the total $\mathrm{Al}$ concentrations appear to be underestimated. The reason for this discrepancy is being evaluated. Our initial assessment indicates that some $\mathrm{Al}$ may have precipitated as fine particulates that were filtered out subsequent to the microwave acid digestion.

Chromium was the most concentrated contaminant of concern in the tank S-112 residual waste samples, occurring at 1,690 to $1,750 \mu \mathrm{g} / \mathrm{g}$-dry waste. The other important contaminants ${ }^{99} \mathrm{Tc}$ and ${ }^{238} \mathrm{U}$ were measured in the residual waste at concentrations that ranged from 0.46 to $0.48 \mu \mathrm{g} / \mathrm{g}$, and 17 to $36 \mu \mathrm{g} / \mathrm{g}$, respectively.

Some solution analyses were conducted on supernatant from as-received sample 20406 and on leachates from sample 20407 extracted by a 1-month single-contact leach test with DDI water at a water:waste ratio of 100:1. Leachable quantities of contaminants $\left({ }^{99} \mathrm{Tc},{ }^{238} \mathrm{U}\right.$, and $\left.\mathrm{Cr}\right)$ measured in the 1-month single-contact leachates relative to the measured concentrations in the unleached bulk solid were 
$17 \%, 0.65 \%$, and $10.7 \%$, respectively. Significant leachable quantities of other metals measured in the extract leachates relative to the bulk-solid composition include $\mathrm{Al}$ (9.3\%), Ca (81\%), and $\mathrm{Na}(87 \%)$. Concentrations of all major anions in the 1-month DDI water single-contact leach test were below the IC detection limit, indicating that hydroxide and carbonate were the major anions in the water leachates.

A hypothetical pore water composition was calculated assuming all the dissolved components measured in the 1-month single-contact leach test were initially dissolved in the entrained pore water. These concentrations were compared with concentrations measured in the supernatant. Results indicate the majority of the ${ }^{99} \mathrm{Tc}, \mathrm{Al}$, and $\mathrm{Na}$ in the 1-month DDI water extracts are from dilution of pore water. In the case of ${ }^{238} \mathrm{U}$, it appears dilution of entrained pore fluid results in precipitation of most of the ${ }^{238} \mathrm{U}$. This may have occurred as a result of diminished hydrolysis and carbonate complexation of dissolved U upon dilution (Le Chatelier's principle). For Ca, nearly all the $\mathrm{Ca}$ in the extracts came from dissolution of a Ca-containing solid phase. For $\mathrm{Cr}$, approximately half of the $\mathrm{Cr}$ in the leachants came from the pore fluid, and a nearly equal quantity came from dissolution from a Cr-containing solid phase. 


\subsection{References}

10 CFR 830.120. “Nuclear Safety Management; Quality Assurance Requirements.” Code of Federal Regulations, U.S. Department of Energy.

Agnew SF. 1997. Hanford Tank Chemical and Radionuclide Inventories. LA-UR-96-3860, Los Alamos National Laboratory, Los Alamos, New Mexico.

ASTM. 1998. D2216-98 Standard Test Method for Laboratory Determination of Water (Moisture) Content of Soil and Rock by Mass. American Society for Testing and Materials, West Conshohocken, Pennsylvania.

ASTM. 1999. D3987-85 Standard Test Method for Shake Extraction of Solid Waste with Water. American Society for Testing and Materials, West Conshohocken, Pennsylvania.

Bethke CM and S Yeakel. 2007. The Geochemist’s Workbench ${ }^{\circledR}$, Release 7.0, Reference Manual. Hydrogeology Program, University of Illinois, Urbana, Illinois.

Brown CF, MM Valenta, RJ Serne, BN Bjornstad, DC Lanigan, C Iovin, RE Clayton, KN Geiszler, ET Clayton, IV Kutnyakov, SR Baum, MJ Lindberg, and RD Orr. 2007. Characterization of Direct Push Vadose Zone Sediments from the T and TY Waste Management Areas. PNNL-16649, Pacific Northwest National Laboratory, Richland, Washington.

Cantrell KJ, KM Krupka, WJ Deutsch, MJ Lindberg, HT Schaef, KN Geiszler and BW Arey. 2008. Hanford Tank 241-C-103 Residual Waste Contaminant Release Models and Supporting Data. PNNL-16738, Pacific Northwest National Laboratory, Richland, Washington.

Chen F, RC Ewing, and SB Clark. 1999. “The Gibbs Free Energies and Enthalpies of Formation of $\mathrm{U}^{6+}$ Phases: An Empirical Method of Prediction.” American Mineralogist 84(4):650-664.

Clesceri LS, AE Greenberg, and AD Eaton. 1998. Standard Methods for the Examination of Water and Wastewater, 20th Edition. Standard Method 2320 B, “Alkalinity by Titration.” American Public Health Association, American Water Works Association, and Water Environment Federation, Washington, D.C.

Deutsch WJ, KM Krupka MJ Lindberg, KJ Cantrell, CF Brown, and HT Schaef. 2006. Hanford Tanks 241-C-106: Impact of Cement Reactions on Release of Contaminant from Residual Waste. PNNL-15544, Pacific Northwest National Laboratory, Richland, Washington.

Deutsch WJ, KM Krupka MJ Lindberg, KJ Cantrell, CF Brown, and HT Schaef. 2007a. Hanford Tanks 241-C-106: Residual Waste Contaminant Release Model and Supporting Data. PNNL-15187, Rev. 1, Pacific Northwest National Laboratory, Richland, Washington.

Deutsch WJ, KM Krupka, MJ Lindberg, KJ Cantrell, CF Brown, and HT Schaef. 2007b. Hanford Tanks 241-C-203 and 241-C-204: Residual Waste Contaminant Release Model and Supporting Data. PNNL-14903, Rev. 1, Pacific Northwest National Laboratory, Richland, Washington. 
Deutsch WJ, KM Krupka MJ Lindberg, KJ Cantrell, CF Brown, SV Mattigod, HT Schaef, and BW Arey. 2007c. Hanford Tanks 241-C-202 and 241-C-203 Residual Waste Contaminant Release Models and Supporting Data. PNNL-16229, Pacific Northwest National Laboratory, Richland, Washington.

DOE-RL. 2007. Hanford Analytical Services Quality Assurance Requirements Documents.

DOE/RL-96-68 Rev. 3, HASQARD, Volumes 1, 2, 3, and 4. U.S. Department of Energy, Richland Operations Office, Richland, Washington.

DOE Order 414.1A. 1999. “Quality Assurance.” U.S. Department of Energy, Washington, D.C.

Ecology, EPA, and DOE. 1996. Hanford Federal Facility Agreement and Consent Order, Milestone M-45-03C. Washington State Department of Ecology, U.S. Environmental Protection Agency, and U.S. Department of Energy, Olympia, Washington.

EPA. 2007. "Method 9056A, Determination of Inorganic Anions by Ion Chromatography,” Rev. 1. In Test Methods for Evaluating Solid Waste: Physical/Chemical Methods. EPA SW-846, U.S. Environmental Protection Agency, Office of Solid Waste and Emergency Response, Washington, D.C. Available at http://www.epa.gov/sw-846/9_series.htm

EPA. 2004. "Method 9040C, pH Electrometric Measurement” Rev. 3. In Test Methods for Evaluating Solid Waste: Physical/Chemical Methods. EPA SW-846, U.S. Environmental Protection Agency, Office of Solid Waste and Emergency Response, Washington, D.C. Accessed May 28, 2007, at http://www.epa.gov/sw-846/9_series.htm

EPA. 1996a. "Method 3052, Microwave Assisted Acid Digestion of Siliceous and Organically Based Matrices,” Rev. 0. In Test Methods for Evaluating Solid Waste: Physical/Chemical Methods. EPA SW-846, U.S. Environmental Protection Agency, Office of Solid Waste and Emergency Response, Washington, D.C. Accessed May 28, 2007, at http://www.epa.gov/sw-846/3_series.htm

EPA. 1996b. “Method 3050B, Acid Digestion of Sediments, Sludges, and Soils,” Rev. 2. In Test Methods for Evaluating Solid Waste: Physical/Chemical Methods. EPA SW-846, U.S. Environmental Protection Agency, Office of Solid Waste and Emergency Response, Washington, D.C. Accessed August 11, 2008, at http://www.epa.gov/sw-846/3_series.htm

Felmy AR, Y Xia, and Z Wang. 2005. "The Solubility Product of $\mathrm{NaUO}_{2} \mathrm{PO}_{4} \cdot x \mathrm{H}_{2} \mathrm{O}$ Determined in Phosphate and Carbonate Solutions.” Radiochima Acta 93(7):401-408.

Kalmykov S and GR Choppin. 2000. "Mixed $\mathrm{Ca}^{2+} / \mathrm{UO}_{2}{ }^{2+} / \mathrm{CO}_{3}{ }^{2-}$ Complex Formation at Different Ionic Strengths.” Radiochima Acta 88(9-11):603-606.

Krupka KM, WJ Deutsch, MJ Lindberg, KJ Cantrell, NJ Hess, HT Schaef, and BW Arey. 2004. Hanford Tanks 241-AY-102 and 241-BX-101: Sludge Composition and Contaminant Release Data. PNNL-14614, Pacific Northwest National Laboratory, Richland, Washington.

Lindberg MJ and WJ Deutsch. 2003. Tank 241-AY-102 Data Report. PNNL-14344, Pacific Northwest National Laboratory, Richland, Washington. 
NIST. 2005. Standard Reference Material 676, Alumina Internal Standard for Quantitative Analysis by $X$-ray Powder Diffraction. National Institute of Standards and Technology, U.S. Department of Commerce, Gaithersburg, Maryland.

Parker DL and WB Barton. 2007. Retrieval Data Report for Single-Shell Tank 241-S-112. RPP-RPT-35112, CH2M HILL Hanford Group, Inc., Richland, Washington.

Pitzer KS. 1991. "Ion Interaction Approach: Theory and Data Correlation.” In Activity Coefficients in Electrolyte Solutions, ed. KS Pitzer, Chap. 3, pp. 75-153, CRC Press, Boca Ratan, Florida.

Pitzer KS and G Mayorga. 1973. “Thermodynamics of Electrolytes. II. Activity and Osmotic Coefficients for Strong Electrolytes with One or Both Ions Univalent.” Journal of Physical Chemistry 77:2300-2308.

Rai D, AR Felmy, NJ Hess, VL LeGore, and DE McCready. 2002. "Thermodynamics of the U(VI)$\mathrm{Ca}^{2+}-\mathrm{Cl}^{-}-\mathrm{OH}^{-}-\mathrm{H}_{2} \mathrm{O}$ System: Solubility Product of Becquerelite.” Radiochima Acta 90:495-503.

Strachan DM, HT Schaef, MJ Schweiger, KL Simmons, LJ Woodcock, and MK Krouse. 2003. “A Versatile and Inexpensive XRD Specimen Holder for Highly Radioactive or Hazardous Specimens." Powder Diffraction 18(1):23-28.

Wagman, DD, WH Evans, VB Parker, RH Schumm, I Halow, SM Bailey, KL Churney, and RL Nuttall. 1982. "The NBS Tables of Chemical Thermodynamic Properties, Selected Values for Inorganic and $\mathrm{C}_{1}$ and $\mathrm{C}_{2}$ Organic Substances in SI Units.” Journal of Physical and Chemical Reference Data 11(Supplement 2):1-392.

Yamamura T, A Kidtamura, A Fukui, S Nishikawa, T Yamamoto, and H Moriyama. 1998. "Solubility of U(VI) in Highly Basic Solutions.” Radiochima Acta 83:139-146. 



\section{Appendix}

SEM Micrographs and EDS Results for

Unleached Residual Waste from Tank S-112 



\section{Appendix}

\section{SEM Micrographs and EDS Results for Unleached Residual Waste from Tank S-112}

This appendix includes the scanning electron microscope (SEM) micrographs for two subsamples (designated as 20407 and 20407 dup) of unleached residual waste from tank S-112 and element compositions derived from the energy dispersive spectroscopy (EDS) analyses of particles in these subsamples imaged by SEM. The operating conditions for the SEM and procedures used for mounting the SEM subsamples are described in Section 2.4 of the main report.

Each page in this appendix contains 1) a backscattered electron (BSE) SEM micrograph (top of each page) of particles in the two subsamples of tank S-112 unleached residual waste, and 2) the tabulated element compositions (in wt\%) (bottom of each page) derived from the EDS analyses of particles identified in the top-right SEM micrograph. The micrograph at the top left of each page shows the same SEM image unobstructed by the identification numbers and locations of the EDS analyses. All SEM micrographs were collected within the BSE mode. 
Backscattered Electron (BSE) SEM Micrograph of Particles in S-112 Sample 20407, Site of Interest 1

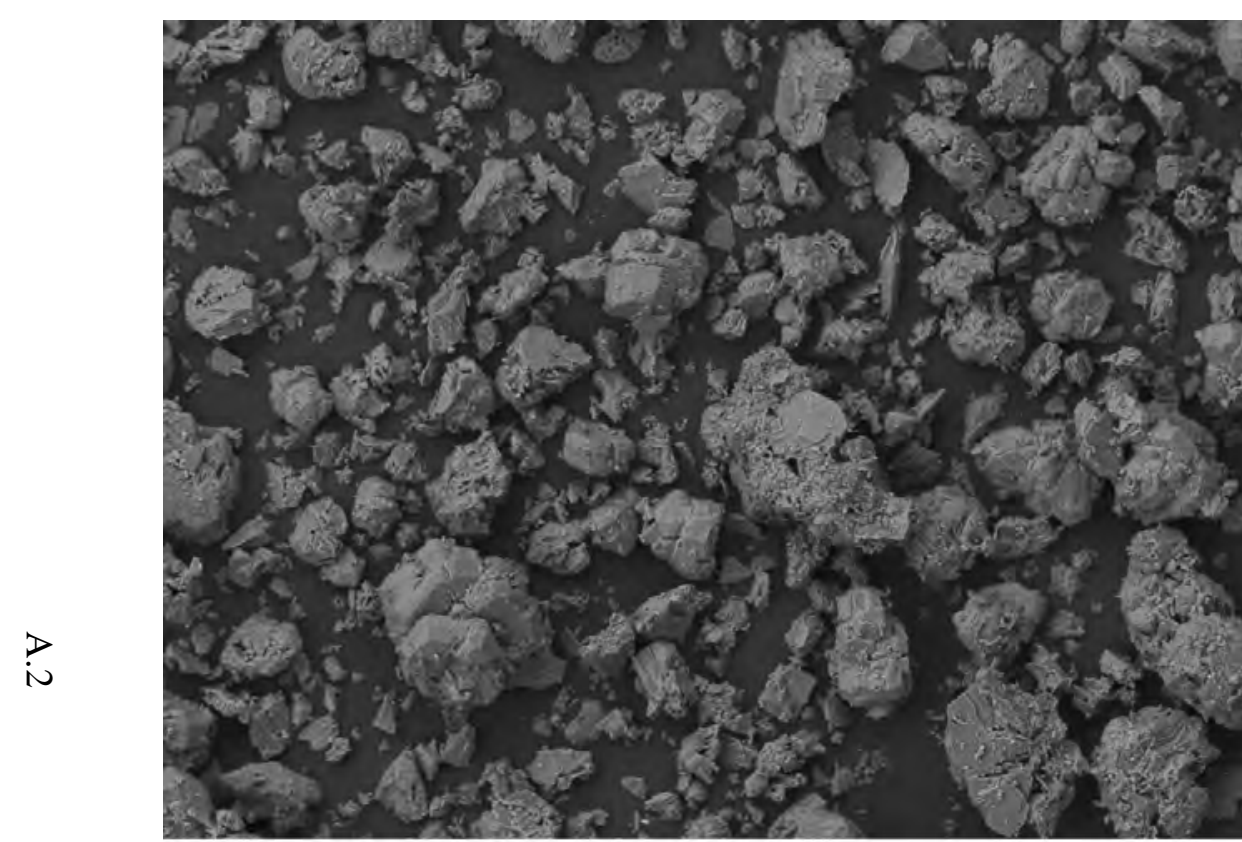

$600 \mu \mathrm{m}$

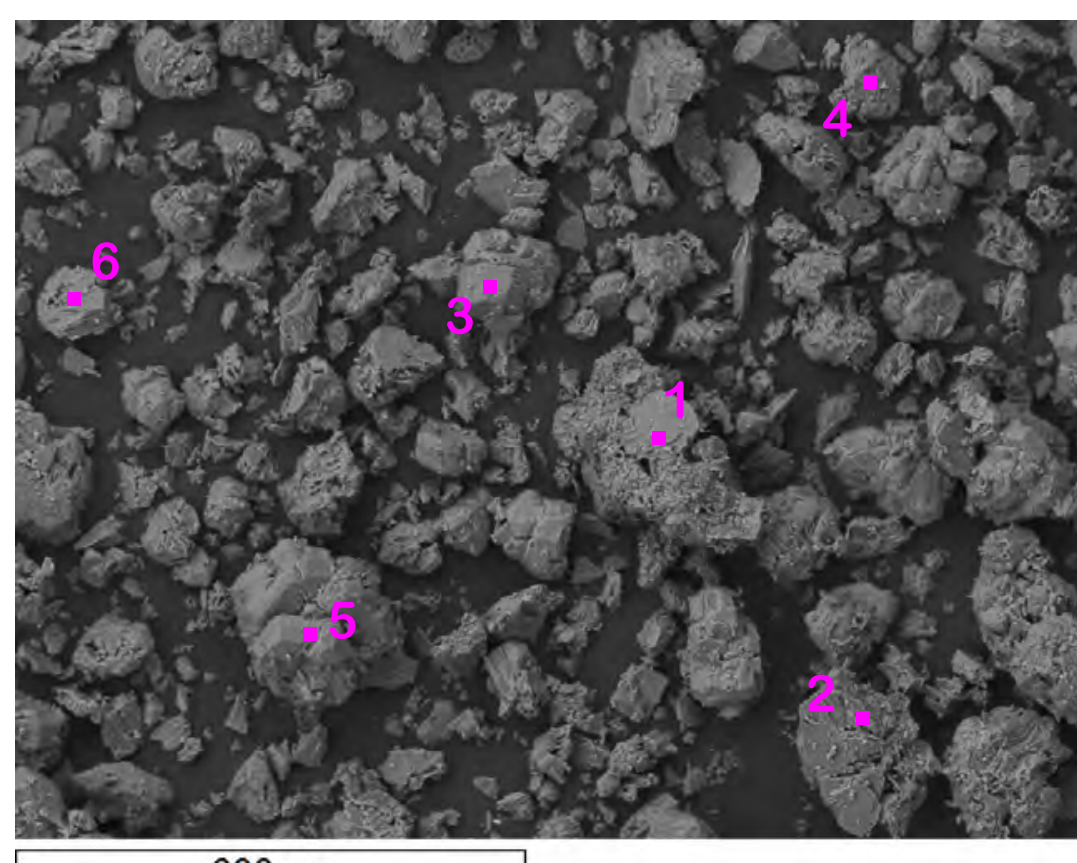

$600 \mu \mathrm{m}$

Element Compositions Derived from EDS Analyses of Particles Identified (in purple) in SEM Micrograph Shown Above Right

\begin{tabular}{|c|c|c|c|c|c|c|c|c|c|c|c|c|c|c|c|c|c|}
\hline \multirow{2}{*}{ Spectrum } & $\mathbf{0}$ & $\mathrm{Na}$ & Al & Si & Mg & $\mathbf{P}$ & Ca & Fe & $\mathrm{Cr}$ & Mn & Sr & $\bar{K}$ & $\mathbf{C u}$ & $\overline{T i}$ & $\mathbf{P b}$ & Cl & Total \\
\hline & \multicolumn{17}{|c|}{ wt \% normalized to $100 \%$} \\
\hline $\begin{array}{ll}1 \\
\end{array}$ & 51.4 & 811.7 & 35.1 & & & & & & $\begin{array}{ll}1.9 \\
\end{array}$ & & & & & & & & (100.0 \\
\hline 2 & 54.9 & 11.4 & 33.5 & & & & & & 0.2 & & & & & & & & 100.0 \\
\hline 3 & 67.2 & 0.4 & 32.0 & & & 0.1 & & & 0.2 & & & & & & & & 100.0 \\
\hline 4 & 64.2 & 9.9 & 25.6 & & & 0.1 & & & 0.2 & & & & & & & & 100.0 \\
\hline 5 & 63.5 & 10.5 & 25.1 & 0.1 & & & 0.3 & & 0.5 & & & & & & & & 100.0 \\
\hline 6 & 59.8 & 12.9 & 27.1 & 0.2 & & & & & & & & & & & & & 100.0 \\
\hline
\end{tabular}


Backscattered Electron (BSE) SEM Micrograph of Particles in S-112 Sample 20407, Site of Interest 2
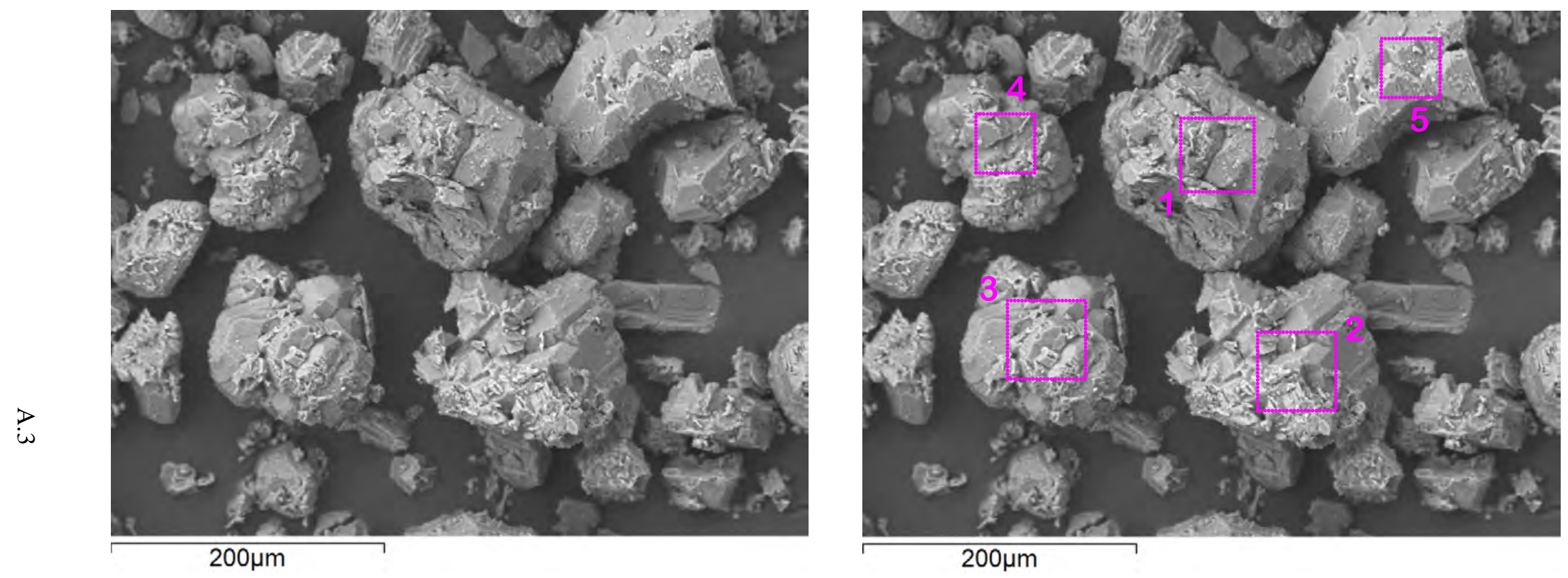

Element Compositions Derived from EDS Analyses of Particles Identified (in purple) in SEM Micrograph Shown Above Right

\begin{tabular}{|c|c|c|c|c|c|c|c|c|c|c|c|c|c|c|c|c|c|}
\hline \multirow{2}{*}{ Spectrum } & $\mathbf{O}$ & $\mathbf{N a}$ & Al & $\mathbf{S i}$ & $\mathbf{M g}$ & $\mathbf{P}$ & Ca & $\mathbf{F e}$ & $\mathbf{C r}$ & Mn & $\mathbf{S r}$ & $\mathbf{K}$ & $\mathbf{C u}$ & $\mathbf{T i}$ & $\mathbf{P b}$ & $\mathbf{C l}$ & Total \\
\hline & \multicolumn{17}{|c|}{ wt $\%$ normalized to $100 \%$} \\
\hline $\bar{~} \overline{11}$ & 259.6 & $\begin{array}{ll}16.8 \\
\end{array}$ & 222.8 & & & & 0.1 & & $\overline{c 0.6}$ & & & & & & & & $\begin{array}{ll}100.0 \\
\end{array}$ \\
\hline 2 & 63.6 & 10.7 & 25.4 & & & & & & 0.3 & & & & & & & & 100.0 \\
\hline 3 & 63.4 & 9.9 & 26.0 & & & & & & 0.6 & & & & & & & & 100.0 \\
\hline 4 & 61.1 & 14.6 & 24.0 & & & & & & 0.4 & & & & & & & & 100.0 \\
\hline 5 & 59.5 & 14.2 & 25.5 & & & & & & 0.9 & & & & & & & & 100.0 \\
\hline
\end{tabular}


Backscattered Electron (BSE) SEM Micrograph of Particles in S-112 Sample 20407, Site of Interest 3
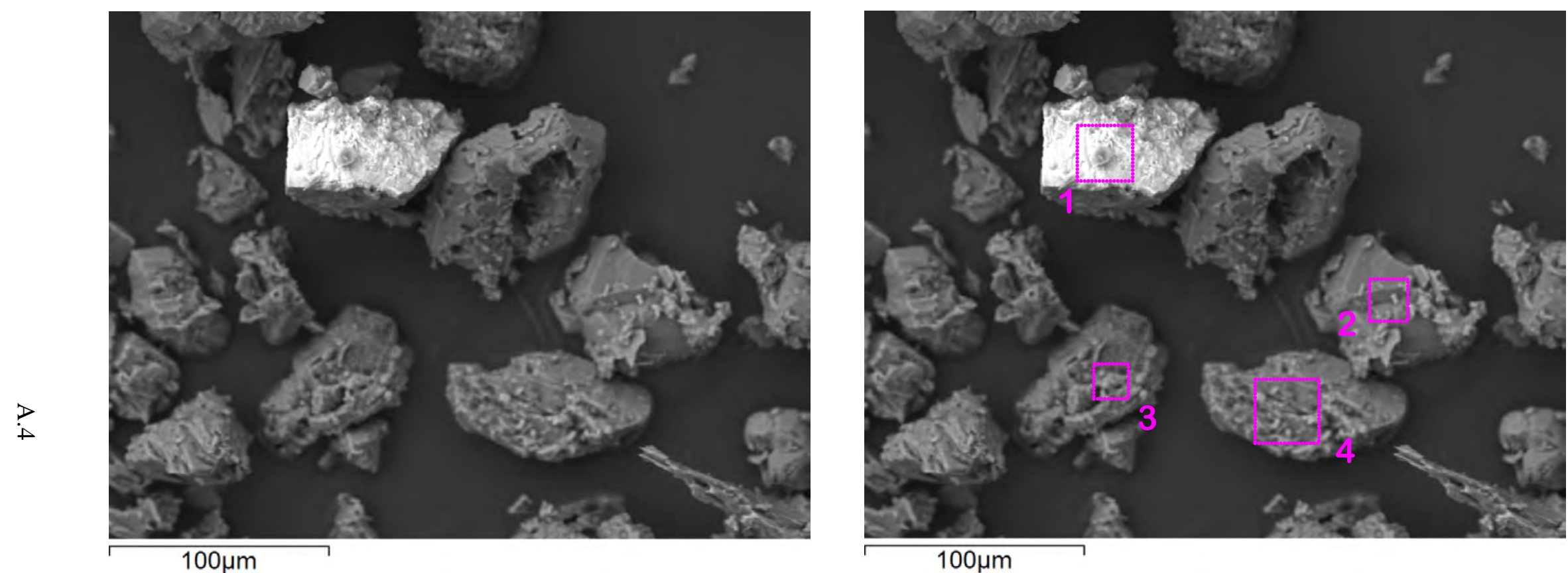

Element Compositions Derived from EDS Analyses of Particles Identified (in purple) in SEM Micrograph Shown Above Right

\begin{tabular}{|c|c|r|r|c|c|c|c|c|c|c|c|c|c|c|c|c|c|}
\hline \multirow{2}{*}{ Spectrum } & $\mathbf{O}$ & $\mathbf{N a}$ & $\mathbf{A l}$ & $\mathbf{S i}$ & $\mathbf{M g}$ & $\mathbf{P}$ & $\mathbf{C a}$ & $\mathbf{F e}$ & $\mathbf{C r}$ & $\mathbf{M n}$ & $\mathbf{S r}$ & $\mathbf{K}$ & $\mathbf{C u}$ & $\mathbf{T i}$ & $\mathbf{P b}$ & $\mathbf{C l}$ & $\mathbf{T o t a l}$ \\
\hline & \multicolumn{8}{|c|}{ wt\% normalized to 100\% } & \\
\hline 1 & 41.3 & 8.2 & 4.2 & & & & & 45.6 & 0.4 & 0.2 & & & & & & & 100.0 \\
\hline 2 & 62.0 & 6.8 & 30.7 & & & & & & 0.4 & & & & & & & & 100.0 \\
\hline 3 & 60.1 & 15.5 & 23.8 & & & & 0.3 & & 0.3 & & & & & & & & 100.0 \\
\hline 4 & 60.1 & 14.1 & 25.7 & 0.2 & & & & & & & & & & & & & 100.0 \\
\hline
\end{tabular}


Backscattered Electron (BSE) SEM Micrograph of Particles in S-112 Sample 20407, Site of Interest 4
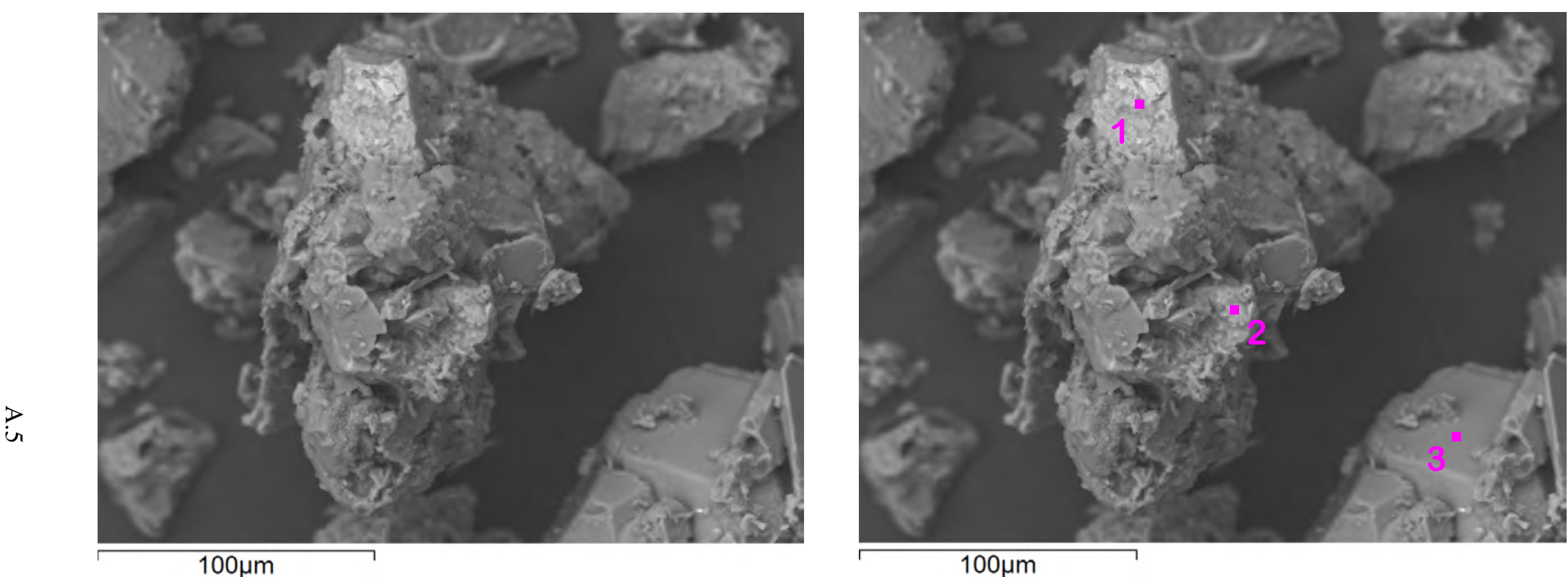

Element Compositions Derived from EDS Analyses of Particles Identified (in purple) in SEM Micrograph Shown Above Right

\begin{tabular}{|c|c|c|r|r|c|c|c|c|c|c|c|c|c|c|c|c|c||}
\hline \hline \multirow{2}{*}{ Spectrum } & $\mathbf{O}$ & Na & Al & Si & Mg & P & Ca & Fe & Cr & Mn & Sr & K & Cu & Ti & Pb & Cl & Total \\
\hline & \multicolumn{10}{|c|}{ wt\% normalized to 100\% } \\
\hline \hline 1 & 58.0 & 1.6 & 7.8 & 17.9 & 0.9 & & & 3.0 & 0.4 & & & 10.4 & & & & & 100.0 \\
\hline 2 & 55.5 & 2.9 & 8.6 & 21.5 & 0.8 & & & 1.0 & 0.2 & & & 9.4 & & & & & 100.0 \\
\hline 3 & 65.5 & 4.9 & 27.6 & 0.5 & & & 0.2 & & 1.3 & & & & & & & & 100.0 \\
\hline
\end{tabular}


Backscattered Electron (BSE) SEM Micrograph of Particles in S-112 Sample 20407, Site of Interest 5
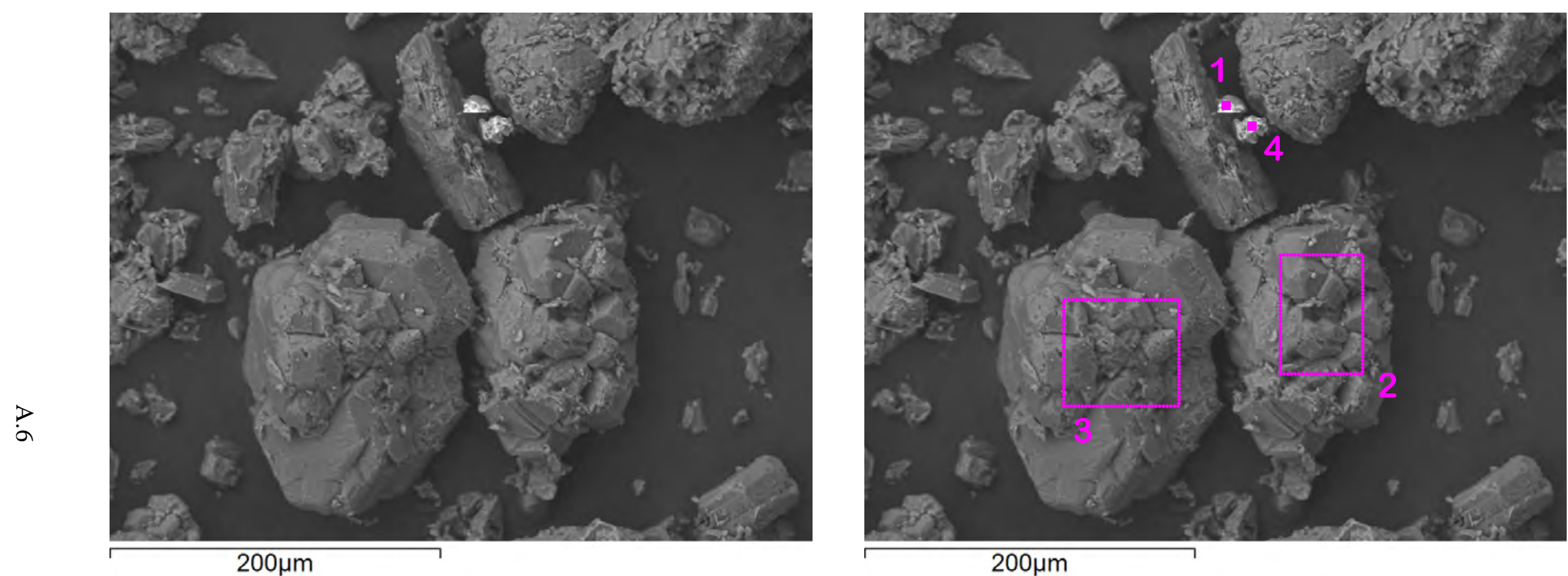

Element Compositions Derived from EDS Analyses of Particles Identified (in purple) in SEM Micrograph Shown Above Right

\begin{tabular}{|c|c|c|c|c|c|c|c|c|c|c|c|c|c|c|c|c|c|}
\hline \multirow{2}{*}{ Spectrum } & $\mathbf{0}$ & Na & $\overline{\mathrm{Al}}$ & $\overline{\mathrm{Si}}$ & Mg & $\overline{\mathbf{P}}$ & $\overline{\mathrm{Ca}}$ & $\mathbf{F e}$ & $\overline{\mathrm{Cr}}$ & Mn & Sr & $\overline{\mathrm{K}}$ & $\overline{\mathrm{Cu}}$ & $\overline{T i}$ & $\overline{\mathbf{P b}}$ & $\overline{\mathrm{Cl}}$ & Total \\
\hline & \multicolumn{17}{|c|}{ wt \% normalized to $100 \%$} \\
\hline 1 & 63.2 & 13.4 & 23.5 & & & & & & & & & & & & & & 100.0 \\
\hline 2 & 65.9 & 5.4 & 27.9 & & & & 0.1 & 0.2 & 0.5 & & & & & & & & 100.0 \\
\hline 3 & 65.9 & 7.7 & 26.0 & & & & & & 0.3 & & & & & & & & 100.0 \\
\hline 4 & 10.2 & 4.4 & 4.5 & & & & & 80.9 & & & & & & & & & 100.0 \\
\hline
\end{tabular}


Backscattered Electron (BSE) SEM Micrograph of Particles in S-112 Sample 20407, Site of Interest 6
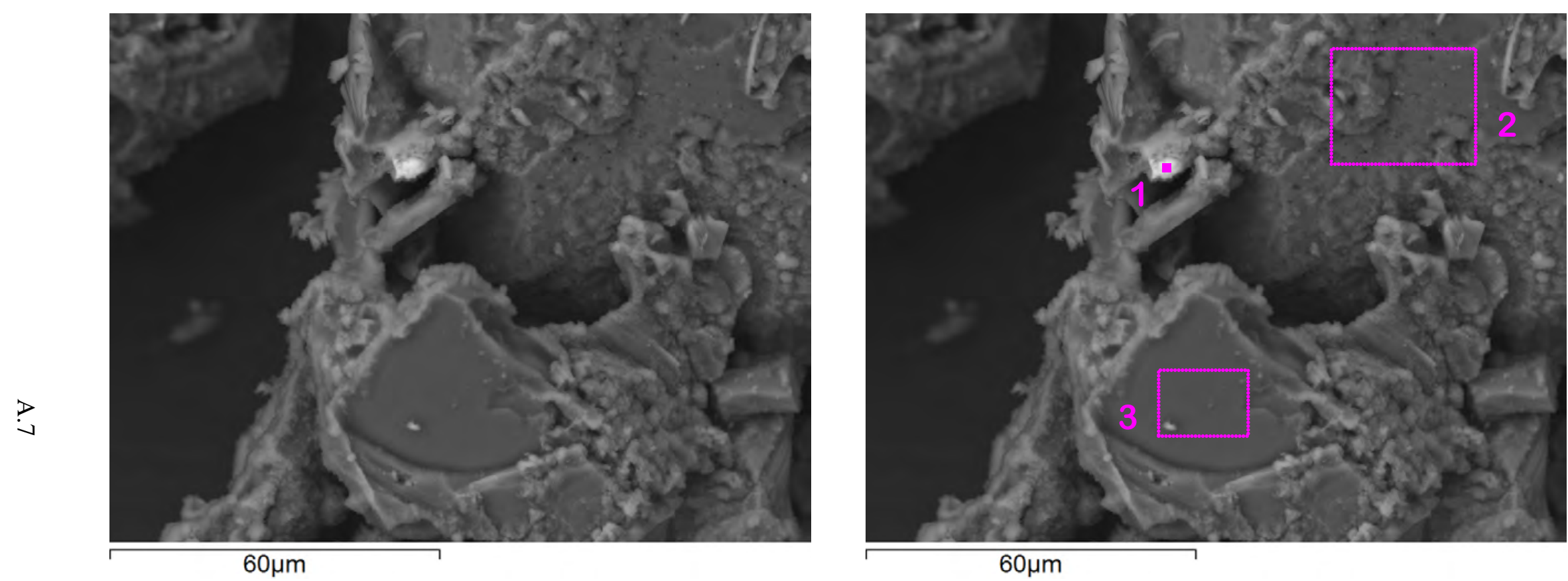

Element Compositions Derived from EDS Analyses of Particles Identified (in purple) in SEM Micrograph Shown Above Right

\begin{tabular}{|c|c|c|c|c|c|c|c|c|c|c|c|c|c|c|c|c|c|}
\hline \multirow{2}{*}{ Spectrum } & $\overline{\mathbf{O}}$ & $\mathrm{Na}$ & Al & $\overline{\mathrm{Si}}$ & Mg & $\overline{\mathbf{P}}$ & $\overline{\mathbf{C a}}$ & $\mathbf{F e}$ & $\mathbf{C r}$ & Mn & $\overline{\mathrm{Sr}}$ & $\overline{\mathbf{K}}$ & $\mathbf{C u}$ & $\overline{T i}$ & $\overline{\mathbf{P b}}$ & $\overline{\mathrm{Cl}}$ & Total \\
\hline & \multicolumn{17}{|c|}{ wt\% normalized to $100 \%$} \\
\hline 11 & 441.0 & 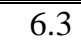 & 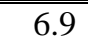 & 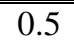 & & & & 43.3 & 22.0 & & & & & & & & $\begin{array}{l}100.0 \\
\end{array}$ \\
\hline 2 & 52.2 & 16.9 & 29.8 & & & & & & 0.5 & & & & 0.6 & & & & 100.0 \\
\hline 3 & 59.8 & 1.4 & 38.8 & & & & & & & & & & & & & & 100.0 \\
\hline
\end{tabular}


Backscattered Electron (BSE) SEM Micrograph of Particles in S-112 Sample 20407, Site of Interest 7

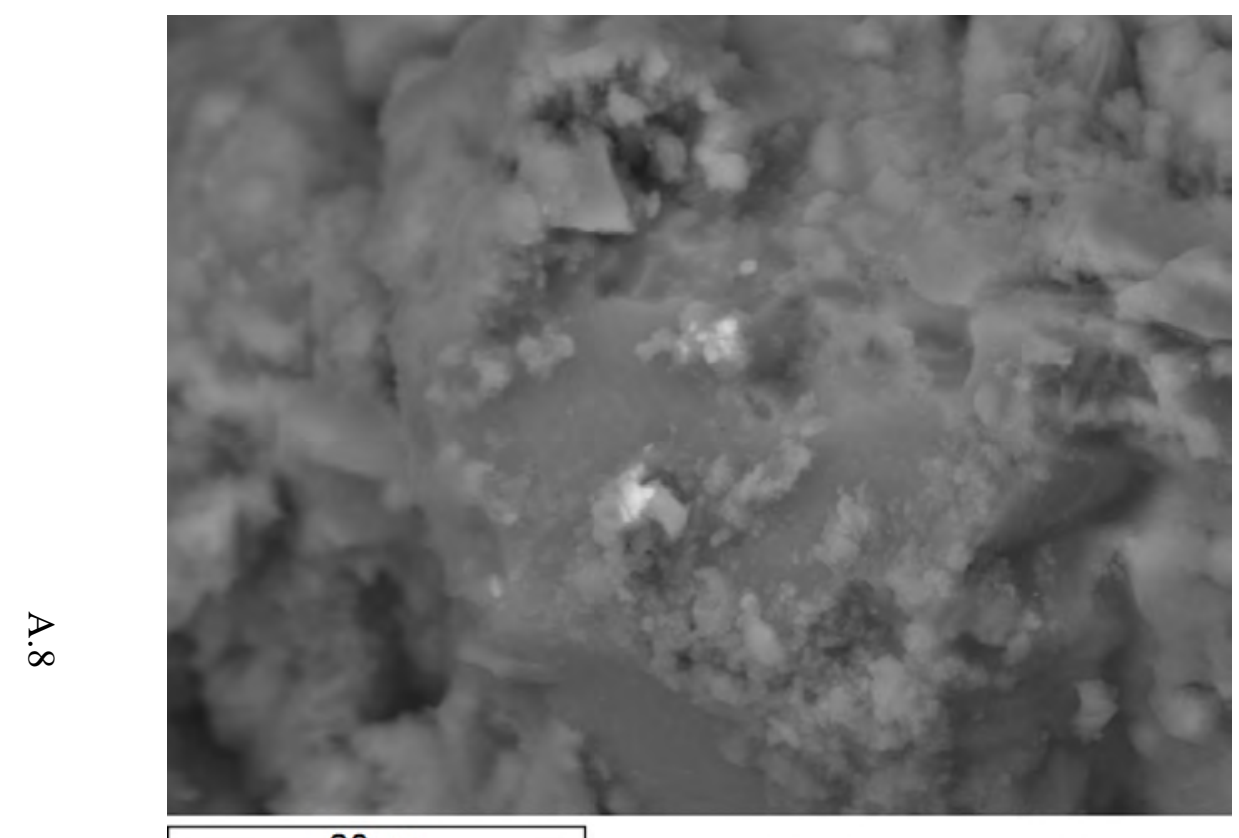

$20 \mu \mathrm{m}$

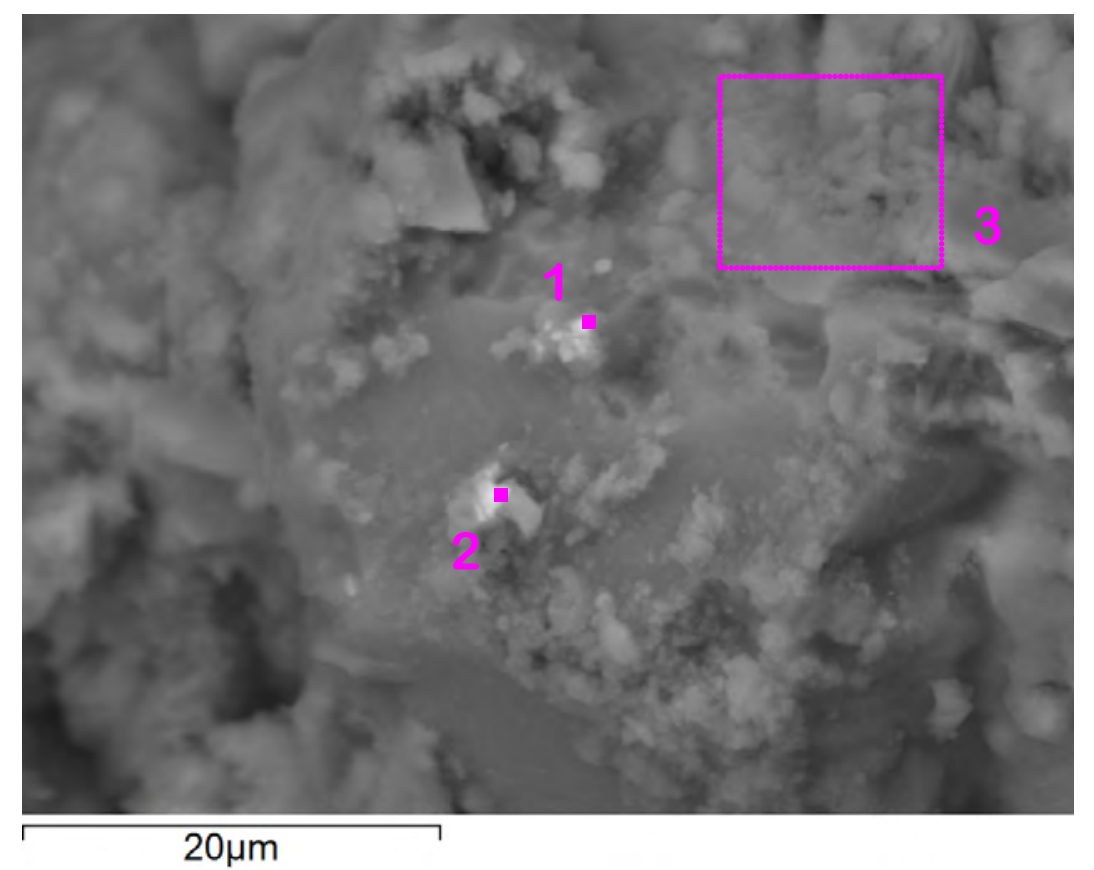

$20 \mu \mathrm{m}$

Element Compositions Derived from EDS Analyses of Particles Identified (in purple) in SEM Micrograph Shown Above Right

\begin{tabular}{|c|c|c|c|c|c|c|c|c|c|c|c|c|c|c|c|c|c|}
\hline \multirow{2}{*}{ Spectrum } & $\mathbf{O}$ & $\mathrm{Na}$ & Al & Si & Mg & $\mathbf{P}$ & $\mathbf{C a}$ & $\mathbf{F e}$ & $\mathrm{Cr}$ & Mn & Sr & $\mathbf{K}$ & $\mathbf{C u}$ & $\mathbf{T i}$ & $\mathbf{P b}$ & Cl & Total \\
\hline & \multicolumn{17}{|c|}{ wt \% normalized to $100 \%$} \\
\hline 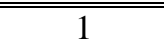 & 60.6 & 5.7 & 25.5 & & & 0.1 & 0.1 & 7.4 & 0.6 & & & & & & & & 100.0 \\
\hline 2 & 53.2 & 10.5 & 18.3 & 0.2 & 0.1 & & 0.1 & 16.8 & 0.9 & & & & & & & & 100.0 \\
\hline 3 & 59.2 & 17.9 & 22.6 & & & 0.1 & & & 0.2 & & & & & & & & 100.0 \\
\hline
\end{tabular}


Backscattered Electron (BSE) SEM Micrograph of Particles in S-112 Sample 20407, Site of Interest 8
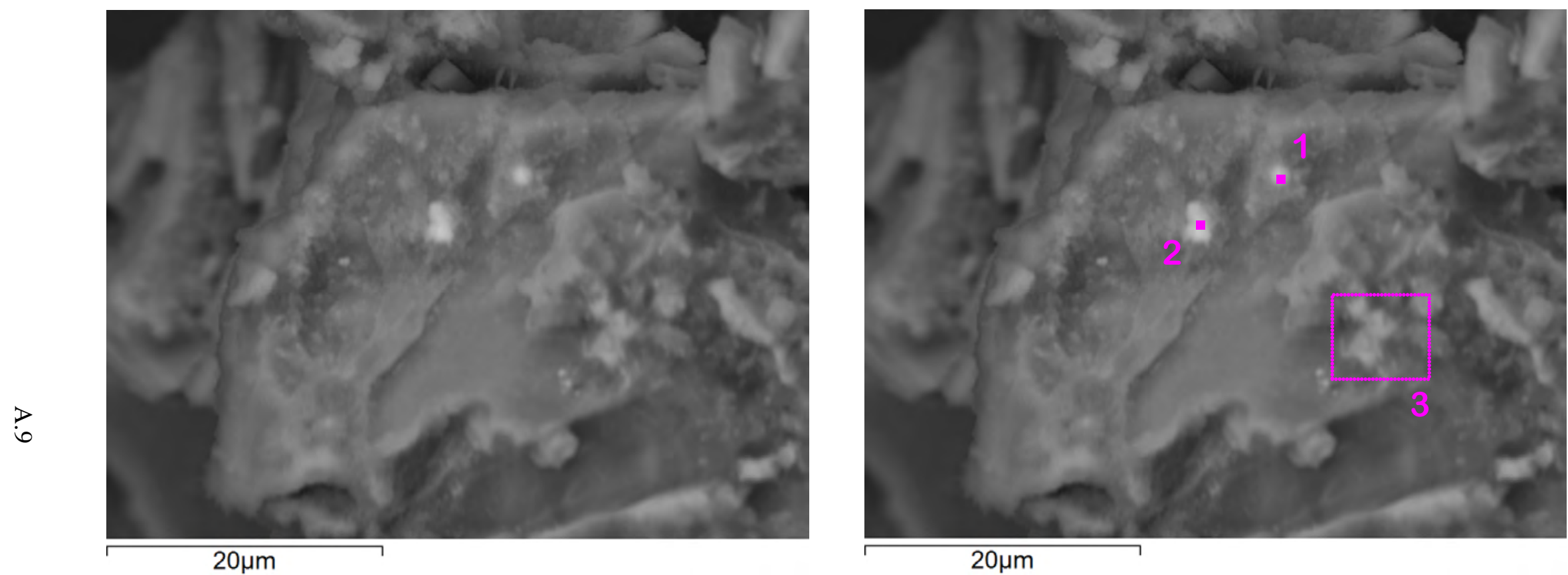

Element Compositions Derived from EDS Analyses of Particles Identified (in purple) in SEM Micrograph Shown Above Right

\begin{tabular}{|c|c|c|c|c|c|c|c|c|c|c|c|c|c|c|c|c|c|}
\hline \multirow{2}{*}{ Spectrum } & $\mathbf{O}$ & $\mathrm{Na}$ & Al & Si & $\mathbf{M g}$ & $\mathbf{P}$ & $\mathbf{C a}$ & $\overline{F e}$ & $\mathbf{C r}$ & Mn & $\mathrm{Sr}$ & $\mathbf{K}$ & $\mathbf{C u}$ & $\mathbf{T i}$ & $\mathbf{P b}$ & $\overline{\mathrm{Cl}}$ & Total \\
\hline & \multicolumn{17}{|c|}{ wt \% normalized to $100 \%$} \\
\hline 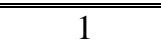 & $\begin{array}{l}59.2 \\
\end{array}$ & 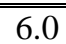 & $\begin{array}{l}17.9 \\
\end{array}$ & & & & $\begin{array}{c}8.4 \\
\end{array}$ & $\bar{~} 0.2$ & $\begin{array}{c}6.4 \\
\end{array}$ & & $\begin{array}{c}1.9 \\
\end{array}$ & & & & & & $\begin{array}{c}100.0 \\
\end{array}$ \\
\hline 2 & 61.6 & 9.4 & 12.9 & & 0.2 & & 11.3 & 0.3 & 4.3 & & & & & & & & 100.0 \\
\hline 3 & 63.7 & 5.3 & 29.3 & 0.2 & & 0.2 & 0.3 & 0.5 & 0.6 & & & & & & & & 100.0 \\
\hline
\end{tabular}


Backscattered Electron (BSE) SEM Micrograph of Particles in S-112 Sample 20407 Duplicate, Site of Interest 1
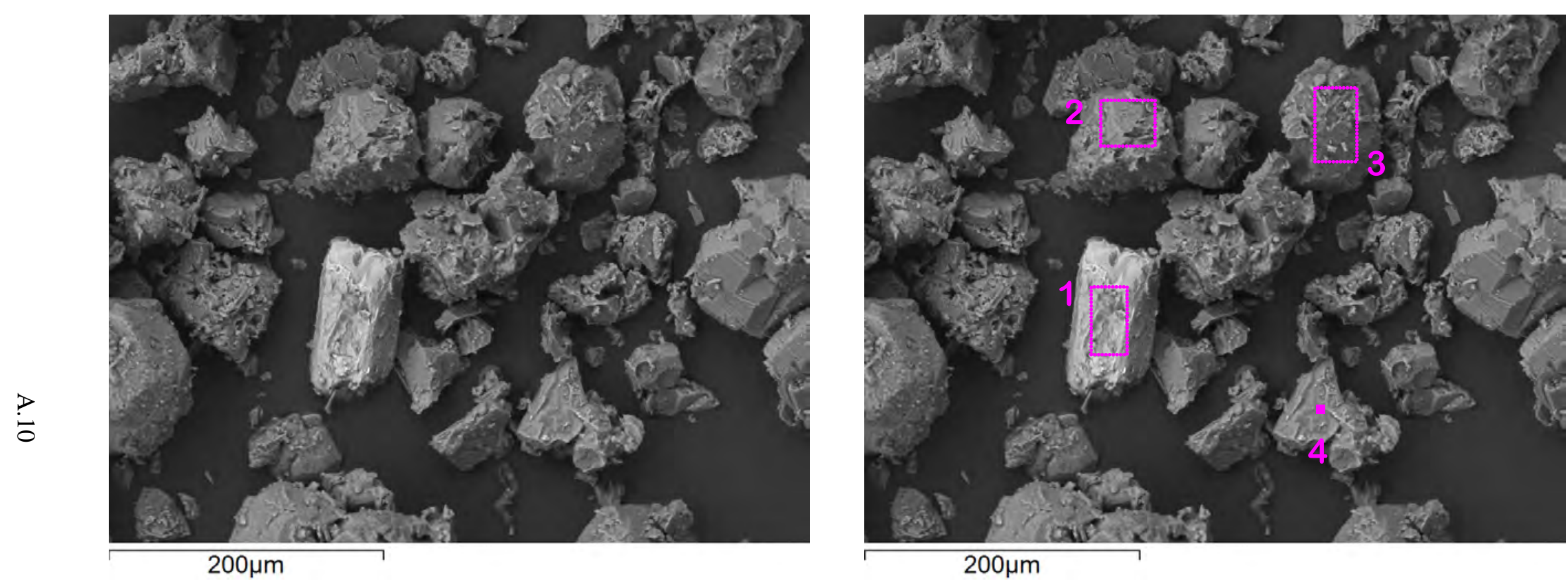

Element Compositions Derived from EDS Analyses of Particles Identified (in purple) in SEM Micrograph Shown Above Right

\begin{tabular}{|c|c|c|c|c|c|c|c|c|c|c|c|c|c|c|c|c|c|}
\hline \multirow{2}{*}{ Spectrum } & $\mathbf{O}$ & $\mathrm{Na}$ & Al & Si & $\mathrm{Mg}$ & $\mathbf{P}$ & $\mathbf{C a}$ & $\mathbf{F e}$ & $\mathrm{Cr}$ & Mn & Sr & $\mathbf{K}$ & $\mathbf{C u}$ & Ti & $\mathbf{P b}$ & $\mathbf{C l}$ & Total \\
\hline & \multicolumn{17}{|c|}{ wt $\%$ normalized to $100 \%$} \\
\hline 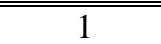 & 44.2 & \begin{tabular}{ll|}
7.5 \\
\end{tabular} & 8.0 & 12.9 & 26.6 & & \begin{tabular}{c|c|}
0.7 \\
\end{tabular} & $\begin{array}{l}19.6 \\
\end{array}$ & & \begin{tabular}{c|c|}
0.4 \\
\end{tabular} & & & & & & & 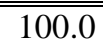 \\
\hline 2 & 63.3 & 12.8 & 23.1 & & & & 0.1 & 0.2 & 0.5 & & & & & & & & 100.0 \\
\hline 3 & 65.5 & 8.7 & 25.8 & & & & & & & & & & & & & & 100.0 \\
\hline 4 & 61.2 & 0.5 & 38.3 & & & & & & & & & & & & & & 100.0 \\
\hline
\end{tabular}


Backscattered Electron (BSE) SEM Micrograph of Particles in S-112 Sample 20407 Duplicate, Site of Interest 2
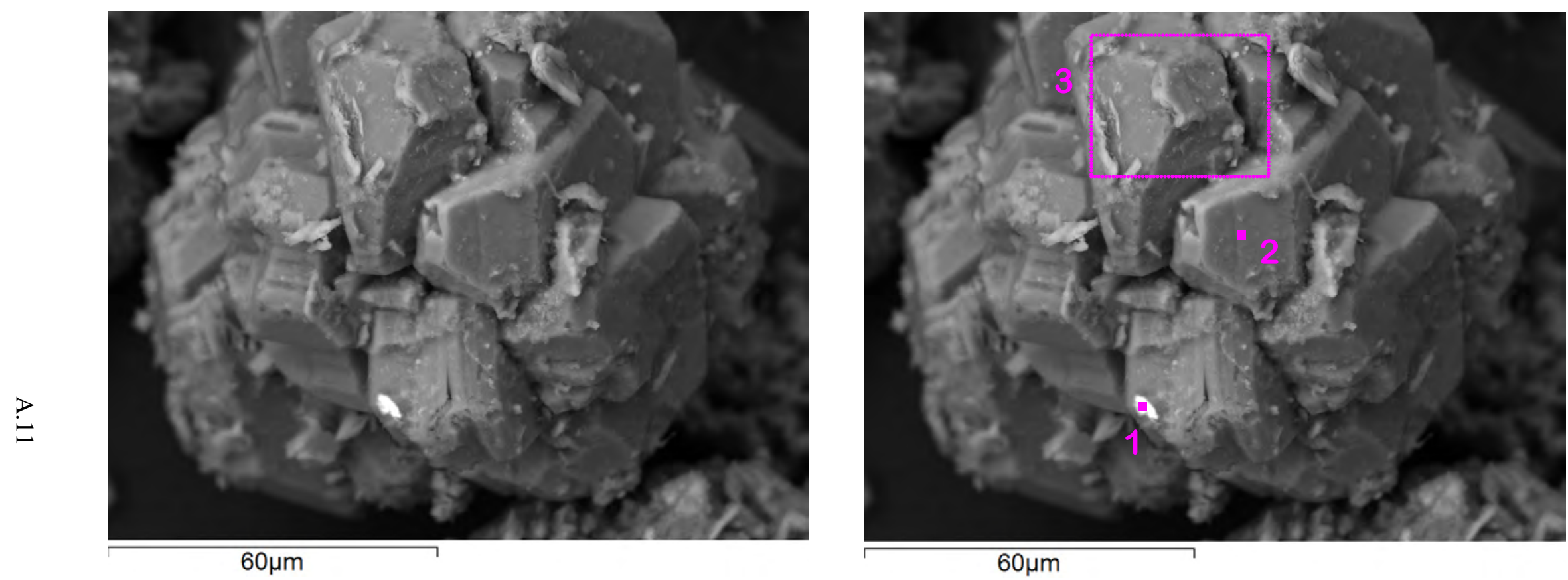

Element Compositions Derived from EDS Analyses of Particles Identified (in purple) in SEM Micrograph Shown Above Right

\begin{tabular}{|c|c|c|c|c|c|c|c|c|c|c|c|c|c|c|c|c|c|}
\hline \multirow{2}{*}{ Spectrum } & $\overline{\mathbf{O}}$ & $\mathrm{Na}$ & $\overline{\mathrm{Al}}$ & Si & Mg & $\overline{\mathbf{P}}$ & $\overline{\mathrm{Ca}}$ & Fe & $\overline{\mathrm{Cr}}$ & Mn & Sr & $\mathbf{K}$ & Cu & $\mathbf{T i}$ & $\mathbf{P b}$ & Cl & Total \\
\hline & \multicolumn{17}{|c|}{ wt $\%$ normalized to $100 \%$} \\
\hline 1 & 22.4 & 13.3 & 8.6 & & & & 0.3 & 47.3 & 8.1 & & & & & & & & 100.0 \\
\hline 2 & 64.4 & 0.4 & 34.9 & & & & & & 0.4 & & & & & & & & 100.0 \\
\hline 3 & 65.7 & 5.9 & 28.0 & & & & & & 0.4 & & & & & & & & 100.0 \\
\hline
\end{tabular}


Backscattered Electron (BSE) SEM Micrograph of Particles in S-112 Sample 20407 Duplicate, Site of Interest 3

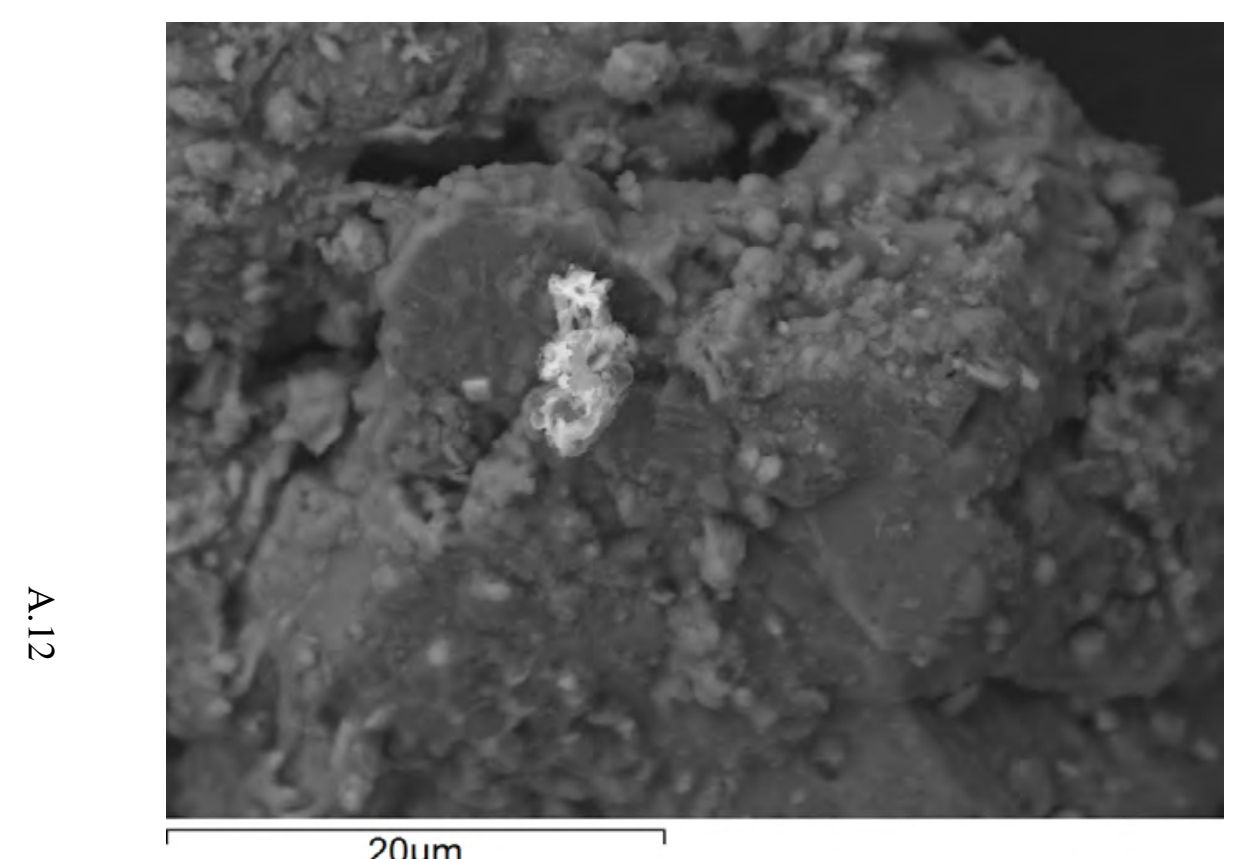

$20 \mu \mathrm{m}$

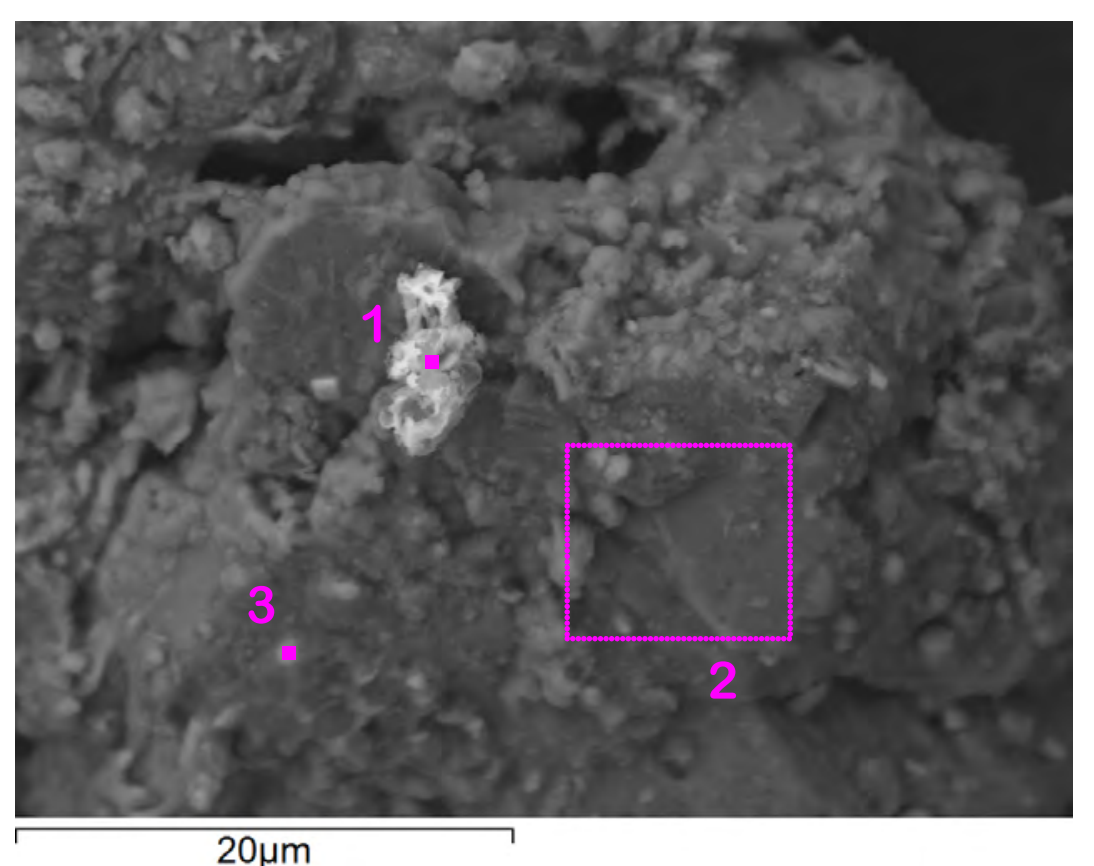

$20 \mu \mathrm{m}$

Element Compositions Derived from EDS Analyses of Particles Identified (in purple) in SEM Micrograph Shown Above Right

\begin{tabular}{|c|c|c|c|c|c|c|c|c|c|c|c|c|c|c|c|c|c|}
\hline \multirow{2}{*}{ Spectrum } & 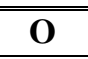 & $\mathrm{Na}$ & $\overline{\mathrm{Al}}$ & $\overline{\mathrm{Si}}$ & Mg & $\overline{\mathbf{P}}$ & $\overline{\mathbf{C a}}$ & Fe & $\overline{\mathrm{Cr}}$ & Mn & Sr & $\overline{\mathrm{K}}$ & $\overline{\mathrm{Cu}}$ & $\overline{T i}$ & $\overline{\mathbf{P b}}$ & $\overline{C \mathbf{C l}}$ & Total \\
\hline & \multicolumn{17}{|c|}{ wt $\%$ normalized to $100 \%$} \\
\hline 1 & 56.8 & 5.9 & 5.9 & 9.1 & & & & 22.2 & & & & & & & & & 100.0 \\
\hline 2 & 51.5 & 29.4 & 18.2 & & & & & & 0.9 & & & & & & & & 100.0 \\
\hline 3 & 53.1 & 27.6 & 18.2 & & & & & & 1.1 & & & & & & & & 100.0 \\
\hline
\end{tabular}


Backscattered Electron (BSE) SEM Micrograph of Particles in S-112 Sample 20407 Duplicate, Site of Interest 4

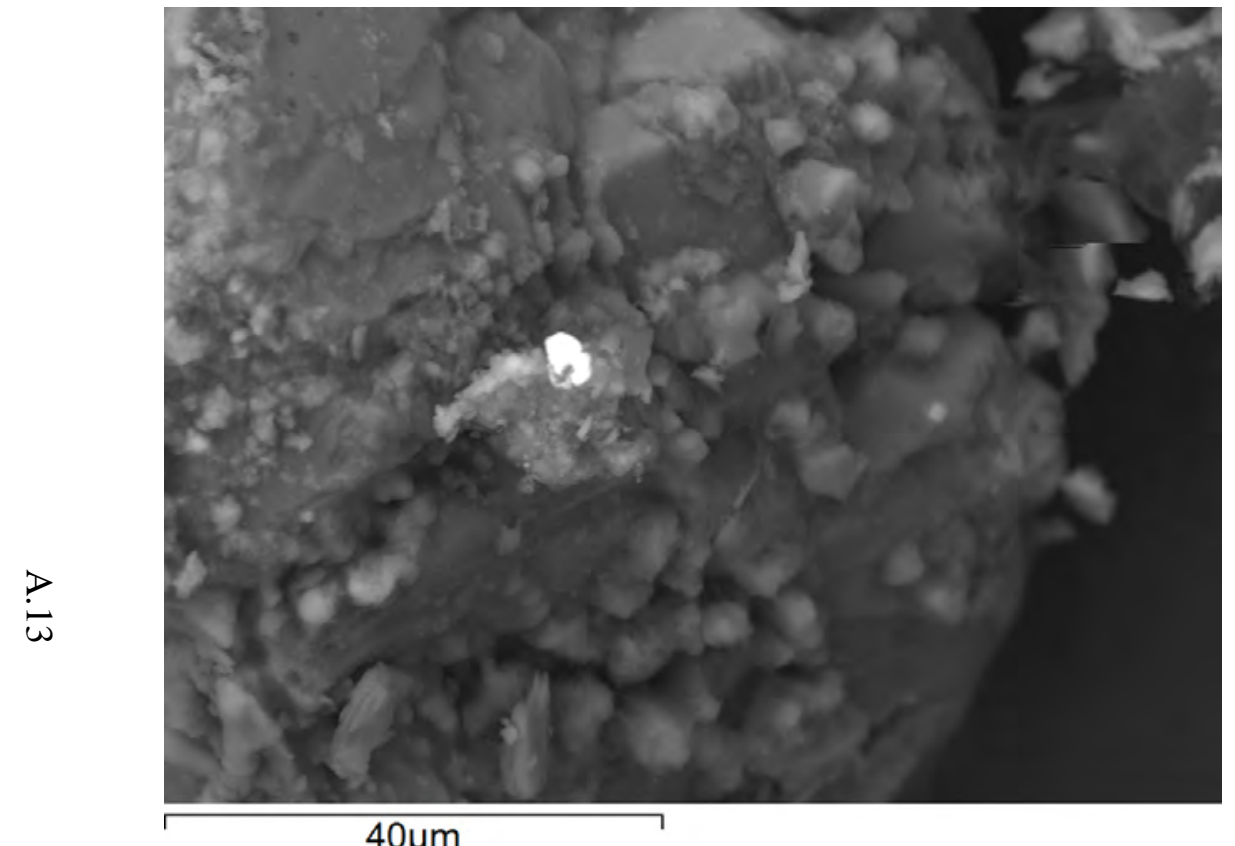

$40 \mu \mathrm{m}$

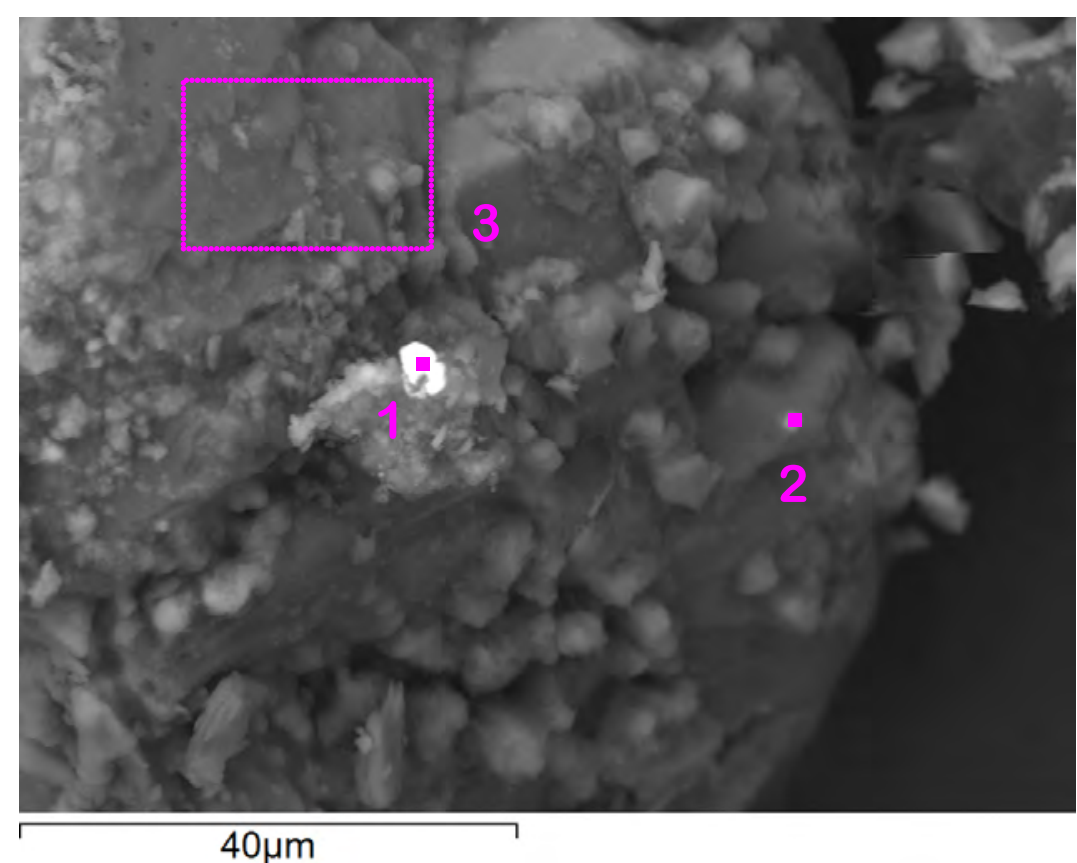

$40 \mu \mathrm{m}$

Element Compositions Derived from EDS Analyses of Particles Identified (in purple) in SEM Micrograph Shown Above Right

\begin{tabular}{|c|c|c|c|c|c|c|c|c|c|c|c|c|c|c|c|c|c|}
\hline \multirow{2}{*}{ Spectrum } & $\overline{\mathbf{O}}$ & $\mathrm{Na}$ & $\overline{\mathrm{Al}}$ & $\overline{\mathrm{Si}}$ & $\overline{\mathrm{Mg}}$ & $\overline{\mathbf{P}}$ & $\overline{\mathbf{C a}}$ & $\overline{\mathrm{Fe}}$ & $\overline{\mathrm{Cr}}$ & $\overline{\mathrm{Mn}}$ & $\overline{\mathrm{Sr}}$ & $\overline{\mathbf{K}}$ & $\overline{\mathrm{Cu}}$ & $\overline{T i}$ & $\mathbf{P b}$ & 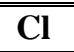 & Total \\
\hline & \multicolumn{17}{|c|}{ wt\% normalized to $100 \%$} \\
\hline 1 & $\begin{array}{l}53.4 \\
\end{array}$ & \begin{tabular}{|c|}
6.4 \\
\end{tabular} & \begin{tabular}{|c|}
6.6 \\
\end{tabular} & $\begin{array}{l}1.2 \\
\end{array}$ & 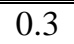 & & 2.9 & 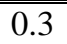 & & & & & & $\bar{~} 0.2$ & 25.9 & $\begin{array}{l}2.8 \\
\end{array}$ & $\begin{array}{l}100.0 \\
\end{array}$ \\
\hline 2 & 68.8 & 5.1 & 18.6 & 0.1 & 0.2 & & 5.5 & & 1.8 & & & & & & & & 100.0 \\
\hline 3 & 69.0 & 6.4 & 24.3 & & & 0.1 & & & 0.1 & & & & & & & & 100.0 \\
\hline
\end{tabular}


Backscattered Electron (BSE) SEM Micrograph of Particles in S-112 Sample 20407 Duplicate, Site of Interest 5
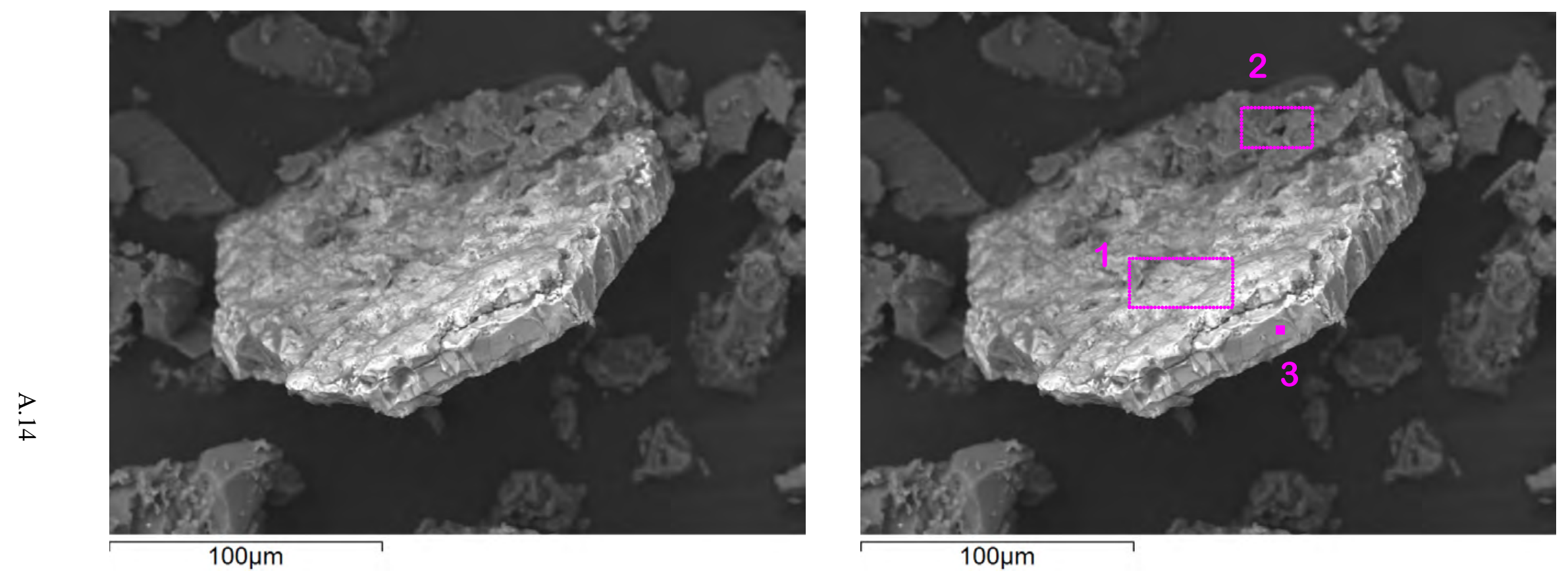

Element Compositions Derived from EDS Analyses of Particles Identified (in purple) in SEM Micrograph Shown Above Right

\begin{tabular}{|c|c|c|c|c|c|c|c|c|c|c|c|c|c|c|c|c|c|}
\hline \multirow{2}{*}{ Spectrum } & $\overline{0}$ & $\mathrm{Na}$ & $\overline{\mathbf{A l}}$ & $\overline{\mathrm{Si}}$ & Mg & $\overline{\bar{P}}$ & Ca & $\overline{F e}$ & $\overline{\mathrm{Cr}}$ & Mn & Sr & $\overline{\mathrm{K}}$ & $\overline{\mathrm{Cu}}$ & $\overline{T i}$ & $\overline{\mathbf{P b}}$ & $\overline{\mathrm{Cl}}$ & Total \\
\hline & \multicolumn{17}{|c|}{ wt \% normalized to $100 \%$} \\
\hline 1 & 39.9 & 16.7 & 5.7 & & & & 0.2 & 35.3 & 2.0 & 0.3 & & & & & & & 100.0 \\
\hline 2 & 63.0 & 13.7 & 22.4 & & & & & 0.8 & 0.2 & & & & & & & & 100.0 \\
\hline 3 & 29.2 & 5.5 & 1.8 & & & & & 62.8 & 0.4 & 0.3 & & & & & & & 100.0 \\
\hline
\end{tabular}


Backscattered Electron (BSE) SEM Micrograph of Particles in S-112 Sample 20407 Duplicate, Site of Interest 6
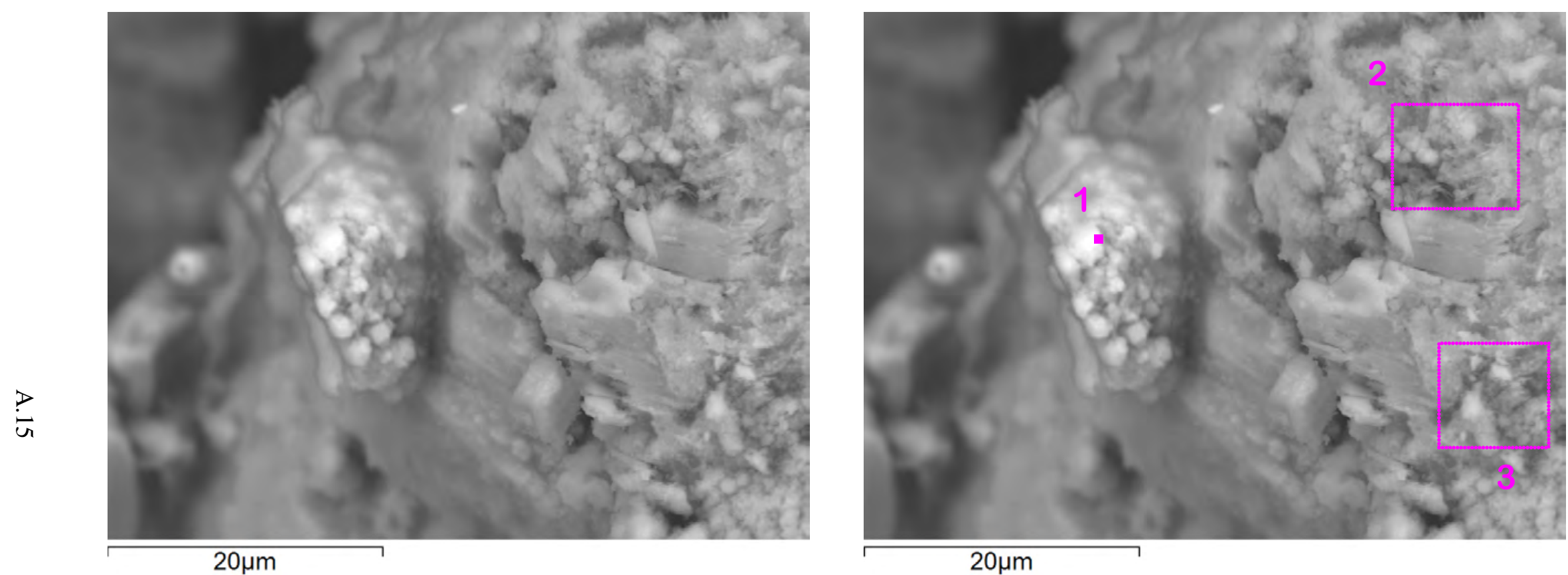

Element Compositions Derived from EDS Analyses of Particles Identified (in purple) in SEM Micrograph Shown Above Right

\begin{tabular}{|c|c|c|c|c|c|c|c|c|c|c|c|c|c|c|c|c|c|}
\hline \multirow{2}{*}{ Spectrum } & $\mathbf{O}$ & $\mathrm{Na}$ & Al & $\overline{S i}$ & Mg & $\overline{\mathbf{P}}$ & Ca & $\mathbf{F e}$ & $\mathbf{C r}$ & Mn & Sr & $\mathbf{K}$ & $\mathbf{C u}$ & Ti & $\mathbf{P b}$ & $\mathbf{C l}$ & Total \\
\hline & \multicolumn{17}{|c|}{ wt $\%$ normalized to $100 \%$} \\
\hline 1 & 62.3 & 2.7 & 7.0 & & & & 22.9 & & 5.0 & & & & & & & & 100.0 \\
\hline 2 & 53.0 & 22.6 & 24.3 & & & & & & & & & & & & & & 100.0 \\
\hline 3 & 58.1 & 14.6 & 26.4 & 0.2 & & & 0.3 & & 0.4 & & & & & & & & 100.0 \\
\hline
\end{tabular}


Backscattered Electron (BSE) SEM Micrograph of Particles in S-112 Sample 20407 Duplicate, Site of Interest 7
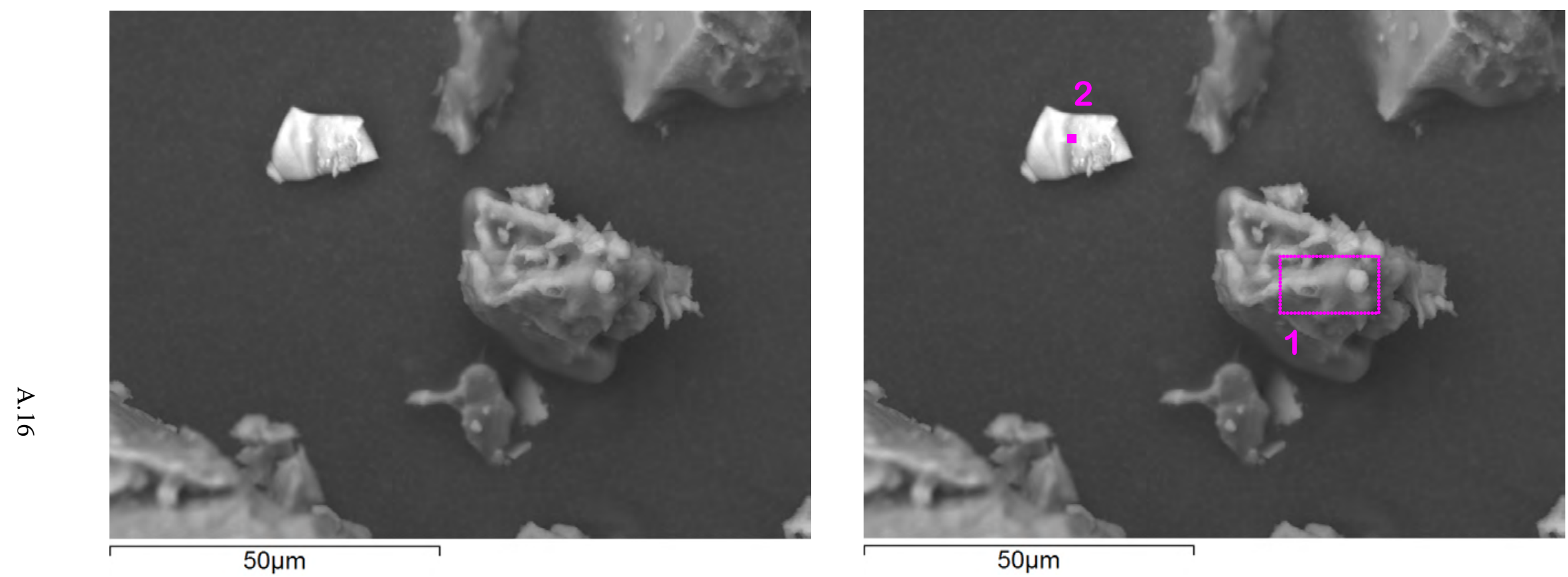

Element Compositions Derived from EDS Analyses of Particles Identified (in purple) in SEM Micrograph Shown Above Right

\begin{tabular}{|c|c|c|c|c|c|c|c|c|c|c|c|c|c|c|c|c|c|}
\hline \multirow{2}{*}{ Spectrum } & $\mathbf{0}$ & $\begin{array}{l}\mathrm{Na} \\
\end{array}$ & Al & $\overline{\mathrm{Si}}$ & Mg & $\overline{\mathbf{P}}$ & $\overline{C \mathbf{C a}}$ & $\mathbf{F e}$ & $\overline{\mathrm{Cr}}$ & Mn & Sr & $\bar{K}$ & $\overline{\mathrm{Cu}}$ & $\overline{T i}$ & $\overline{\mathrm{Pb}}$ & $\overline{\mathrm{Cl}}$ & Total \\
\hline & \multicolumn{17}{|c|}{ wt\% normalized to $100 \%$} \\
\hline 1 & 58.9 & 18.4 & 22.7 & & & & & & & & & & & & & & 100.0 \\
\hline 2 & 37.6 & 1.2 & 1.2 & 0.4 & & & & 59.6 & & & & & & & & & 100.0 \\
\hline
\end{tabular}


Backscattered Electron (BSE) SEM Micrograph of Particles in S-112 Sample 20407 Duplicate, Site of Interest 8
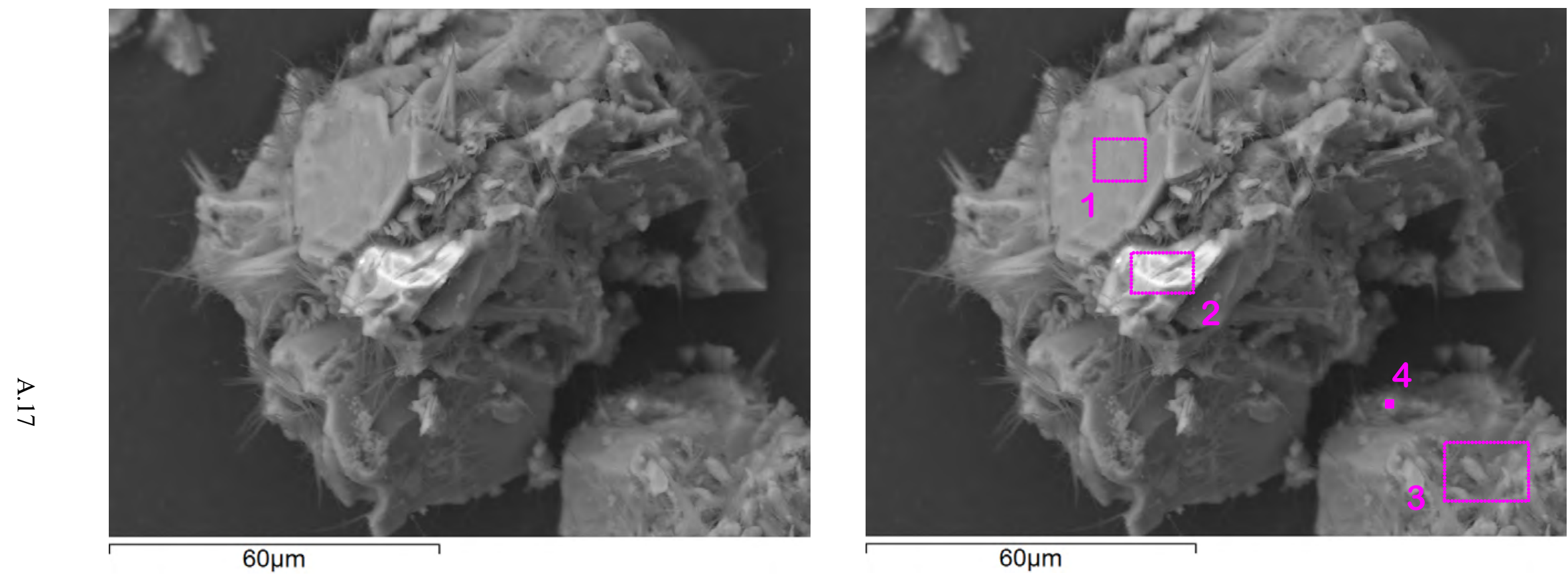

Element Compositions Derived from EDS Analyses of Particles Identified (in purple) in SEM Micrograph Shown Above Right

\begin{tabular}{|c|c|c|c|c|c|c|c|c|c|c|c|c|c|c|c|c|c|}
\hline \multirow{2}{*}{ Spectrum } & $\mathbf{O}$ & $\mathrm{Na}$ & Al & Si & Mg & $\mathbf{P}$ & Ca & $\mathbf{F e}$ & $\mathrm{Cr}$ & Mn & Sr & $\mathbf{K}$ & $\mathbf{C u}$ & $\mathbf{T i}$ & $\mathbf{P b}$ & Cl & Total \\
\hline & \multicolumn{17}{|c|}{ wt\% normalized to $100 \%$} \\
\hline 11 & $\begin{array}{l}53.3 \\
\end{array}$ & 6.2 & 32.3 & & & & & & \begin{tabular}{|c|}
8.3 \\
\end{tabular} & & & & & & & & $\begin{array}{c}100.0 \\
\end{array}$ \\
\hline 2 & 48.2 & 3.3 & 4.9 & 16.6 & 3.6 & & 7.9 & 14.6 & & 0.3 & & & & 0.5 & & & 100.0 \\
\hline 3 & 65.5 & 9.2 & 24.9 & 0.2 & & & & & 0.2 & & & & & & & & 100.0 \\
\hline 4 & 68.7 & 5.5 & 25.5 & 0.1 & & & & & 0.2 & & & & & & & & 100.0 \\
\hline
\end{tabular}





\section{Distribution}

No. of

$\underline{\text { Copies }}$

\section{OFFSITE}

D. A. Dunning

Oregon Department of Energy

625 Marion Street, N.E.

Salem, OR 97301-3737

D. I. Kaplan

Westinghouse Savannah River Company

Building 774-43A, Room 215

Aiken, SC 29808

D. Kosson

Vanderbilt University

VU Station B \#351831

2301 Vanderbilt Place

Nashville, TN 37235-1831

C. Langston

Westinghouse Savannah River Company

Building 774-43A

Aiken, SC 29808

S. Lilligren

Nez Perce Tribe

P.O. Box 365

Lapwai, ID 83540

P. R. Reed

U.S. Nuclear Regulatory Commission MS 9 F39

Washington, D.C. 20555-0001

W. Rigsbee

Yakama Nation

P.O. Box 151

Toppenish, WA 98948
No. of

$\underline{\text { Copies }}$

ONSITE

2 DOE Office of River Protection

R. W. Lober

H6-60

R. A. Quinterro

H6-60

2 DOE Richland Operations Office

DOE Public Reading Room (2) H2-53

8 CH2M HILL Hanford Group, Inc.

J. N. Appel

R2-58

M. P. Connelly (2)

H6-03

S. J. Eberlein(1)

H6-03

F. M. Mann(1)

H6-03

D. M. Nguyen

R2-58

D. Parker

H6-03

Washington State Department of Ecology

M. Barnes

H0-57

20 Pacific Northwest National Laboratory

B. W. Arey

K8-93

P. R. Bredt

K6-24

T. M. Brouns

K9-69

C. F. Brown

P7-22

R. W. Bryce

E6-35

K. J. Cantrell (2)

K6-81

W. J. Deutsch

SEQUI

K. M. Geiszler(1)

P7-22

A. R. Felmy

K8-96

M. D. Freshley

K9-33

K. M. Krupka (1)

K6-81

M. J. Lindberg

P7-22

R. J. Serne

P7-22

H. T. Schaef

K6-81

W. Um

P7-22

J. M. Zachara

K8-96

Hanford Technical Library (2)

P8-55 